\title{
Towards integrated nurse-led self-management support in routine diabetes care
}

Citation for published version (APA):

van Dijk-de Vries, A. N. (2015). Towards integrated nurse-led self-management support in routine diabetes care. [Doctoral Thesis, Maastricht University]. Maastricht University. https://doi.org/10.26481/dis.20151216ad

Document status and date:

Published: 01/01/2015

DOI:

10.26481/dis.20151216ad

Document Version:

Publisher's PDF, also known as Version of record

\section{Please check the document version of this publication:}

- A submitted manuscript is the version of the article upon submission and before peer-review. There can be important differences between the submitted version and the official published version of record.

People interested in the research are advised to contact the author for the final version of the publication, or visit the DOI to the publisher's website.

- The final author version and the galley proof are versions of the publication after peer review.

- The final published version features the final layout of the paper including the volume, issue and page numbers.

Link to publication

\footnotetext{
General rights rights.

- You may freely distribute the URL identifying the publication in the public portal. please follow below link for the End User Agreement:

www.umlib.nl/taverne-license

Take down policy

If you believe that this document breaches copyright please contact us at:

repository@maastrichtuniversity.nl

providing details and we will investigate your claim.
}

Copyright and moral rights for the publications made accessible in the public portal are retained by the authors and/or other copyright owners and it is a condition of accessing publications that users recognise and abide by the legal requirements associated with these

- Users may download and print one copy of any publication from the public portal for the purpose of private study or research.

- You may not further distribute the material or use it for any profit-making activity or commercial gain

If the publication is distributed under the terms of Article $25 \mathrm{fa}$ of the Dutch Copyright Act, indicated by the "Taverne" license above, 
Towards integrated

nurse-led self-management support in routine diabetes care 
The studies presented in this dissertation were conducted under the auspices of the School for Public Health and Primary Care (CAPHRI) at Maastricht University. CAPHRI is part of the Netherlands School of Primary Care Research (CaRe), which has been acknowledged since 1995 by the Royal Netherlands Academy of Art and Sciences (KNAW).

The studies described in this dissertation were funded by the Dutch Diabetes Research Foundation (Diabetes Fonds) with grant No. 2010.13.1366 (Voice of the Patient programme), and by the 'Annadal Foundation' in Maastricht, an independent financial support fund in the field of healthcare.

C A.N. van Dijk - de Vries, Maastricht 2015

Layout: Tiny Wouters

Printed by: Gildeprint

ISBN: 978-94-6233-160-0 


\title{
Towards integrated nurse-led self-management support in routine diabetes care
}

\author{
PROEFSCHRIFT
}

ter verkrijging van de graad van doctor aan de Universiteit Maastricht, op gezag van de Rector Magnificus, Prof. dr. L.L.G. Soete, volgens het besluit van het College van Decanen,

in het openbaar te verdedigen op woensdag 16 december 2015 om 12:00 uur

door

Adriana Neeltje van Dijk - de Vries

Geboren op 15 juli 1982 te Hoogeveen 


\section{Promotores}

Em. Prof. dr. J. Th. M. van Eijk

Prof. dr. T. van der Weijden

\section{Co-promotor}

Dr. M.A. van Bokhoven

\section{Beoordelingscommissie}

Prof. dr. A.J. Beurskens (voorzitter)

Prof. dr. H. Bosma

Prof. dr. B.W.J.H. Penninx, onderzoeksinstituut EMGO, VU medisch centrum Prof. dr. F.G. Schellevis, NIVEL

Prof. dr. N.K. de Vries 


\section{CONTENTS}

CHAPTER 1

General Introduction

CHAPTER 2

The ideal of biopsychosocial chronic care: How to make it real?

A qualitative study among Dutch stakeholders

\section{CHAPTER 3}

Integrating nurse-led Self-Management Support (SMS) in routine primary care: design of a hybrid effectiveness-implementation study among type 2 diabetes patients with problems of daily functioning and emotional distress. A study protocol.

\section{CHAPTER 4}

Experiences of practice nurses and general practitioners with implementation of biopsychosocial self-management support in diabetes care

\section{CHAPTER 5}

Patients' readiness to receive psychosocial care by practice nurses in routine diabetes consultations: A mixed methods study

CHAPTER 6

Lessons learnt from a cluster-randomised trial evaluating the effectiveness of Self-Management Support (SMS) delivered by practice nurses in routine diabetes care

\section{CHAPTER 7}

Identification of patients with emotional distress by practice nurses in routine diabetes care

\section{CHAPTER 8}

General discussion

Summary

Samenvatting

Valorisatie

Dankwoord 



\section{CHAPTER 1}

General introduction 
Chapter 1 
This thesis presents the outcomes of a project to improve the daily functioning of patients with type 2 diabetes mellitus by the implementation of a nurse-led intervention for integrated self-management support in routine care. This introductory chapter will describe the background of this implementation project. It starts with an overview of the chronic care setting, in which self-management support of patients with chronic conditions has become more and more relevant. Then the concept of self-management support, and the skills that are needed to manage diabetes in daily life, will be explained. Subsequently, this chapter describes an intervention that has proven to effectively increase patients' self-management skills, and the Dutch routine care setting in which this intervention has been integrated. The introduction ends with the aim, research questions and an outline of the thesis.

\section{BACKGROUND}

With the ageing of the population and increasing unhealthy lifestyles, health care systems face the overall burden of growing numbers of people with one or more chronic diseases. ${ }^{1}$ Complex conditions such as diabetes will impose an even larger burden in the future, not only because they affect a larger proportion of the population but also because they have started to appear earlier in life. ${ }^{2}$

To meet the needs of the increasing numbers of patients with long-term conditions, western health care systems are making the transition from a largely acute care model towards a chronic care model. ${ }^{3-6}$ This changes the roles of health professionals. Their basic task is prescribing the medical interventions for chronically ill, but this only determines a small part in the management of a chronic condition. The majority of disease management is done by patients themselves, outside the clinical setting. ${ }^{4} 7$ Therefore, patients need to be supported in their 'self-management'. By now, selfmanagement support has been widely recognised as a key component of care for patients with chronic conditions. Evidence across multiple chronic conditions has shown that effective self-management support can improve patients' self-care behaviours, health outcomes and daily functioning., $7-9$ 


\section{SELF-MANAGEMENT}

The term self-management refers to the ability of patients to make decisions and take actions in their daily life that minimize the impact of chronic disease on physical health status and functioning, and to cope with the psychological effects of their chronic condition(s). ${ }^{8,10}$ This thesis will follow the definition of self-management given by Lorig and Holman, including patients' decisions and actions regarding the medical as well as emotional and role management tasks. ${ }^{10}$ This means a 'biopsychosocial', or 'integrated' approach of self-management rather than a focus on only the medical management tasks. The rationale of the study is that for patients struggling with a chronic disease a good monitoring and treatment of problems in patients' medical, emotional and social functioning will help them to manage their own life, and to prevent a downward spiral in their daily functioning. As described by means of the Disablement Process by Verbrugge and Jette ${ }^{11}$, chronic conditions are symptoms of the body system that affect generic physical and mental actions (functional impairments), and activities in daily life (social participation). This has an impact on patients' quality of life and emotional well-being. This impact is influenced by personal and environmental factors that speed or slow disablement. Promoting patients' selfmanagement skills will help them to break through the downward spiral of the disablement process and to learn them to cope with possible future deterioration of their condition. In this thesis, techniques derived from problem solving therapy and cognitive therapy (reattribution) will be used to improve patients' self-management skills. Problem solving and reattribution techniques are traditionally applied as therapeutic interventions. Our focus is on supporting patients to apply these techniques in their everyday life.

\section{SELF-MANAGEMENT SUPPORT IN DIABETES CARE}

This thesis focuses on self-management support in the care for patients with type 2 diabetes mellitus. The diagnosis of this chronic endocrinological disease is defined by the presence of abnormally high glucose levels in the bloodstream, which can be caused by either insulin resistance or defective insulin secretion or by a combination of these processes. 
In the Netherlands, 740.000 persons had diabetes care in 2007 , a number that has been predicted to increase over the coming years to about 1.3 million people in 2025 (i.e. $8 \%$ of the Dutch population). ${ }^{12}$ The treatment of type 2 diabetes mellitus has been described in national guidelines. ${ }^{13,14}$ The main goal of the care for diabetes patients is to restore the blood glucose level to as close to a normal state as possible (between 4 and $8 \mathrm{mmol} / \mathrm{l})$. To achieve this goal, medical treatment of diabetes involves dietary modifications and exercise, and oral medications, insulin injections or an insulin pump to combat hyperglycaemia. Other goals of diabetes management are to prevent or treat the many complications that can result from the disease itself and from its treatment. These complications include cardiovascular disease, blindness, kidney failure, and lower limb amputation.

Type 2 diabetes can have a large impact on all domains of patients' lives. ${ }^{15}$ Qualitative studies have illustrated the social demands of diabetes on daily life. ${ }^{16,17}$ Patients are confronted with various changes in lifestyle, daily routines, physical functioning, and future perspectives. Patients may experience losses with regard to health, spontaneity towards planning activities, and lifestyle choices, which may easily provoke negative thoughts in patients about their own possibilities and social functioning. Patients can also experience various emotions like anger, fear, frustration, and depression. ${ }^{15}$ More than 20 years of research has shown that symptoms of distress and depression are prevalent among patients with type 2 diabetes. ${ }^{18,19}$ A systematic review revealed a significantly higher prevalence of depression among patients with type 2 diabetes (17.6\%) compared to a non-diabetic comparison group $(9.8 \%) .^{20}$ Emotional health problems like depression and distress are associated with a negative impact on glycaemic control, decreased adherence to treatment, higher complication rates and decreased well-being. ${ }^{21,22}$ A downward spiral may appear since poor glycaemic control can adversely affect mood and thus reinforce the relationship between diabetes and depressive symptoms. ${ }^{23}$ Numerous studies have examined the complex relationship between depression and diabetes. However, there is still no consistent empirical evidence about its causality, direction and underlying psychosocial or biological mechanisms. ${ }^{18,24}$ 


\section{ROUTINE DIABETES CARE}

Looking closely to the organisation of the Dutch chronic care setting, one can argue that the focus of diabetes care is predominantly on the medical aspects rather than on the psychosocial aspects of self-management. In the Netherlands, the care for patients with one or more somatic chronic conditions is organized by means of disease management programs. Since 2010, health insurers negotiate with regional collaborative care groups of family practices about a bundle of services with a fixed annual price per patient. This combines costs of multiple health professionals. The care group can deliver care themselves or subcontract other health providers. The negotiations are driven by the care as described in national 'care standards' that have been developed and authorised by caregivers organisations, patient associations, and public health authorities. These care standards are mainly based on the existing medical guidelines, protocols, and performance indicators. ${ }^{25}$ As a result of substitution of care from general practitioners (GPs) to practice nurses (PNs), PNs in the family practices provide routine follow-up consultations to chronic patients with diabetes, COPD and cardiovascular diseases. PNs provide quarterly diabetes consultations according Dutch national guidelines for diabetes care and the national 'care standard'. ${ }^{13,14,26}$ Patients consult a GP on an annual basis for a more extensive review of their diabetes control and the complications. ${ }^{13,26}$ In the national 'care standard' for diabetes care, patients' self-management is explicitly promoted by means of using individual treatment plans that contain agreements only regarding biomedical targets and lifestyle changes. Though the need for psychosocial care has been emphasised, performance indicators in the care standard do not involve psychosocial aspects of diabetes. ${ }^{14}$ Such a narrow focus on medical management is also apparent in the biomedical indicators that are used for financial reimbursement and quality of care. ${ }^{27}$

\section{AN EVIDENCE-BASED INTERVENTION}

Due to the high prevalence of depression among diabetes patients and the adverse effects of depression on diabetes compared to the limited numbers of patients who are actually detected and treated for depression, the necessity of screening and treatment for depressive symptoms in diabetes patients has been emphasised in various studies. ${ }^{19,23,28}$ Several screening instruments and effective interventions for patients with psychological problems are available, and may be feasible for 
dissemination in family practice. ${ }^{29}$ The starting point of this thesis was an evidencebased nurse-led minimal psychological intervention for elderly patients with type 2 diabetes and COPD with comorbid mild to moderate depressive symptoms. This minimal psychological intervention, based on techniques of reattribution and problem solving treatment, had already been evaluated in a randomised controlled trial. The intervention had proven to be effective: nine months after receiving the intervention, depressive symptoms of patients were significantly lower, there was a positive effect on patients' quality of life, and patients experienced less anxiety, reported more selfefficacy skills, demonstrated better glycaemic control and showed more participation in comparison to control patients. ${ }^{30-32}$ The intervention, delivered by specifically trained nurses who visited the patients at home, showed the probability that the intervention was cost-effective over usual care. ${ }^{33}$ Patients were positive about the intervention and more than 90 percent of the participants would recommend it to other patients with a chronic illness. ${ }^{34}$

\section{THIS THESIS}

The need to improve the emotional and social self-management skills of chronic patients was recognized by a regional care group in the South of the Netherlands and the dominant health insurer in that area. It was decided to implement and evaluate the evidence-based minimal psychological intervention in the regular diabetes care of that region. This intervention was integrated into the care as delivered by PNs, who see patients on a regular basis and have more time for consultation than GPs. ${ }^{35,36}$ This implied some crucial changes to the intervention for implementation purposes. A detection procedure needed to be added to identify eligible patients for he selfmanagement intervention. The PNs were provided with tools to be used during routine consultations to distinguish between active self-managers, patients who would benefit from self-management support, and patients who need more specialised psychosocial diagnostics or treatment. Patients who needed support were provided the nurse-led intervention. Patients with symptoms of severe mental health problems were referred to the GP. The resulting stepped approach of a detection phase and a follow-up phase has been called 'Self-Management Support' (SMS), which was aimed to prevent or to stop a downward spiral in patients' daily functioning. 
The aim of this thesis is to evaluate the implementation of an evidence-based intervention for biopsychosocial self-management of diabetes patients into the routine chronic care setting. The implementation strategies and the effectiveness of SMS in daily practice are simultaneously evaluated by using a hybrid effectivenessimplementation randomised trial design. We defined the following research questions to get a comprehensive understanding of the context, the process of implementation and the effectiveness of the integrated self-management approach for the daily functioning of patients with type 2 diabetes:

1. what is the perspective of stakeholders on the need and urgency regarding the improvement of the psychosocial aspects of diabetes care?

2. what are the barriers to and facilitators of successful implementation of a biopsychosocial self-management approach in routine diabetes care as experienced by practice nurses, general practitioners and patients?

3. what is the effectiveness of a biopsychosocial self-management approach provided by practice nurses during routine consultations for patient's daily functioning and health?

\section{OUTLINE}

In chapter 2, the outcomes of semi-structured interviews with primary care stakeholders regarding the current status of chronic care and the needs to improve a biopsychosocial approach of self-management support will be presented. Chapter 3 describes the study protocol of the hybrid design of the SMS-study. It presents the process evaluation of the implementation, and the 2-armed cluster-randomised trial to evaluate the effectiveness of SMS. The process of implementation from the perspective of the health professionals will be evaluated in chapter 4 . The patients' perspective on the biopsychosocial care approach will be examined in chapter 5 . Chapter 6 reports the effects of SMS in terms of patients' daily functioning and health status. Alongside the SMS-study, we have further explored the identification and outcomes of the added nurse-led detection procedure in routine consultations. This will be reported in chapter 7. Finally, the general discussion, reported in chapter 8 , addresses the outcomes and implications of this study for daily practice as well as for further research. 


\section{REFERENCES}

1. Pomerleau J, Knai C, Nolte E, The burden of chronic disease in Europe, in Caring for people with chronic conditions: a health system perspective, Nolte E and McKee M, Editors. 2008, Open University Press: Berkshire. p. 15-41.

2. Busse R, Blümel M, Scheller-Kreinsen D, et al. Tackling chronic disease in Europe. Strategies, interventions and challenges. Copenhagen: The World Health Organization, on behalf of The European Observatory on Health Systems and Policies, 2010.

3. Nolte E, McKee M, Caring for people with chronic conditions: introduction, in Caring for people with chronic conditions: a health system perspective Nolte E and McKee M, Editors. 2008, Open University Press: Berkshire. p. 1-13.

4. Wagner EH, Austin BT, Davis C, et al. Improving Chronic Illness Care: Translating Evidence Into Action. Health Aff 2001;20:64-78.

5. Battersby M, Von Korff M, Schaefer J, et al. Twelve evidence-based principles for implementing selfmanagement support in primary care. Jt Comm J Qual Patient Saf 2010;36:561-70.

6. Holman H, Lorig K. Patient self-management: a key to effectiveness and efficiency in care of chronic disease. Public Health Rep 2004;119:239-43.

7. Bodenheimer T, Wagner EH, Grumbach K. Improving primary care for patients with chronic illness. JAMA 2002;288:1775-79.

8. Rijken $\mathrm{M}$, Jones $\mathrm{M}$, Heijmans $\mathrm{M}$, et al., Supporting self-management, in Caring for people with chronic conditions: a health system perspective, Nolte E and McKee M, Editors. 2008, Open University Press: Berkshire. p. 116-42.

9. Franek J. Self-management support interventions for persons with chronic disease: an evidencebased analysis. Ont Health Technol Assess Ser 2013;13:1-60.

10. Lorig KR, Holman H. Self-management education: history, definition, outcomes, and mechanisms. Ann Behav Med 2003;26:1-7.

11. Verbrugge L, Jette A. The disablement process. Soc Sci Med 1994;38:1-14.

12. Baan $\mathrm{CA}$, van Baal $\mathrm{PH}$, Jacobs-van der Bruggen MA, et al. [Diabetes mellitus in the Netherlands: estimate of the current disease burden and prognosis for 2025]. Ned Tijdschr Geneeskd 2009;153:A580.

13. Rutten G, De Grauw W, Nijpels G, et al. NHG-Standaard Diabetes mellitus type 2 (derde herziening) [NHG Practice Guideline Diabetes mellitus type 2 (Third revision)]. Huisarts Wet 2013;56:512-25.

14. Netherlands Diabetes Federation. NDF Care Standard. Transparancy and quality of diabetes care for people with type 2 diabetes. Amersfoort: Nederlandse Diabetes Federatie (NDF), 2007.

15. Pearce MJ, Pereira K, Davis E. The psychological impact of diabetes: A practical guide for the nurse practitioner. J Am Assoc Nurse Pract 2013;25:578-83.

16. Hinder S, Greenhalgh T. "This does my head in". Ethnographic study of self-management by people with diabetes. BMC Health Serv Res 2012;12:83.

17. Townsend A, Wyke S, Hunt K. Self-managing and managing self: practical and moral dilemmas in accounts of living with chronic illness. Chronic IIIn 2006;2:185-94.

18. Egede L, Dismuke C. Serious Psychological Distress and Diabetes: A Review of the Literature. Curr Psychiatry Rep 2012;14:15-22.

19. Pouwer F. Should we screen for emotional distress in type 2 diabetes mellitus? Nat Rev Endocrinol 2009;5:665-71.

20. Ali S, Stone MA, Peters JL, et al. The prevalence of co-morbid depression in adults with Type 2 diabetes: a systematic review and meta-analysis. Diabet Med 2006;23:1165-73.

21. Fisher L, Mullan JT, Arean P, et al. Diabetes distress but not clinical depression or depressive symptoms is associated with glycemic control in both cross-sectional and longitudinal analyses. Diabetes Care 2010;33:23-28.

22. Egede LE, Ellis C. Diabetes and depression: Global perspectives. Diabetes Res Clin Pract 2010;87: 302-12. 
23. Lustman PJ, Clouse RE. Depression in diabetic patients: The relationship between mood and glycemic control. J Diabetes Complications 2005;19:113-22.

24. Riley AA, McEntee ML, Gerson L, et al. Depression as a Comorbidity to Diabetes: Implications for Management. J Nurse Pract 2009;5:523-35.

25. Tsiachristas A, Hipple-Walters B, Lemmens KMM, et al. Towards integrated care for chronic conditions: Dutch policy developments to overcome the (financial) barriers. Health Policy 2010; 101:122-32.

26. Rutten GEHM, De Grauw WJC, Nijpels G, et al. NHG-Standaard Diabetes mellitus type 2 (Tweede herziening) [NHG Practice Guideline Diabetes mellitus type 2 (Second revision)]. Huisarts Wet 2006; 49:137-52.

27. Struijs J, de Jong-van Til J, Lemmens L, et al. Bundled payments of diabetes care: Effects on care delivery process and quality of care at three-year follow-up. Bilthoven: National Institute for Public Health and the Environment (RIVM), 2012.

28. Hermanns N, Caputo S, Dzida G, et al. Screening, evaluation and management of depression in people with diabetes in primary care. Prim Care Diabetes 2013;7:1-10.

29. Zwaanswijk M, Verhaak PFM. Effectieve kortdurende interventies voor psychische problemen: een kennissynthese over hun toepasbaarheid in de huisartsenvoorziening. Utrecht: Nivel, 2009.

30. Lamers F, Jonkers CCM, Bosma $\mathrm{H}$, et al. A minimal psychological intervention in chronically ill elderly patients with depression: a randomised trial. Psychother Psychosom 2010;79:217-26.

31. Jonkers CCM, Lamers $\mathrm{F}$, Bosma $\mathrm{H}$, et al. The effectiveness of a minimal psychological intervention on self-management beliefs and behaviors in depressed chronically ill elderly persons: a randomized trial. Int Psychogeriatr 2012;24:288-97.

32. Lamers $\mathrm{F}$, Jonkers CCM, Bosma $\mathrm{H}$, et al. Treating depression in diabetes patients: does a minimal psychological intervention affect diabetes-specific quality of life and glycemic control? A randomized controlled trial. J Adv Nur 2011;67:788-99.

33. Jonkers CCM, Lamers F, Evers SMAA, et al. Economic evaluation of a minimal psychological intervention in chronically ill elderly patients with minor or mild to moderate depression: a randomised trial (the DELTA study). Int J Technol Assess Health Care 2009;25:497-504.

34. Jonkers $\mathrm{C}$, Lamers $\mathrm{F}$, Bosma $\mathrm{H}$, et al. Process evaluation of a minimal psychological intervention to reduce depression in chronically ill elderly persons. Patient Educ Couns 2007;68:252-57.

35. Heiligers PJM, Noordman J, Korevaar JC, et al. Kennisvraag: praktijkondersteuners in de huisartspraktijk (POH's) klaar voor de toekomst? [Knowledge base: Practice nurses in the GP practices, ready for the future?]. Utrecht: Netherlands Institute for Health Services Research (NIVEL), 2012.

36. Elissen A, Nolte E, Knai C, et al. Is Europe putting theory into practice? A qualitative study of the level of self-management support in chronic care management approaches. BMC Health Serv Res 2013; 13:117. 


\section{CHAPTER 2}

The ideal of biopsychosocial chronic care:

How to make it real?

\section{A qualitative study among Dutch stakeholders}

Anneke van Dijk - de Vries

Albine Moser

Vera-Christina Mertens

Jikke van der Linden

Trudy van der Weijden

Jacques Th. M. van Eijk

BMC Fam Pract 2012;13:1 


\section{ABSTRACT}

\section{Background}

Chronically ill patients often experience psychosocial problems in everyday life. A biopsychosocial approach is considered to be essential in chronic care. In Dutch primary health care the current biomedically oriented clinical practice may conflict with the biopsychosocial approach. This study is aimed to explore the views of Dutch stakeholders on achieving a biopsychosocial approach to the care of patients with chronic diseases.

\section{Methods}

In a qualitative explorative study design, we held semi-structured interviews with stakeholders, face-to-face or by telephone. Data were analysed using content analysis. Thirty representatives of Dutch patients with chronic illnesses, primary care professionals, policy makers, health inspectorate, health insurers, educational institutes and researchers were interviewed.

\section{Results}

Stakeholders were aware that a systematic biopsychosocial care approach is lacking in current practice. Opportunities for effective change are multidimensional. Achieving a biopsychosocial approach to care relates to active patient participation, the training of professionals, highquality guidelines, protocols and tools, integrated primary care, research and financial issues.

\section{Conclusions}

Although the principles and importance of the biopsychosocial model have been recognized, the provision of care that starts from the medical, emotional or social needs of individual patients does not fit in easily with the current Dutch health care system. All parties involved need to make a commitment to break through the wall of biomedically oriented care. Together they need to equip health professionals with skills to understand patients' multifaceted needs and to reward integrated biopsychosocial care. Patients need to be empowered to be active partners in their own care. 


\section{BACKGROUND}

Like that in other Western countries, Dutch primary health care is being challenged by the rapidly rising prevalence of chronic diseases. ${ }^{1,2}$ Given the long-term nature of chronic conditions, there is a growing recognition that patients need to be supported in managing their own health. ${ }^{3}$ Good self-management skills are associated with improved patient-reported outcomes and reduced health care costs. ${ }^{4}$ Lorig distinguishes three self-management tasks: medical, emotional and role tasks. ${ }^{4}$ Ideally, health professionals should systematically and simultaneously address the way patients cope with these tasks. This would require them to apply the biopsychosocial model, rather than using a narrow biomedical focus on patient care. ${ }^{5}$ Although the biopsychosocial model is considered to be essential in chronic care, it appears to be poorly embedded in the Dutch primary care system. In the last decade, chronic care for patients with type 2 diabetes, COPD and cardiovascular disease has been largely transferred from general practitioners (GPs) to practice nurses (PNs). The indicators describing the GPs' and PNs' performance are only defined in terms of biomedically oriented clinical guidelines and standards of quality of care. ${ }^{6,7}$ The reimbursement of care expenditures by insurance companies, which is now regulated on the basis of 'diagnosis treatment combinations' (DTC, a Dutch variant of Diagnosis Related Groups) is also based on these guidelines and care standards. ${ }^{8}$ Consequently, most interventions are defined in terms of control of biomedical aspects, like glycaemic control in diabetes patients, ignoring the psychosocial impact of chronic disease. ${ }^{4,8,9}$ It is not surprising, therefore, that chronic patients with psychosocial problems often receive only biomedically oriented, and thus incomplete, treatment. $^{10,11}$

This study examined the views of stakeholders (representatives of patients, primary care professionals, health policy makers and inspectorate, health insurers, educational institutes and research) on implementing the biopsychosocial model in Dutch care for chronic patients.

The research questions were:

1. What are the views of stakeholders in Dutch chronic care on the current state of biopsychosocial care?

2. Which barriers and facilitators do stakeholders perceive as regards the implementation of biopsychosocial chronic care? 


\section{METHODS}

A qualitative explorative design was used to get a bottom-up overview of stakeholders' views regarding the biopsychosocial care of people with chronic diseases.

\section{Participant recruitment}

Stakeholders who were knowledgeable about chronic care in the Dutch setting were invited to participate. To obtain richly detailed data, we selected participants using purposive sampling and snowball sampling, ${ }^{12}$ ensuring that all groups of stakeholders were included: patients, primary care professionals such as GPs and PNs, policy makers, health inspectors, health insurers, health education professionals, and researchers. Thirty stakeholders were invited by letter. Participation was voluntary. Informed consent was obtained. This consent was audio recorded. Nobody refused to participate.

\section{Data collection}

Nine face-to-face and 21 telephone interviews were held between December 2009 and June 2010, based on an open-ended, semi-structured interview guide. The interview guide was partly adapted to fit the respondents' background or on the basis of findings of prior interviews. The interviews lasted 16 to 59 minutes. The interviewers ( $A v D, V M, J L)$ started with face-to-face interviews. In view of the distances to be travelled, they then continued with telephone interviews, since faceto-face contact with respondents and immersion in their environment was not considered necessary to receive the relevant information about the subject of our study. Telephone interviews have been reported to be a valid data collection tool. ${ }^{13}$ Signals like hesitations and pauses were used as cues to ask probing questions. All interviews were recorded. As regards transcriptions in qualitative research, Strauss and Corbin ${ }^{14}$ recommended (p.30): "The general rule of the thumb here is to transcribe only as much as is needed (...) The actual transcribing should be selective". We made comprehensive summaries, and transcribed fragments related to the research questions verbatim. 


\section{Analysis}

A content analysis was performed, based on the constant comparative method. ${ }^{14}$ Codes and categories relating to biopsychosocial care emerged inductively from the interview data and deductively from the constant comparison. We first read the interview summaries to get an impression of the data, and then listened to the audiotaped interviews again (AM) to check the accuracy of the transcriptions. Next, relevant sections of the interview data were coded by $A M$, using codes that were often based on descriptions used by respondents. These codes were grouped into categories and subcategories which best characterized the data collected. Throughout the analysis, the codes and categories were constantly compared and contrasted within and among the interviews. Data saturation ${ }^{14}$ was reached after 14 interviews. The remaining interviews served to obtain representative data of the phenomenon under study and to fill the categories. Memos ${ }^{14}$ were written throughout the process.

\section{Validity}

Several strategies were used to ensure credibility $^{15}$ (internal validity). Firstly, 63 stakeholders in chronic care (including all interviewees) were invited for an invitational conference, at which we presented them with the first draft of our results, to validate the study outcomes. The conference was attended by 34 participants (including 13 of the interviewees). Data saturation was confirmed by a discussion about the needs and opportunities to achieve a biopsychosocial approach to care, which was recorded in field notes. With regard to the interviews and analysis process, research team meetings were held to fine-tune the activities between the various interviewers ${ }^{16}$ and researchers. They met frequently to reflect upon the interview guide, sampling and summaries of the interviews, as well as on the analysis process, codes, and categories and subcategories that emerged. A member check was performed by submitting each interview summary to the respondent for approval.

\section{RESULTS}

The sample consisted of 30 stakeholders, from various backgrounds. Most were involved in two $(n=12)$ or three $(n=3)$ domains. Patients were represented by three persons with a chronic illness and two board members of a national patient federation (one of whom had recently moved to a professional association for PNs). The sample 
included six GPs and three PNs. Mental health care was represented by two participants involved in professional associations of primary care mental health workers and one psychiatrist. Three participants were involved in medical education (training GPs and PNs). Three participants were involved in the development of national guidelines. The sample also included two health insurers and two health inspectors. Four participants were involved in national health policy. Researchers $(n=11)$ included professors and others involved in research on primary care, chronic care, mental health care, implementation science, and general practice. Most of them were also professionally involved in health care $(n=4)$, guideline development $(n=2)$, mental care $(n=1)$, national health policy $(n=1)$ or medical education $(n=2)$.

\section{Achieving a biopsychosocial approach to chronic care}

Respondents underlined the impact of chronic conditions on psychosocial functioning and patients' needs for support in dealing with a chronic disease in everyday life. Although they considered a biopsychosocial approach to be inherent in being a primary care professional, respondents confirmed the current lack of a systematic approach in providing psychosocial care to patients with a chronic disease. The present use of the biopsychosocial model mainly depends on the individual skills of the professionals rather than on a well-planned strategy. Respondents perceived a need for simultaneous changes at various levels.

\section{Recognition of psychosocial problems: a shared responsibility}

Primary care professionals need to be aware that psychosocial care is an important adjunct to medical care. Both patients and professionals argued that it is difficult to determine when or whether health professionals should be involved, as psychosocial problems were perceived as belonging to the normal life of chronically ill people. Hence, neither doctors nor patients do sufficiently address psychosocial problems.

'What is the dividing line between a 'normal reaction' and a 'pathological reaction'? When does a mood problem turn into a depression? When is gloominess no longer acceptable?' [researcher]

Respondents attached great importance to providing care that starts from the perceived, multifaceted needs of patients. In this regard, interviewees emphasized that patients and their social environment need to play an active role in the whole 
care process. Their participation is crucial for the early recognition of psychosocial problems and for discussing them with a doctor during consultations.

'The patients themselves and their social environment obviously play an important role as well. The patient has to notice that this is more than just their chronic somatic disorder, that there is something wrong with their attitude, their situation, their mood. ... This care environment may also include the patient's relatives.' [researcher, health policy maker]

Some wondered how a health professional assesses patients' needs, or to what extent patients themselves define their needs. One patient noted that many (particularly older) patients are passive recipients of care, who look up to a health professional as an authority. Patients' expectations about psychosocial care in general practice seemed to be low, as they think health professionals do not have time to address this kind of problem or cannot empathize with problems the way fellow patients can.

\section{Training of health professionals}

Most respondents considered training to be a major facilitating factor to ensure that the biopsychosocial model becomes integrated in chronic care. Respondents representing educational institutes confirmed their intention to train their students to develop a joint focus on the biological, psychological and social dimensions of illness. However, they argued that teaching programmes should make a greater effort to teach students to start from the patient as a person rather than the disease.

'Right from the start of the courses in year 1, students should think in terms of patients and care needs. So the teaching courses really need to be changed. Doctors should not be trained so much to think in terms of diseases, but to think in terms of care needs.' [professional involved in research, teaching and guideline development]

Primary care professionals (especially GPs and PNs) should be sensitized to identify psychosocial needs associated with medical health problems, and care providers in chronic care also need to be trained to work in multidisciplinary teams. Other issues that were mentioned included more training in communicative competencies like listening or recognizing nonverbal signals, and training to monitor patients' perceived problems in daily functioning. 


\section{Guidelines, protocols and tools}

Current guidelines for chronic care do not adequately integrate medical and psychosocial aspects, or multimorbidity. Multimorbidity can relate to multiple somatic diseases but also to psychosocial problems. Respondents mentioned the complicated task of incorporating and presenting all these aspects in conveniently structured guidelines. Some suggested allowing more room for the patient's perspective in guidelines, by involving patients in the guideline development process.

Quality assurance indicators, preferably derived from clinical practice guidelines, were also mentioned. To date, outcome parameters have been dominated by biomedical indicators such as HbA1c (blood sugar level). The public health quality indicators defined by the Dutch Health Inspectorate also include only biomedical parameters. Respondents underlined the need for process and outcome quality indicators for psychosocial care.

There is no interest in my patients' quality of life, which is what should really be the performance measure. In practice, your performance is judged on the basis of very simple outcome measures $-x$ number of decimals of the $\mathrm{HbA1c}$ values. [GP, researcher]

The majority of respondents said hat GPs and PNs needed additional tools such as questionnaires to help them with signalling, diagnosing and selecting interventions, as well as monitoring and evaluating biopsychosocial care. Several respondents mentioned systematic screening to identify patients with a need for psychosocial care, while at the same time being cautious about the downside, i.e. the generation of false-positive screening results. Some suggested a stepwise method of case-finding to differentiate between mild, moderate and serious problems and to provide care that fits the patient's needs. In addition to tools to detect specific issues (like social isolation or poly-pharmacy), respondents asked for communication techniques or less laborious assessment instruments to identify individual patients' needs.

'My ideal, if we could start again, would be that I should diagnose, for instance, a diabetes patient, that of course we offer all the options that science has to offer, but that in addition to that we'd have a kind of list, 10 to 20 points, that you take the patient through to see what their problems are in everyday life. ... Using the doctor's experience to list current problems and expectations and then check the same list every year or so to see if you are still working on the same goals.' [GP, researcher] 


\section{Integrated primary care}

Respondents perceived an integrated primary care system as one of the cornerstones of biopsychosocial care, involving clearly defined pathways and effective teamwork among all caregivers in primary and secondary care.

What we need is a closely integrated first-line health care system, with clear lines. Everyone involved should know their own place in the collaborative model.' [GP, researcher]

Disease management programmes that include prevention, monitoring and treatment might already represent a step forward to integrated chronic care. However, some caution is needed as these programmes are still driven by diseases rather than by patient needs.

Some pointed out that integrated primary care starts within the small-scale setting of a GP practice. Delegation of tasks from GPs to PNs, practice assistants and/or nurse practitioners, and the variety of responsibilities and specialities makes effective teamwork very complex. In addition to this, there are several kinds of mental health care professionals involved in Dutch primary care. This highlights the need for a clear division of tasks, responsibilities and communication processes among the various health professionals.

'A sort of step-by-step plan: what aspects should be the responsibility of the GP, what should be done by a psychiatric nurse? As a practice nurse, you need to be aware of your limitations. There comes a point where I have to say: this is beyond by professional competence, and should be dealt with by the practice psychiatric nurse.' [Health care professional]

Some emphasized that GPs should remain primarily responsible for the patient's care process. Others mentioned that PNs are increasingly taking on a coordinating casemanager role for chronic patients. A concern was that PNs who provide care for patients with a physical chronic disease may not correctly identify and treat psychosocial problems, since they have little experience with psychological and social health problems.

\section{Financial issues}

The professionals mostly mentioned a lack of time to incorporate psychosocial care in their routine practice. Time constraints were related to the available consultation 
time, workload and financial constraints. In this regard, respondents commented on the payment system for primary care. Some emphasized the potential benefits of the Dutch reimbursement system, which offers all-inclusive payment for people with chronic conditions to a multidisciplinary team. This stimulates the delivery of efficient and integrated chronic care. However, the emphasis on diagnosis-treatment combinations (DTCs) rather than on aspects like comorbidity or multimorbidity does not encourage professionals to start from the multifaceted biopsychosocial needs of individual patients.

'I'm not against DTCS at all; I think they're the best way to work in an outputdriven manner. I really think they are necessary in health care. But you may wonder whether the current DTC concepts are useful. I could imagine that I might see a patient and think I will define a DTC not with the aim of treating the disease but actually treating the patient. Looking at the patient in a holistic manner. That's the right way.' [professional involved in research, teaching and guideline development]

Respondents argued that psychosocial care should be a general module within all DTCs. This would mean making it an integrated part of all national care standards on which health insurers base their payments. If no reimbursement is given, professionals in the field will not systematically include this aspect in their daily care.

\section{Research}

The majority of respondents mentioned research as an essential prerequisite for achieving a biopsychosocial approach to care. If interventions are to be incorporated in care standards and hence included in the reimbursement fees, they have to be evidence-based. The development of evidence-based biopsychosocial selfmanagement interventions needs to be given greater priority on the research agenda of major funding organisations. Respondents preferred intervention research with patient-reported outcomes such as quality of care, patient satisfaction and healthcare consumption. However, this kind of research is complex among patients with comorbidity or multimorbidity, and patients with multifaceted health problems are often excluded. Respondents also suggested more research with the aim of improving integrated primary care. In addition, they stressed the importance of research into the patients' needs. 


\section{DISCUSSION}

Our results show that the biopsychosocial model in chronic care is an ideal shared by the respondents, and the interview findings were confirmed by the invitational conference. Treating patients as whole persons in their social and personal context implies that health professionals should take time to detect and address psychosocial problems in patients with a physical chronic disease. The stakeholders in our study agreed that this is insufficiently happening in current practice.

Barriers to the use of the biopsychosocial model during medical encounters relate to care providers being inadequately equipped for this approach, resulting in both overdiagnosis and under-diagnosis of psychological problems. ${ }^{10}$ Stakeholders in our study asked for tools to distinguish between normal responses to chronic illness and 'disorders' that need specialist care. Such discriminative tools can be helpful in guiding health professionals towards psychosocial aspects of being chronically ill, but when taken too literally, they can also create unnecessary boundaries. ${ }^{17}$ Some have $\operatorname{argued}^{17,18}$ that seeing symptoms in the light of what is going on in a persons' life might enhance biopsychosocial care. Rather than labelling patients according to psychiatric criteria, they allocate an important role to patients' own stories and watchful waiting. This asks for a paradigm shift towards a biopsychosocial selfmanagement approach that really starts from the patients' perceived needs. Health professionals already have to be familiarized with this care approach during their professional training. In this regard, Dutch experts on care for the elderly ${ }^{19}$ recently called for interprofessional training for health professionals, as effective communication and teamwork skills are required to implement biopsychosocial selfmanagement by patients.

A biopsychosocial self-management approach requires health professionals who view patients as experts on their own lives and thus responsible for their own health. It also supposes that patients express their needs regarding their medical, emotional and role tasks. This is critical in patients with low health literacy and/or low socioeconomic status, as they are at higher risk for distress and depression than their counterparts with higher socio-economic status, and are less able to use a pro-active coping style. ${ }^{20}$ The expectation that relatively short consultations with primary care professionals can address complex biomedical and psychosocial problems in addition to the other tasks like forming partnerships, providing preventive care and coordinating care has been criticized, especially with regard to the socially 
disadvantaged. ${ }^{21}$ Stretching consultation times and providing financial resources might not be the only solution. What is needed is nation-wide patient empowerment. The various patient societies in the Netherlands can use their networks and capacities to encourage individual patients to become more actively involved in their own care. ${ }^{22}$ We believe that the current structure of Dutch health care funding impedes the introduction of biopsychosocial care. The shift from a primarily government-funded model to a regulated, quasi free-market model and the introduction of DTCs in primary care, offering 'all-inclusive' reimbursement for people with a chronic condition, have resulted in greater power for health insurers. Their interest in financial efficiency means that professionals are showered with documentation on 'hard' (biomedical) outcome parameters for administrative and billing purposes. ${ }^{23,24}$ Furthermore, the disease-oriented DTCs may provoke fragmentation of care as they focus on a single chronic disease. ${ }^{8}$ Guidelines and standards based on a biopsychosocial self-management approach (like the Dutch care standard on COPD ${ }^{25}$ ) can hardly prevent the problem of focusing on the disease rather than on the patient. DTCs should include general reimbursement categories such as care coordination and focusing attention on the way patients cope with the consequences of their chronic disease in everyday life.

Unexpected side-effects of the quasi free-market system are the niches for bottom-up societal initiatives such as small-scale community care. ${ }^{26}$ The collective sense of responsibility for patients' well-being that is found in small, autonomous care teams might facilitate biopsychosocial care. Further research is necessary to investigate the impact of such initiatives on patients' wellbeing and biopsychosocial selfmanagement, as well as on health care costs.

There is no doubt about the negative impact of psychosocial problems on treatment compliance, $^{27}$ deterioration of chronic conditions ${ }^{28,29}$ and health care costs. ${ }^{30}$ Empathic communication and raising positive expectations have a favourable influence on patient outcomes. ${ }^{31}$ Hence, neglecting psychosocial aspects of chronic disease in health care is in direct conflict with scientific evidence. Health professionals need to wake up to this notion, and need to define their position in clinical guidelines and standards. This would allow biopsychosocial care to also become an integrated part of the reimbursement of care. Patients should be involved in the guideline development process to ensure that their values and biopsychosocial needs are incorporated in evidence-based guidelines. ${ }^{32}$ 


\section{CONCLUSIONS}

The current Dutch health care system does not encourage the provision of selfmanagement support that starts from the medical, emotional and social needs of individual patients - often with more than one chronic condition. All key players in this field need to break through the barrier of disease-oriented biomedical care. Scientific research, educational institutes and guideline developers have to equip multidisciplinary health teams with skills, tools and guidelines that help them to provide care starting from the patients' needs. If we expect patients to be responsible for their own health and be active partners in care, empowerment needs to be given high priority on the agenda of patient organisations. In addition, health policy makers, health insurers and the health inspectorate have the challenging task of developing a supportive health care and financial system in which health professionals are given incentives to provide biopsychosocial care. It is important that these key players take up their responsibility to realize the ideal of biopsychosocial chronic care. 


\section{REFERENCES}

1. Pomerleau J, Knai C, Nolte E, The burden of chronic disease in Europe, in Caring for people with chronic conditions: a health system perspective, Nolte E and McKee M, Editors. 2008, Open University Press: Berkshire. p. 15-41.

2. Blokstra A, Baan C, Boshuizen $\mathrm{H}$, et al., eds. Impact of the ageing population on burden of disease. Projections of chronic disease prevalence for 2005-2025. [Vergrijzing en toekomstige ziektelast. Prognose chronische ziektenprevalentie 2005-2025]. 2007, National Institute for Public Health and the Environment (RIVM): Eindhoven.

3. Rijken $\mathrm{M}$, Jones $\mathrm{M}$, Heijmans $\mathrm{M}$, et al., Supporting self-management, in Caring for people with chronic conditions: $a$ health system perspective, Nolte E and McKee M, Editors. 2008, Open University Press: Berkshire. p. 116-42.

4. Lorig KR, Holman H. Self-management education: history, definition, outcomes, and mechanisms. Ann Behav Med 2003;26:1-7.

5. Engel G. The need for a new medical model: a challenge for biomedicine. Science 1977;196:129-36.

6. Rutten GEHM, De Grauw WJC, Nijpels G, et al. NHG-Standaard Diabetes mellitus type 2 (Tweede herziening) [NHG Practice Guideline Diabetes mellitus type 2 (Second revision)]. Huisarts Wet 2006; 49:137-52.

7. Netherlands Diabetes Federation. NDF Care Standard. Transparancy and quality of diabetes care for people with type 2 diabetes. Amersfoort: Nederlandse Diabetes Federatie (NDF), 2007.

8. Tsiachristas A, Hipple-Walters B, Lemmens KMM, et al. Towards integrated care for chronic conditions: Dutch policy developments to overcome the (financial) barriers. Health Policy 2010; 101:122-32.

9. Pouwer F. Should we screen for emotional distress in type 2 diabetes mellitus? Nat Rev Endocrinol 2009;5:665-71.

10. Lucassen P, Van Rijswijk E, Van Weel-Baumgarten E, et al. Making fewer depression diagnoses: beneficial for patients? Ment Health Fam Med 2008;5:161-65.

11. Van Eijk JTM, Bosma H, Jonkers CC, et al. Prescribing antidepressants and benzodiazepines in the Netherlands: is chronic physical illness involved? Depress Res Treat 2010;Article ID 105931.

12. Polit DF, Beck CT, Nursing Research. Generating and assessing evidence for nursing practice. 8 th ed. 2008, Philadelphia: Wolters Kluwer Lippincot Williams \& Wilkins.

13. Novick G. Is there a bias against telephone interviews in qualitative research? Res Nurs Health 2008; 31:391-98.

14. Strauss A, Corbin J, Basics of qualitative research: grounded theory procedures and techniques. 2 ed. 1990, Newbury Park: Sage Publications, Inc.

15. Lincoln YS, Guba EG, Naturalistic Inquiry. 1985, Newbury Park, CA: Sage Publications Inc.

16. Boutain DM, Hitti J. Orienting multiple interviewers: the use of an interview orientation and standardized interview. Qual Health Res 2006;16:1302-09.

17. Borrell-Carrio F, Suchman AL, Epstein RM. The Biopsychosocial Model 25 Years Later: Principles, Practice, and Scientific Inquiry. Ann Fam Med 2004;2:576-82.

18. Van Weel-Baumgarten $E$, Lucassen $P$, Hassink-Franke L, et al. A different way of looking at depression. Int J Clin Pract 2010;64:1493-95.

19. Brouns M, Schadé B, Vlaskamp L, eds. Shared responsibility. Basics for a shift in paradigm in the training and care for the elderly. [Gedeelde verantwoordelijkheid. Basis voor een paradigmashift in de opleidingen en de zorg voor ouderen]. 2010, College voor Beroepen en Opleidingen in de Gezondheidszorg: Utrecht.

20. Koster A, Bosma H, Kempen GIJM, et al. Socioeconomic differences in incident depression in older adults: The role of psychosocial factors, physical health status, and behavioral factors. J Psychosom Res 2006;61:619-27.

21. Fiscella K, Epstein RM. So Much to Do, So Little Time: Care for the Socially Disadvantaged and the 15Minute Visit. Arch Intern Med 2008;168:1843-52. 
22. Van de Bovenkamp HM, Trappenburg MJ, Grit KJ. Patient participation in collective healthcare decision making: the Dutch model. Health Expect 2010;13:73-85.

23. Epstein RM, Fiscella K, Lesser CS, et al. Why the nation needs a policy push on patient-centered health care. Health Aff (Millwood) 2010;29:1489-95.

24. Okma KGH. Learning and Mislearning across Borders: What Can We (Not) Learn from the 2006 Health Care Reform in the Netherlands? Commentary on Rosenau and Lako. J Health Polit Policy Law 2008; 33:1057-71.

25. Long Alliantie Nederland. National care standard for COPD [Zorgstandaard COPD]. Amersfoort: Long Alliantie Nederland; 2010.

26. De Veer AJE, Brandt HE, Schellevis FG, et al. Small scale community care: innovative but well-known. A study of client experiences, family care givers, home care professionals and familiy physicians. [Buurtzorg: nieuw en toch vertrouwd. Een onderzoek naar de ervaringen van clienten, mantelzorgers, medewerkers en huisartsen]. Utrecht: Netherlands Institute for Health Services Research (NIVEL), 2008.

27. DiMatteo MR, Lepper HS, Croghan TW. Depression is a risk factor for noncompliance with medical treatment: meta-analysis of the effects of anxiety and depression on patient adherence. Arch Int Med 2000;160:2101-07.

28. Fisher L, Mullan JT, Arean P, et al. Diabetes distress but not clinical depression or depressive symptoms is associated with glycemic control in both cross-sectional and longitudinal analyses. Diabetes Care 2010;33:23-28.

29. Penninx BW. Inflammatory markers and depressed mood in older persons: results from the health, Aging and Body composition study. Biol Psychiatry 2003;54:566-72.

30. Egede LE, Ellis C. Diabetes and depression: Global perspectives. Diabetes Res Clin Pract 2010;87: 302-12.

31. Verheul W, Sanders A, Bensing J. The effects of physicians' affect-oriented communication style and raising expectations on analogue patients' anxiety, affect and expectancies. Patient Educ Couns 2010; 80:300-06.

32. Boivin A, Currie K, Fervers Ba, et al. Patient and public involvement in clinical guidelines: international experiences and future perspectives. Qual Saf Health Care 2010;19:1-4. 


\section{CHAPTER 3}

Integrating nurse-led Self-Management Support (SMS) in routine primary care: design of a hybrid effectiveness-implementation study among type 2 diabetes patients with problems of daily functioning and emotional distress. A study protocol

Anneke van Dijk - de Vries

Marloes A. van Bokhoven

Berend Terluin

Trudy van der Weijden Jacques Th. M. van Eijk

BMC Fam Pract 2013;14:77 


\section{ABSTRACT}

\section{Background}

Psychosocial problems are more prevalent among patients with chronic diseases than among the general population. They may lead to a downward spiral of poor adherence, deterioration of the condition and decline in daily functioning. In addition to medical management, systematic attention to emotional and role management tasks during routine chronic care seems mandatory. We intend to integrate an existing nurse-led minimal psychological intervention to support patients' self-management, which appeared to be effective and costeffective, in routine care by primary care nurses, so we adjusted it to fit the host setting. The resulting Self-Management Support (SMS) programme involves early detection of patients with emotional distress and problems of daily functioning, as well as self-management support through problem solving and reattribution techniques. Strategies to embed SMS in daily practice include training and booster sessions for practice nurses as well as organisational and financial arrangements. This study aims to simultaneously evaluate the implementation process and effects of SMS in routine care, using a hybrid effectiveness-implementation design.

\section{Methods / Design}

Registration data, questionnaires and interviews will be used to explore the facilitators, barriers and costs regarding successful implementation of SMS. The effects of SMS will be evaluated in a pragmatic cluster-randomised controlled trial with a baseline measurement and follow-up measurements after 4 and 12 months. The population will consist of 46 practice nurses and their type 2 diabetes patients ( $N=460 ; 10$ per practice nurse). The practice nurses will be randomly assigned to the intervention or control group. Practice nurses of the intervention group will receive SMS training. Patients for the intervention and control groups will be recruited by a researcher-led self-administered screening procedure to decide which patients of those scheduled for routine consultation are likely to be detected by the practice nurses as eligible for the self-management support. Primary outcome measure is patients' daily functioning. Secondary measures include emotional well-being, participation, autonomy and control over the disease.

\section{Discussion}

Our hybrid study design is complicated by the detection method used by the practice nurses. This method is an implementation issue in itself that has consequences for the realisation and power of the effect evaluation. 


\section{BACKGROUND}

The prevalence rate of psychosocial problems is higher among patients with chronic somatic diseases than among the general population. ${ }^{1-4}$ Problems like depression or distress may hamper the ability to manage a chronic condition. ${ }^{5} \mathrm{~A}$ reciprocal relationship has been suggested: emotional distress may interfere with control over the disease, and at the same time, poor control over the disease can lead to emotional distress. Persistent negative feelings have implications for adherence to medication and lifestyle regiments, motivation, self-efficacy and problem solving. ${ }^{6,7}$ Patients therefore face not only the day-to-day medical management, but also the challenge to deal with their emotions and problems of daily functioning in order to remain in control of their illness. ${ }^{6,8}$ To improve the outcomes of chronic care, Lorig and Holman argue that three self-management tasks should be addressed in primary care: medical management, emotional management and role management. ${ }^{8}$ However, Dutch guidelines for the care of chronic diseases like type 2 diabetes mellitus primarily focus on medical and lifestyle management. ${ }^{9,10}$ This seems too narrow a focus, as there is also room for improvement in the detection and treatment of emotional problems in the chronically ill., ${ }^{4,11,12}$

Our study intends to facilitate a shift towards a chronic care approach that combines attention to both biomedical and psychosocial aspects. We believe that equipping practice nurses (PNs) with the ability to provide this might be an effective way to realise such a biopsychosocial approach in chronic care. ${ }^{13}$ PNs in the Dutch primary care setting see patients on a regular basis, as they have the task of providing routine check-ups. ${ }^{14}$ Since diabetes patients were the first to be cared for by PNs, we aim to integrate an existing nurse-led minimal psychological intervention (MPI) in the diabetes follow-up care by PNs. The nurse-led MPI has proved to be effective in supporting the self-management skills of diabetes and COPD patients with minor to moderate depression. ${ }^{15-18}$

The MPI can only be adopted by PNs if a detection method is added that enables PNs to distinguish between patients who are active self-managers, patients who would benefit from the psychosocial support, and patients who need more specialised psychosocial diagnostics or treatment. We call the resulting stepped approach to detection and treatment 'Self-Management Support' (SMS). In addition to adapting 
the MPI to become SMS, we need to arrange for a training course with booster sessions, and ensure the allocation of time and organisational support to enable the PNs to adopt SMS in their current practice. For a thorough understanding of the effectiveness of SMS, the facilitators and barriers to its implementation in routine care need to be taken into account. Therefore, we want to start a hybrid effectivenessimplementation trial to examine the effectiveness of SMS in terms of patient outcomes, and focus on implementation outcomes.

\section{Aim}

The aim of our study is to evaluate the process and effectiveness of SMS implemented as an integral part of the care for patients with type 2 diabetes mellitus provided by PNs. We will simultaneously address the following research questions:

1. What is the uptake of the SMS programme by the practice nurses, and what barriers hamper the implementation of SMS in routine primary care? (Study of the implementation strategies for SMS)

2. What is the effectiveness of SMS in terms of daily functioning, emotional health status, social participation, self-management behaviour, and health care use by patients with type 2 diabetes? (Study of the SMS clinical intervention)

The effectiveness of SMS (question 2) will be considered while taking the barriers to the implementation process (question 1 ) into account.

\section{METHODS}

\section{Design}

In our study, we will use a hybrid effectiveness-implementation design to focus on implementation issues and the effectiveness of SMS at the same time. Curran and colleagues have presented a continuum of three types of such hybrid effectivenessimplementation (E-I) study designs, ${ }^{19}$ ranging from effectiveness research with minimal implementation strategies (type 1) to designs where effectiveness and implementation are equally balanced (type 2) and an implementation approach with minimal focus on effectiveness outcomes (type 3). We will examine the effects of SMS on patient outcomes and simultaneously focus on implementation outcomes, hence it is a type 2 hybrid E-I study design. 
Below, we first describe our implementation strategies (intervention) and then explain our evaluation methods regarding the implementation and effects of SMS in routine care (evaluation).

\section{Intervention}

In a previous study, the nurse-led minimal psychological intervention (MPI) was carried out by trained research nurses. ${ }^{20}$ In our present study, practice nurses who provide diabetes care will have to adopt the MPI in their current practice. This required changes with regard to the clinical intervention as well as the organisational context in which the intervention will be integrated. ${ }^{21}$ This section explains the steps that will be taken to implement the resulting SMS in routine diabetes care.

\section{Implementation strategy 1: Adaptation of clinical intervention}

The nurse-led MPI has been altered from a 'research object' to an intervention that can be systematically embedded in routine primary care. Adaptations were needed regarding the target group, providers, detection of eligible patients and selfmanagement support. The shift from MPI to SMS is summarised in table 3.1.

Table 3.1 The SMS approach contrasted with the original MPI

\begin{tabular}{|c|c|c|}
\hline & MPI & SMS \\
\hline Target group & $\begin{array}{l}\text { Chronic patients with mild or non- } \\
\text { severe major depression }\end{array}$ & $\begin{array}{l}\text { Chronic patients with emotional } \\
\text { distress and problems of daily } \\
\text { functioning }\end{array}$ \\
\hline Providers & $\begin{array}{l}\text { Research nurses } \\
\text { not involved in usual care }\end{array}$ & $\begin{array}{l}\text { Practice nurses } \\
\text { providing usual chronic care }\end{array}$ \\
\hline Diagnostic approach & $\begin{array}{l}\text { For research purposes. } \\
\text { Using an extensive diagnostic } \\
\text { interview, following strict } \\
\text { psychiatric criteria }\end{array}$ & $\begin{array}{l}\text { As part of daily care. } \\
\text { Using simple tools, } \\
\text { following a stepped care approach } \\
\text { that fits the primary care setting }\end{array}$ \\
\hline $\begin{array}{l}\text { Self-management support } \\
\text { intervention }\end{array}$ & $\begin{array}{l}\text { 1. cognitive therapy (reattribution) } \\
\text { 2. problem solving }\end{array}$ & $\begin{array}{l}\text { 1. problem solving } \\
\text { 2. cognitive therapy (reattribution) }\end{array}$ \\
\hline
\end{tabular}

\section{Target group}

The original effective nurse-led MPI was provided specifically to patients with a diagnosis of depression, whereas a wide range of psychological and social problems occur in a routine primary care setting. What primarily matters in daily practice is to 
what extent patients experience problems of daily functioning. ${ }^{12}$ SMS was therefore designed for chronic patients who encounter problems of daily functioning and emotional distress.

\section{Providers}

Instead of research nurses providing the intervention as an add-on to usual care, SMS will be integrated in usual care provided by PNs. PNs work in general practice under supervision of a GP. They see type 2 diabetes patients every 3 months for a diabetes check-up. SMS is to become an integral part of these check-ups.

\section{Detection procedure}

The diagnostic procedure that was used to recruit patients for the study to evaluate the original MPI is not feasible in routine primary care: it was limited to depression, and included an extensive and time-consuming diagnostic interview (the Mini International Neuropsychiatry Interview) to confirm a diagnosis of depression according to psychiatric criteria. For SMS, PNs will have to decide during routine diabetes check-ups whether watchful waiting, offering psychosocial self-management support or a referral to the GP because of symptoms of mental health problems is most appropriate. Therefore, we have introduced a stepped approach that allows interventions not sooner or more intense than necessary and not later or less intense than required. The approach is as follows. During each regular diabetes check-up, PNs will explore whether the patient is experiencing problems in daily life. Then they verbally administer the 'Daily Functioning Thermometer' (DFT), a visual analogue scale to rate the overall burden of diabetes. (See the Measurements section below for more information about the instruments.) Practice nurses will also verbally administer the 3-item Distress Screener (DS), a quick-scan instrument for emotional distress and an indicator of potential underlying severe mental health problems. ${ }^{22}$ Patients with DS $>3$ will be asked to complete the Four-Dimensional Symptom Questionnaire (4DSQ) ${ }^{23}$ immediately after the consultation. This self-report measure is widely used in Dutch primary care to distinguish non-specific general distress from depression, anxiety and somatisation. Scoring the 50 items of the 4DSQ should take 5-10 minutes. The completed 4DSQ will be returned to the PN, who will score the 4DSQ using a scoring form. Patient's scores on the 4DSQ will distinguish between mild, moderate and severe mental health problems. Patients who experience problems of daily functioning (DFT >4) and emotional health problems (DS >3 combined with moderate 
scores on subscales of the 4DSQ) will receive self-management support from the PN. If a patient has only 'mild' scores on the 4DSQ, the PNs will opt for watchful waiting. The same option will be used for patients with moderate scores on the 4DSQ who do not report problems of daily functioning due to diabetes (DFT $\leq 4)$. These patients will be informed by telephone that there is as yet no indication for extra consultations. Patients with a 'severe' score on at least one of the subscales will be referred to the GP. The detection protocol is summarised in table 3.2.

Table 3.2 Detection protocol

\begin{tabular}{lll}
\hline & DFT $\leq 4$ & DFT $>4$ \\
\hline DS $\leq 3$ & No indication & Watchful waiting \\
DS $>3$ & On the basis of the 4DSQ: & On the basis of the 4DSQ: \\
& Mild: watchful waiting & Mild: watchful waiting \\
& Moderate: watchful waiting & Moderate: self-management support by PN \\
& Severe: referral to GP & Severe: referral to GP \\
\hline
\end{tabular}

\section{Self-management support programme}

The self-management support by the PN will be provided during extra 20-minute consultations. Its aim is to teach patients to take responsibility for the day-to-day management of their diabetes and its consequences. This self-management support is based on the MPI. The intervention strategy has been derived from principles of learning theory and has been described elsewhere. ${ }^{24}$ PNs will help patients to define problems and solutions themselves, applying the techniques of problem-solving and reattribution. Problem-solving consists of 7 stages that efficiently address psychosocial problems and their possible solutions. ${ }^{25}$ It starts by creating a link between emotional symptoms and problems, and explaining the rationale of the treatment: resolution of the problems may lead to resolution of the symptoms (step 1).

Step 2 involves clarifying and defining the problem. The third step is to set achievable goals. Once an achievable goal has been set, the patient will be asked to brainstorm about all potential solutions (step 4). Step 5 involves considering the pros and cons and selecting a preferred solution. In step 6 , the solution will be implemented in daily life, and step 7 involves evaluating the progress. The problem-solving approach can easily be understood by patients and can also easily be taught to practice nurses. ${ }^{25}$ Patients with strong emotional involvement will be supported using the reattribution technique. This starts by exploring and defining the patient's problem, after which the patient is challenged to link cognitions to behaviour. 
To this end, patients may keep a diary to record thoughts, behaviours and related feelings. After possibilities to alter specific behaviours have been explored, an action plan will be formulated indicating how the goals can be achieved. ${ }^{20}$ If specific problems appear to be persistent and serious over time, action will be undertaken to provide more specialised care. PNs are instructed to refer these patients to the GP.

In the original MPI, the cognitive approach appeared to benefit more highly educated patients more than lower educated ones. ${ }^{18}$ The SMS will be implemented in a region in the south of the Netherlands that is characterised by relatively low socio-economic status, ${ }^{26}$ so in order to increase the benefit for patients with low socio-economic status, we will put greater emphasis on the problem-solving technique during the training of PNs.

A flowchart of SMS is presented in figure 3.1.

\section{Implementation strategy 2: involvement of regional GP organisation}

SMS will be implemented in one region in the south of the Netherlands. A group of 77 general practices (103 GPs) in the region, who collaborate in a GP organisation, was involved from the beginning of the SMS project, and they have prioritised the integration of SMS in the care for type 2 diabetes patients. The GPs are responsible for about 16,000 patients with type 2 diabetes mellitus. The region is characterised by relatively low socio-economic status, health status and life expectancy and substantial ageing of the population. ${ }^{26,27}$ Based on earlier research findings we estimate that as many as 2400 patients with type 2 diabetes mellitus (15\%) may suffer from emotional distress accompanied by problems of daily functioning. ${ }^{28}$ 


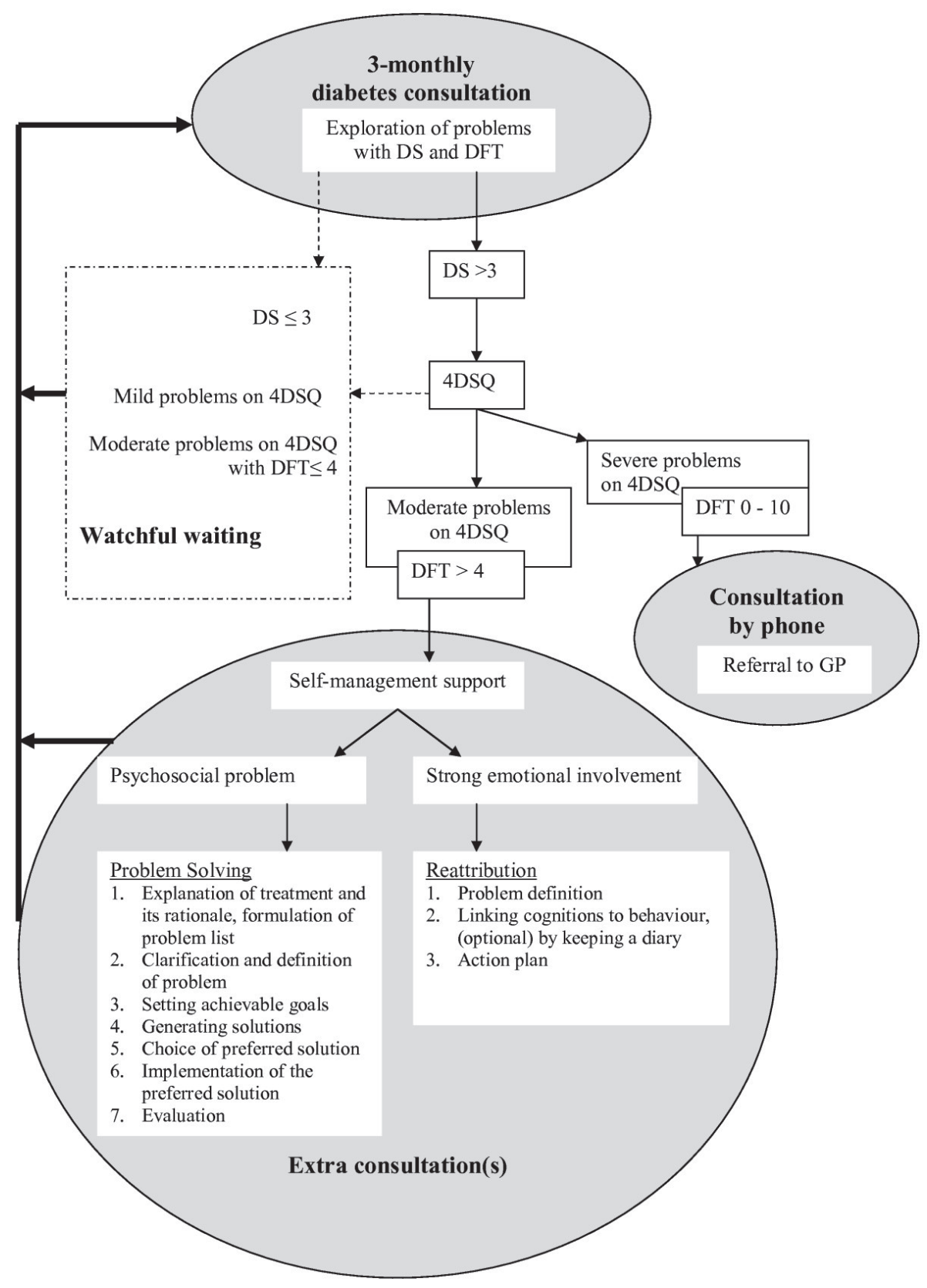




\section{Implementation strategy 3: financial support}

The reimbursement of diabetes care in the Netherlands is regulated by means of diagnosis-treatment combinations (DTC), a Dutch variant of the Diagnosis Related Groups. $^{29}$ For each care group, health insurers purchase integrated care by negotiating a fixed price per patient per year. The elements of care with corresponding tariffs are defined in a shared care protocol. This is driven by the Dutch 'care standard' for diabetes, ${ }^{9}$ which is based on existing guidelines, protocols and performance indicators. During the study, a health insurance company will reimburse the extra time spent on SMS by PNs and GPs. The reimbursement will be integrated in the DTC for diabetes care.

\section{Implementation strategy 4: training}

The PNs in the intervention group will be trained to carry out SMS in three 8-hour training sessions. The training programme is based on a nurses' training course that has been shown to be feasible, attractive and successful. PNs learn how to help patients identify their problems and set achievable goals. ${ }^{24}$ The training programme will also focus on exploration skills. PNs will learn to use instruments to establish the severity of psychosocial problems in a stepped approach (first DFT and DS, and if appropriate further exploration using 4DSQ). The training sessions will take place in small groups, to facilitate active participation of the PNs, for example by role-play. These three training sessions will be followed up by booster sessions and telephone consultations, whose frequency will depend on the PNs' needs. Booster sessions will be used to maintain and improve the PNs' SMS skills. PNs will make audiotapes during consultations, which will be reflected on during booster sessions.

\section{Implementation strategy 5: registration system for SMS}

SMS will be integrated in the registration system that GPs and PNs use for diabetes care. The steps to be taken during the detection phase of SMS as well as the different stages of the self-management support by the PN are displayed in the regular registration system. PNs will record how patients rate their burden of diabetes (DFT), as well as their scores on the distress screener (DS). This information will be displayed at the next diabetes check-up. The system also helps PNs compute the outcomes of the 50 item of the 4DSQ. The PNs will also record the self-management support steps that are taken during each consultation, and the patients' action plans. 


\section{Evaluation of the implementation process}

\section{Design}

A process evaluation will be done to analyse the facilitators and barriers regarding integration of SMS in routine care. We will gather quantitative and qualitative data about the intervention as an integral part of the routine diabetes care, as well as about the health professionals (PNs and GPS) and patients, and the impact of SMS on the practice organisation and the community. ${ }^{30}$ How SMS has been implemented and received by the participants will be measured by means of the following concepts, as recommended by Saunders and colleagues. ${ }^{31}$ fidelity, dose delivered, dose received, reach, recruitment and context. In addition, the costs of implementing SMS in routine care will be assessed. The process evaluation will include formative evaluation with respect to the new components of the clinical intervention, as these aspects may need to be refined or optimised to make them fit the local setting.

\section{Variables and measurements}

Fidelity refers to the extent to which SMS has been implemented as planned. At each diabetes consultation, the PNs will record which steps of the SMS protocol have been carried out. The outcomes on the DS, DFT and 4DSQ, the choices that have been made regarding further treatment and the patients' action plans will also be recorded. The registration system also offers room for comments. PNs will be asked to give an explanation if they deviate from the SMS protocol.

Dose delivered is measured as the number of components of SMS per patient that have been carried out as intended. Data will be derived from the registration system.

Dose received includes two components: satisfaction and exposure. Exposure refers to the extent to which participants (patients and health professionals) are actively engaged with the SMS programme and use the tools of SMS in daily practice. Engagement and satisfaction of participants will be measured among the providers (PNs and GPs) and among the patients.

PNs will be asked to complete an evaluation form after the training sessions, with questions about the clarity of wording of the components of the training course. With regard to the integration of SMS in routine diabetes consultations, issues discussed with PNs during booster sessions will be recorded during the follow-up period. This 
will provide qualitative information about the barriers and facilitators that PNs may experience. At the end of the follow-up period (one year after the SMS training course), we will develop a questionnaire including all the barriers and facilitators that have been discussed during the booster sessions. PNs will be asked to individually rate all these issues.

The engagement and satisfaction of GPs will be evaluated by means of selfadministered questionnaires. All participating GPs from the intervention arm will be asked about their involvement in the SMS programme and their views on the impact of SMS for their practice.

How patients experience being involved in the SMS programme will be explored in detail by holding semi-structured interviews with a purposive sample of patients who have received the SMS from their PN. These interviews will be held during the followup period. The topics include patients' experiences with the detection phase of SMS, the self-management support, the opportunities for and barriers to the implementation of their action plans in daily life, and their suggestions for improvement of the SMS. Interviews with patients will be audio-taped and transcribed verbatim.

Recruitment refers to the way we have approached and invited the PNs and GPs to become involved in the project to implement and evaluate SMS.

Reach refers to the participation rate and will be measured as the number of GPs and PNs who actually participated.

Context refers to the factors relating to the practice, the community, the social/political context, or other situational issues that affect either the implementation of SMS or its outcomes. To examine context issues in terms of the implementation and effect of SMS, we will draw up the minutes of meetings with the regional care group of general practitioners, the health insurer and our research team.

\section{Cost evaluation}

We will measure the direct costs of SMS. In addition to the training and booster sessions, these will include the time to integrate SMS in routine diabetes consultations. PNs will record the time they spend on each stage of the stepped SMS approach. 


\section{Data analysis}

Data of the implementation study will be analysed by means of descriptive statistics. The qualitative interviews with patients will be analysed by interpretative phenomenological analysis, a framework that can be used to develop in-depth descriptions of patients' experiences. The purpose is to explore the patients' perceptions of what is important in relation to SMS. We will abstract themes and cluster them for each case. ${ }^{32}$ Abstracting and clustering of the themes will be done independently by two researchers.

\section{Clinical effect evaluation}

\section{Design}

The effect evaluation of SMS involves a pragmatic 2-armed cluster-randomised controlled trial (cluster-RCT) with PNs as the unit of randomisation. Allocation concealment will be achieved by having an independent experienced research assistant perform a blockwise randomisation using a random number seed computer program. PNs ( $n=46)$ will be assigned to an intervention group or control group at an allocation ratio of $1: 1$, after stratification into PNs working alone in a practice, PNs working in a team and PNs working in different practices. PNs working in the same general practice will be randomised to the same trial arm.

PNs in the intervention arm will be trained to apply SMS in addition to the usual care, which consists of 3-monthly diabetes check-ups according to the current guidelines. ${ }^{10}$ PNs in the control arm will be instructed to provide usual care.

Patients with emotional distress and problems of daily functioning will be included in the effect evaluation. To maintain the balance between the intervention and control groups, a screening procedure will be carried out by the research centre. A selfadministered postal questionnaire will be used to detect eligible patients.

Approval for this study has been obtained from the Medical Ethics Committee of Maastricht University/University Hospital Maastricht. 


\section{Sample size calculation}

Assuming an alpha of 0.05 and a beta of 0.90 , an improvement in perceived daily functioning (defined as a score less than or equal to 4 on the Daily Functioning Thermometer (DFT), our primary outcome) at T12 occurring in $20 \%$ of the patients in the intervention group versus $5 \%$ of those in the control group requires at least a net number of 116 patients per arm ( $\mathrm{N}=232 ; 5$ patients per practice nurse). It will be necessary to take account of a possible dependence between observations on patients of the same practice nurse. The intra-class correlation coefficient (ICC) is assumed to be 0.04 , a median value for cluster-RCTs in the primary care setting. ${ }^{33}$ Assuming a $30 \%$ loss to follow-up ${ }^{17}$ we need to recruit at least 331 patients (8 per PN). Since participation in the screening procedure will not necessarily mean that patients also give informed consent for the effect evaluation, 10 consecutive patients for each $\mathrm{PN}$ will be invited to participate in the effect evaluation $(\mathrm{N}=460)$.

\section{Patient recruitment}

All patients with a clinically established diagnosis of type 2 diabetes mellitus who are able to read and write Dutch will be sent a letter by their GP, explaining SMS and asking for informed consent to participate. Patients will receive this letter six weeks before a planned diabetes consultation with their PN. The enclosed screening questionnaire will contain the same instruments that PNs in the intervention group are going to use to detect whether patients are eligible for the self-management support, i.e. the 'Daily Functioning Thermometer' (DFT) and the 3-item Distress Screener (DS). ${ }^{22}$ For more information about these instruments, see the section on Measurements below. Patients will be asked to return the completed questionnaire to the research centre and give informed consent for their data to be used for recruitment if they are found to be at risk. For each practice nurse, 10 consecutive patients with scores of DFT $>4$ and DS $>3$ will be asked to participate in the study and to give informed consent for the follow-up measurements. To prevent bias, PNs will not be notified about the outcomes of the recruitment procedure.

A flowchart of the trial is shown in figure 3.2. 
Figure 3.2 Flowchart of the SMS-trial

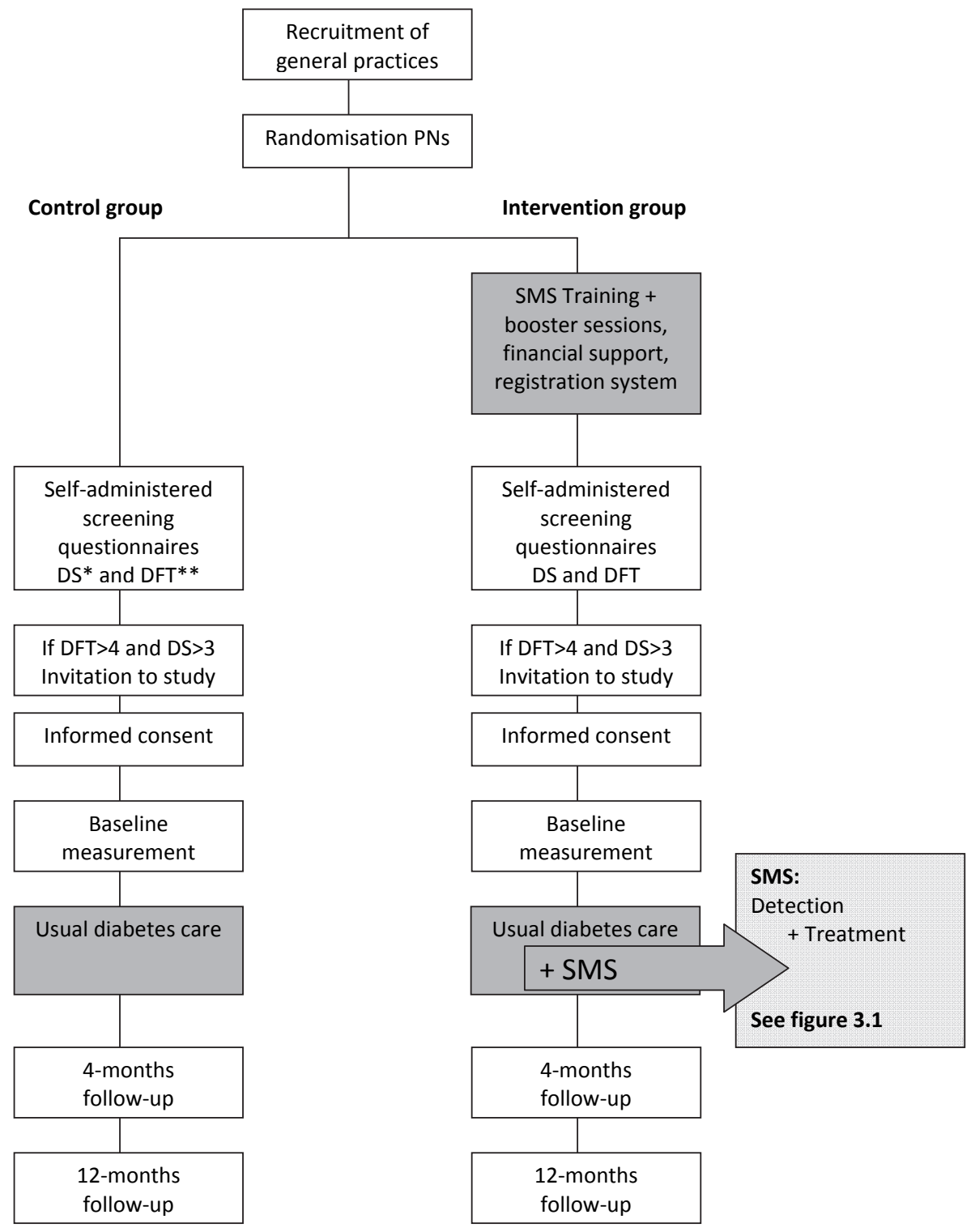




\section{Measurements}

To assess the effectiveness of SMS, follow-up measurements will be carried out at baseline and 4 and 12 months after inclusion. Table 3.3 provides an overview of the measures of the effect evaluation and the times of assessment.

Table 3.3 Effect evaluation: Outcome measures and time of assessment

\begin{tabular}{|c|c|c|c|c|c|c|c|}
\hline \multicolumn{2}{|l|}{ Concept } & Measurement & Items & $\begin{array}{l}\text { Moment in time } \\
\text { 3-monthly diabetes } \\
\text { consultations } \\
\text { during follow-up }\end{array}$ & TO & $\mathrm{T}-4$ & $\mathrm{~T}-12$ \\
\hline \multicolumn{8}{|l|}{ Primary outcome } \\
\hline \multicolumn{2}{|l|}{ Daily functioning } & DFT & 1 & & $*$ & $*$ & $*$ \\
\hline \multicolumn{8}{|c|}{ Secondary outcomes } \\
\hline \multicolumn{2}{|c|}{$\begin{array}{l}\text { Diabetes-related emotional } \\
\text { distress }\end{array}$} & PAID & 20 & & $*$ & $*$ & $*$ \\
\hline \multirow{2}{*}{\multicolumn{2}{|c|}{ Mental health problems }} & PSYCHLOPS & 9 & & $*^{1}$ & $*$ & $*$ \\
\hline & & 4DSQ & 50 & $*^{2}$ & & $*$ & $*$ \\
\hline \multicolumn{2}{|l|}{ Quality of life } & SF-12 & 12 & & $*$ & $*$ & $*$ \\
\hline \multicolumn{2}{|c|}{ Participation and autonomy } & IPA & $32+9$ & & $*$ & $*$ & $*$ \\
\hline \multicolumn{2}{|l|}{ Job performance } & SF-HLQ & 5 & & $*$ & $*$ & $*$ \\
\hline \multicolumn{2}{|c|}{$\begin{array}{l}\text { Self-management knowledge } \\
\text { and behaviour }\end{array}$} & $\mathrm{PIH}-\mathrm{NL}$ & 12 & & $*$ & $*$ & $*$ \\
\hline \multicolumn{2}{|c|}{ General self-efficacy } & GSES-12 & 12 & & $*$ & $*$ & $*$ \\
\hline \multicolumn{2}{|c|}{ Control over the disease } & $\begin{array}{l}\text { Average blood glucose } \\
\text { level (HbA1c) }\end{array}$ & 1 & $*$ & & & \\
\hline \multicolumn{3}{|l|}{ Health care use } & 5 & & $*$ & $*$ & $*$ \\
\hline \multicolumn{8}{|l|}{ Covariates } \\
\hline \multirow{6}{*}{$\begin{array}{l}\text { Patient } \\
\text { demographics }\end{array}$} & \multicolumn{2}{|l|}{ Sex } & 1 & & $*$ & & \\
\hline & \multicolumn{2}{|l|}{ Age } & 1 & & $*$ & & \\
\hline & \multicolumn{2}{|c|}{ Year of diagnosis } & 1 & & $*$ & & \\
\hline & \multicolumn{2}{|c|}{ Treatment of diabetes } & 1 & & $*$ & & \\
\hline & \multicolumn{2}{|c|}{ Marital status } & 1 & & $*$ & & \\
\hline & \multicolumn{2}{|l|}{ Education } & 1 & & $*$ & & \\
\hline \multirow{3}{*}{$\begin{array}{l}\text { Practice nurse } \\
\text { demographics }\end{array}$} & \multicolumn{2}{|l|}{ Age } & 1 & & $*$ & & \\
\hline & \multicolumn{2}{|l|}{ Training } & 1 & & $*$ & & \\
\hline & \multicolumn{2}{|c|}{$\begin{array}{l}\text { Type of general practice(s) } \\
\text { (one GP, two GPs, group, health } \\
\text { centre) }\end{array}$} & 1 & & $*$ & & \\
\hline
\end{tabular}

1 Only patients in intervention arm. Risk of contamination. 2 Only eligible patients (Distress Screener $>3$ )

\section{Background variables}

Patient variables that will be reported are sex, age, year of diagnosis, treatment of diabetes (insulin therapy or tablets), marital status and education. Furthermore, we will record the age of the PNs, the number of PNs for diabetes management working in a general practice, as well as the educational background of the PNs. 


\section{Primary outcome measure}

The primary outcome will be daily functioning as measured by means of the Daily Functioning Thermometer (DFT). This is a visual analogue scale (VAS) on which patients can rate the overall burden of diabetes on their daily functioning by indicating a position along a continuous vertical $100 \mathrm{~mm}$ line between 0 ('no burden at all') and 10 ('extreme burden'). The VAS score is determined by measuring the distance to the point marked by the patient, in millimetres. The DFT is comparable to the Distress Thermometer (DT), an easily understood, valid and feasible self-report measure of distress used among various groups of cancer patients. ${ }^{34}$ A cut-off score of 4 has been chosen to differentiate between patients who could benefit from selfmanagement support by the PN (DFT >4) and patients who have apparently found a satisfactory way to live with the consequences of their diabetes (DFT $\leq 4)$. A pilot study among 7 patients with type 2 diabetes mellitus confirmed the face validity of the DFT.

\section{Secondary outcome measures}

Three instruments will assess patients' emotional health status.

Diabetes-related emotional distress will be measured by means of the Problem Areas in Diabetes questionnaire (PAID). This 20-item scale (with five-point Likert scales) describes common problematic situations for diabetes patients, each representing a unique area of diabetes-specific emotional distress. The sum of the scores for the 20 items is multiplied by 1.25 to get a final score between 0 and 100. The Dutch PAID has good internal consistency and validity. ${ }^{35-37}$

The Four-Dimensional Symptom Questionnaire (4DSQ) will be used to measure the presence and severity of mental health problems. ${ }^{23}$ The levels of distress (16 items), depression ( 6 items), anxiety (12 items) and somatisation (16 items) will be assessed. The reference period is 'the past week'. The item scores are summated to obtain scale scores. The 4DSQ has been found to be a valid self-reported questionnaire in the primary care setting. ${ }^{23}$ For a more qualitative evaluation of emotional problems that patients experience, we will use the Psychological Outcome Profiles (PSYCHLOPS). The PSYCHLOPS asks patients to describe and score their own emotional health problems. It is a validated patient-generated measure with pre-therapy, during-therapy and post-therapy versions. The instrument is intended to measure individual changes. It is responsive to change and is internally consistent. ${ }^{38}$ Both PSYCHLOPS and 4DSQ explicitly expect patients to define and rate their emotional health problems. An 
increased awareness about their emotional problems of daily functioning could influence the issues discussed during the diabetes consultation, which could result in reduced contrast between the two groups. We will not use the 4DSQ and the PSYCHLOPS in the control group at TO, as the timing of the baseline measurement is just before a diabetes consultation, whereas the assessment at T4 is further removed from a diabetes consultation. Inclusion of the PSYCHLOPS and 4DSQ at both T4 and at the end of the follow-up period (T12) will provide insight into individual changes. In the intervention group, inclusion of the PSYCHLOPS at baseline will provide valuable information about the patients' individual emotional problems. The 4DSQ does not need to be included in the baseline measurement as it is already part of the SMS intervention.

Quality of life, i.e. functional health and well-being from the patient's point of view, will be measured by means of the 12-item Short-Form Health Survey (SF-12), a validated subset of the generic health status questionnaire SF-36. ${ }^{39,40}$ Data will be summarised in 2 scales: a physical component summary (PCS) and a mental component summary (MCS).

Participation and autonomy will be measured by means of the Impact on Participation and Autonomy (IPA) questionnaire. The IPA has proved to be valid, reliable and responsive to change. ${ }^{41}$ Thirty-two items (five-point Likert scales) cover five domains of participation: 'autonomy indoors', 'family role', 'autonomy outdoors', 'social life and relationships' and 'work and education'. A score for each subscale will be calculated. In addition, 9 items will evaluate the extent to which limitations are experienced as problematic: 'no problems', 'minor problems' or 'major problems'. These items will be scored separately. ${ }^{42}$

Five items from the Short-Form Health and Labour Questionnaire (SF-HLQ) will be used to measure difficulties of job performance due to health problems. The SF-HLQ is a generic and validated measurement to collect data about productivity loss relating to health problems. ${ }^{43}$

Patients' self-management knowledge and behaviours regarding their diabetes will be measured by the Partners in Health (PIH) scale. ${ }^{44}$ This scale reliably and validly measures aspects of patient progress within a self-management programme for a 
chronic condition. We will use the Dutch version (PIH-NL). The 12 items (0-8 Likert scales with 0 indicating high self-management and 8 low self-management) cover four domains of patients' competency in relation to the self-management of their chronic condition (knowledge, coping, management of condition and adherence to treatment).

The General Self-Efficacy Scale (GSES-12) will be used to assess the patients' belief in their ability to organise and engage in certain behaviours. The sum score of the 12 items (five-point Likert scales) reflects an internally consistent and stable unidimensional construct of general self-efficacy. ${ }^{45,46}$

At each diabetes consultation, the blood glucose level over the past 2 to 3 months (HbA1c) will be measured and recorded in the registration system.

The effect of SMS on patients' health care utilisation refers to individual numbers of visits to the general practice, specialist referrals and admissions, mental health care consultations, use of home care and hours of paid and unpaid household help. Patients will record their health care use retrospectively (over the last month) in the patient questionnaires administered at baseline and after 4 and 12 months. Data about referrals to the GP, and the number of contacts with the general practice will be collected from the GP's registration system.

\section{Data analysis of the effect evaluation}

The effectiveness of SMS will be assessed by intention-to-treat analyses. The comparability of patients in the intervention and control groups regarding baseline characteristics and demographics will be described and tested for significant differences (t-tests and Chi-square tests). The average changes in DFT score will be calculated, as well as the number of patients that have DFT $\leq 4$ after receiving SMS (T4 and T12). Separate scores will be calculated for the subscales of the secondary outcome measures. Changes in the primary and secondary outcomes between the intervention and control groups will be analysed using multilevel analyses (linear and logistic regression methods) as this will account for intracluster correlation among PNs. Multivariate regression analyses will be used to adjust the results for co-variables such as patient characteristics (age, sex, socio-economic status) and PN characteristics (age, educational background). 


\section{DISCUSSION}

This paper describes a study protocol to implement and evaluate an evidence-based, nurse-led minimal psychological intervention (MPI) in routine diabetes care in the Dutch primary care setting. The intervention itself has already been found to be an effective and cost-effective method to improve self-management by chronic patients with mild to moderate depression, but its effect was evaluated in a trial with standardised conditions regarding the inclusion of patients, and the care was delivered by research nurses. ${ }^{20}$ Both GPs and a health insurer have prioritised the inclusion of the MPI in routine diabetes care, so there was an 'implementation momentum' within the system. ${ }^{19}$ Actually making this happen required adaptations to be introduced regarding providers, target group and detection procedure. The new approach has been named Self-Management Support (SMS).

\section{Our hybrid design and its potential}

The effects of integrating SMS in the routine primary care setting can only be evaluated when it is implemented in the 'real world'; the implementation strategies will be decisive for the success of SMS at the practice and patient levels. The essential adjustments to the intervention with regard to both providers and recipients require further insights into the effectiveness of SMS. An understanding of both the prerequisites of integrating SMS in routine care and the effectiveness of SMS is essential for future planning. In terms of the continuum of design types proposed by Curran and colleagues, ${ }^{19}$ our study is an example of a type 2 hybrid effectivenessimplementation (E-I) study design. The effects and the implementation process will be evaluated simultaneously.

Curran and colleagues ${ }^{19}$ argue that the combination of two study designs in a hybrid study may have the potential to accelerate the translation of research into routine practice. They refer to the dominant approach of translating research into practice that starts with clinical efficacy research, then clinical effectiveness research, and finally implementation research. The potential for rapid integration of research into practice is also apparent in our study. SMS evolved from a joint endeavour of the regional care organisation of general practitioners, the health insurer and the evaluators. The intervention has been developed as a generic approach to support patients' self-management. The outcomes of the implementation and evaluation of 
SMS will provide a broad perspective on barriers, facilitators and effects of the detection and treatment of psychosocial problems by PNs in chronic care. Hence, if SMS appears to be successfully implemented and has relevant effects, it could in the near future also be applied to patients with other chronic conditions. The shared vision of stakeholders regarding SMS and their involvement in the development and evaluation is expected to facilitate a rapid large-scale integration of SMS in routine care.

\section{Our hybrid design and its methodological challenges}

In hybrid E-I studies, the world of implementation science has to combine with the tradition and vocabulary of researchers from clinical research backgrounds. This implies a complex balance in the design itself between internal validity and factors associated with implementation, but also can be an obstacle to funding and publication. $^{19,47}$

Our study involves an additional methodological issue with respect to hybrid design, viz. the new detection method that is introduced in our study to integrate the original MPI in routine care. Its feasibility in routine diabetes consultations is not yet known, and needs to be evaluated as part of our process evaluation. However, an adequate detection method is also a prerequisite for clinical effectiveness of SMS. The methodological issues regarding the detection method are further explained below.

In order to integrate the MPI in the daily care by PNs, we had to introduce a new detection method to fit the primary care setting. The MPI has been adapted to become a self-management intervention for patients with problems of daily functioning and emotional distress. As there was no primary care instrument available to detect patients with these psychosocial problems, we have introduced new instruments in the form of the Distress Screener and the Daily Functioning Thermometer, and defined the cut-off criteria.

The Distress Screener and the Daily Functioning Thermometer are assumed to be valid for the early detection of patients with emotional distress and problems of daily functioning. ${ }^{22,34}$ These instruments will be integrated into the routine diabetes consultations provided by PNs. Our implementation strategies (i.e. providing training, financial support and a registration system) will determine whether PNs are able to integrate the instruments in their daily practice. Evaluation of the implementation 
process will show what numbers of patients are detected, whether patients with problems of daily functioning (according to the DFT) and with moderate psychological problems (according to the Four-Dimensional Symptom Questionnaire, 4DSQ) are representative of the group of patients that are in need of the self-management support, and to what extent PNs have the skills to integrate the tools in their routine consultations. The feasibility, power and success of our detection method are unknown and will determine the success and feasibility of the whole SMS approach.

The detection method will an integral part of the tasks of the PNs during a routine diabetes consultation. PNs will be given a reasonable degree of freedom in applying the detection method in their consultations, as we use a pragmatic approach without strict internal controls. We aim to avoid interference of research activities with daily practice as much as possible, which has implications for the recruitment of patients for the effect evaluation.

In theory, all patients with diabetes would be eligible for participation in the effect evaluation of SMS, as the PNs will apply the detection part of SMS in every diabetes consultation. However, we have chosen to limit the effect evaluation to patients with actual problems of daily functioning and emotional distress. This will increase the contrast between the intervention and control groups, so we need to include patients that are likely to be detected during regular care and receive further treatment. We had to set up a researcher-led parallel screening procedure to detect eligible patients from both the intervention and control groups.

Based on our pragmatic approach, the conditions for this screening procedure are:

1. The self-administered screening questionnaire is sent to the patient's home address and includes the instruments that PNs apply during consultation.

2. The screening does not interfere with daily practice in the control arm. As the DFT and DS consist of simple and generic questions, we do not expect any interference with daily care.

3. The time interval between the researcher-led screening and the nurse-led detection procedure needs to be limited. We have decided to send the screening questionnaire six weeks before the individual diabetes consultation appointment. 
However, we cannot avoid the risk that natural fluctuations in the emotional health status of patients will result in different outcomes on the DFT and DS in the nurse-led detection compared to the researcher-led postal screening. The time interval could become too long, for example if a consultation appointment is cancelled. We thus have to take into account that conclusions based on the researcher-led screening questionnaires will not always correspond to those of the same instruments applied by the PNs during the consultations. As a consequence, a certain number of patients in our study sample will only be exposed to the detection part of SMS, without receiving follow-up treatment, while some patients who are not included in the effect evaluation may receive the self-management support. This may reduce the contrast between the intervention and control arms.

In conclusion, the strength of the clinical effectiveness evaluation in our study greatly depends on two risk factors of our hybrid design:

1. the extent to which PNs are able to detect patients who need the selfmanagement support; and

2. the match between the patients who are detected by the researcher-led screening and those detected by the PN.

If PNs in our study would, for any reason, not detect or not treat patients who are recruited for the effect evaluation on the basis of the researcher-led screening, it may become difficult to demonstrate the clinical effectiveness of SMS. Nevertheless, the clinical effectiveness outcomes of SMS integrated in routine care are very important for decisions about future planning and (financial) support for SMS. If we are unable to demonstrate clinical effectiveness of SMS, the speed of translation of the evidencebased intervention into routine care may even be threatened due to the methodological issues of a hybrid effectiveness-implementation design. We will try to minimise the risks by providing training to PNs, followed by booster sessions, using a formative evaluation method that gives us the opportunity to refine the detection procedure, and by a researcher-led screening that closely resembles the detection at the consultation in terms of timing and procedure. 


\section{REFERENCES}

1. Härter $\mathrm{M}$, Baumeister $\mathrm{H}$, Reuter $\mathrm{K}$, et al. Increased 12-month prevalence rates of mental disorders in patients with chronic somatic diseases. Psychother Psychosom 2007;76:354-60.

2. Ali S, Stone MA, Peters JL, et al. The prevalence of co-morbid depression in adults with Type 2 diabetes: a systematic review and meta-analysis. Diabet Med 2006;23:1165-73.

3. Van den Bemt L, Schermer T, Bor $\mathrm{H}$, et al. The risk for depression comorbidity in patients with COPD. Chest 2009;135:108-14.

4. Pouwer F. Should we screen for emotional distress in type 2 diabetes mellitus? Nat Rev Endocrinol 2009;5:665-71.

5. Jerant A, Kravitz R, Moore-Hill M, et al. Depressive symptoms moderated the effect of chronic illness self-management training on self-efficacy. Med Care 2008;46:523-31.

6. Fisher L, Mullan JT, Arean P, et al. Diabetes distress but not clinical depression or depressive symptoms is associated with glycemic control in both cross-sectional and longitudinal analyses. Diabetes Care 2010;33:23-28.

7. DiMatteo MR, Lepper HS, Croghan TW. Depression is a risk factor for noncompliance with medical treatment: meta-analysis of the effects of anxiety and depression on patient adherence. Arch Int Med 2000;160:2101-07.

8. Lorig KR, Holman H. Self-management education: history, definition, outcomes, and mechanisms. Ann Behav Med 2003;26:1-7.

9. Netherlands Diabetes Federation. NDF Care Standard. Transparancy and quality of diabetes care for people with type 2 diabetes. Amersfoort: Nederlandse Diabetes Federatie (NDF), 2007.

10. Rutten GEHM, De Grauw WJC, Nijpels G, et al. NHG-Standaard Diabetes mellitus type 2 (Tweede herziening) [NHG Practice Guideline Diabetes mellitus type 2 (Second revision)]. Huisarts Wet 2006;49:137-52.

11. Van Eijk JTM, Bosma $\mathrm{H}$, Jonkers CC, et al. Prescribing antidepressants and benzodiazepines in the Netherlands: is chronic physical illness involved? Depress Res Treat 2010;Article ID 105931.

12. Van Weel-Baumgarten E, Lucassen $P$, Hassink-Franke L, et al. A different way of looking at depression. Int J Clin Pract 2010;64:1493-95.

13. Van Dijk-de Vries A, Moser A, Mertens VC, et al. The ideal of biopsychosocial chronic care: How to make it real? A qualitative study among Dutch stakeholders. BMC Fam Pract 2012;13:14.

14. Moser A, van der Bruggen $\mathrm{H}$, Widdershoven $\mathrm{G}$, et al. Self-management of type 2 diabetes mellitus: a qualitative investigation from the perspective of participants in a nurse-led, shared-care programme in the Netherlands. BMC Public Health 2008;8:91.

15. Jonkers $\mathrm{C}$, Lamers $\mathrm{F}$, Bosma $\mathrm{H}$, et al. Process evaluation of a minimal psychological intervention to reduce depression in chronically ill elderly persons. Patient Educ Couns 2007;68:252-57.

16. Jonkers CCM, Lamers F, Evers SMAA, et al. Economic evaluation of a minimal psychological intervention in chronically ill elderly patients with minor or mild to moderate depression: a randomised trial (the DELTA study). Int J Technol Assess Health Care 2009;25:497-504.

17. Lamers $\mathrm{F}$, Jonkers $\mathrm{CCM}$, Bosma $\mathrm{H}$, et al. A minimal psychological intervention in chronically ill elderly patients with depression: a randomised trial. Psychother Psychosom 2010;79:217-26.

18. Lamers $\mathrm{F}$, Jonkers CCM, Bosma $\mathrm{H}$, et al. Treating depression in diabetes patients: does a minimal psychological intervention affect diabetes-specific quality of life and glycemic control? A randomized controlled trial. J Adv Nur 2011;67:788-99.

19. Curran GM, Bauer M, Mittman B, et al. Effectiveness-implementation hybrid designs: combining elements of clinical effectiveness and implementation research to enhance public health impact. Med Care 2012;50:217-26.

20. Lamers $\mathrm{F}$, Jonkers CCM, Bosma $\mathrm{H}$, et al. Effectiveness and cost-effectiveness of a minimal psychological intervention to reduce non-severe depression in chronically ill elderly patients: the design of a randomised controlled trial. BMC Public Health 2006;6:161. 
21. Durlak J, DuPre E. Implementation matters: a review of research on the influence of implementation on program outcomes and the factors affecting implementation. Am J Community Psychol 2008;41: 327-50.

22. Braam C, van Oostrom SH, Terluin B, et al. Validation study of a Distress Screener. J Occup Rehabil 2009;19:231-37.

23. Terluin B, van Marwijk HWJ, Ader HJ, et al. The Four-Dimensional Symptom Questionnaire (4DSQ): a validation study of a multidimensional self-report questionnaire to assess distress, depression, anxiety and somatization. BMC Psychiatry 2006;6:34.

24. Van Eijk JTM, Diederiks JPM, Kempen GIJM, et al. Development and feasibility of a nurse administered strategy on depression in community-dwelling patients with a chronic physical disease. Patient Educ Couns 2004;54:87-94.

25. Mynors-Wallis L. Problem solving treatment in general psychiatric practice. Advan Psychiatr Treat 2001;7:417-25.

26. De Hollander A, Hoeymans N, Melse J, et al., Zorg voor gezondheid - Volksgezondheid Toekomst Verkenning 2006 [Public Health Forecast 2006]. RIVM rapport 270061003; Volksgezondheid Toekomst Verkenning. Houten: Bohn Stafleu Van Loghum, 2006.

27. De Jong A, Van Duin C. Regionale prognose 2009-2040: vergrijzing en omslag in groei naar krimp [Local forecast 2009-2040: ageing and demographic change from growth to shrinkage]. Bevolkingstrends 2009;4e kwartaal.

28. Penninx BW, Beekman ATF, Ormel J, et al. Psychological Status among elderly people with chronic disease: does type of disease play a part? J Psychosom Res 1996;40:521-34.

29. Tsiachristas A, Hipple-Walters B, Lemmens KMM, et al. Towards integrated care for chronic conditions: Dutch policy developments to overcome the (financial) barriers. Health Policy 2010; 101:122-32.

30. Hulscher M, Laurant M, Grol R, Process evaluation of change interventions, in Improving Patient Care. The Implementation of Change in Clinical Practice, Grol R, Wensing M, and Eccles M, Editors. Oxford: Elsevier Butterwork Heineman, 2005. p. 256-72.

31. Saunders RP, Evans MH, Joshi P. Developing a Process-Evaluation Plan for Assessing Health Promotion Program Implementation: A How-To Guide. Health Promot Pract 2005;6:134-47.

32. Fade S. Using interpretative phenomenological analysis for public health nutrition and dietetic research: a practical guide. Proc Nutr Soc 2004;63:647-53.

33. Campbell MK, Fayers PM, Grimshaw JM. Determinants of the intracluster correlation coefficient in cluster randomized trials: the case of implementation research. Clin Trials 2005;2:99-107.

34. Tuinman MA, Gazendam-Donofrio SM, Hoekstra-Weebers JE. Screening and referral for psychosocial distress in oncologic practice. Cancer 2008;113:870-78.

35. Polonsky WH, Anderson BJ, Lohrer PA, et al. Assessment of diabetes-related distress. Diabetes Care 1995;18:754-60.

36. Snoek FJ, Pouwer F, Welch GW, et al. Diabetes-related emotional distress in Dutch and U.S. diabetic patients: cross-cultural validity of the problem areas in diabetes scale. Diabetes Care 2000;23: 1305-09.

37. Welch G, Weinger K, Anderson B, et al. Responsiveness of the Problem Areas In Diabetes (PAID) questionnaire. Diabet Med 2003;20:69-72.

38. Ashworth M, Robinson S, Godfrey E, et al. Measuring mental health outcomes in primary care: the psychometric properties of a new patient-generated outcome measure, 'PSYCHLOPS' ('psychological outcome profiles') Primary Care Mental Health 2005;3:261-70.

39. Aaronson NK, Muller M, Cohen PD, et al. Translation, validation, and norming of the Dutch language version of the SF-36 Health Survey in community and chronic disease populations. J Clin Epidemiol 1998;51:1055-68.

40. Ware JE, Kosinski M, Keller S. A 12-item short-form health survey: construction of scales and preliminary tests of reliability and validity. Med Care 1996;34:220-33.

41. Cardol M, De Haan RJ, De Jong BA, et al. Psychometric properties of the Impact on Participation and Autonomy Questionnaire. Arch Phys Med Rehabil 2001;82:210-16. 
42. Cardol M. Vragenlijst 'Impact op Participatie en Autonomie' (IPA) Handleiding. [Questionnaire 'Impact on Participation and Autonomy' (IPA) Manual]. 2005 [cited 201518 June]; Available from: http://www.nivel.nl/sites/default/files/bestanden/INT-handleiding_vragenlijstIPA.pdf.

43. Hakkaart-van Roijen L, Bouwmans C. Manual Short Form-Health and Labour Questionnaire (SF-HLQ). Rotterdam, the Netherlands: Erasmus Universitair Medisch Centrum Rotterdam, Institute for Medical Technology Assessment, 2007.

44. Petkov J, Harvey $\mathrm{P}$, Battersby $\mathrm{M}$. The internal consistency and construct validity of the partners in health scale: validation of a patient rated chronic condition self-management measure. Qual Life Res 2010;19:1079-85.

45. Bosscher RJ, Smit JH. Confirmatory factor analysis of the General Self-Efficacy Scale. Behav Res Ther 1998;36:339-43.

46. Sherer M, Maddux JE, Mercadante B, et al. The self-efficacy scale: construction and validation. Psychol Rep 1982;51:663-71.

47. Cully JA, Armento ME, Mott J, et al. Brief cognitive behavioral therapy in primary care: a hybrid type 2 patient-randomized effectiveness implementation design. Implement Sci 2012;7:64. 


\section{CHAPTER 4}

Experiences of practice nurses and general practitioners with implementation of biopsychosocial self-management support in diabetes care

Anneke van Dijk - de Vries

Marloes A. van Bokhoven Job Metsemakers

Catharina C.M. Jonkers Trudy van der Weijden Jacques Th. M. van Eijk Submitted for publication 


\section{ABSTRACT}

\section{Objective}

To gain insight into the experiences of health professionals, making a shift from a biomedical towards a more explicit biopsychosocial approach of chronic care by integrating psychosocial 'Self-Management Support (SMS) in their care practice.

\section{Design}

A prospective process evaluation in which qualitative and quantitative data were collected by means of recordings, interviews and structured questionnaires.

\section{Setting}

Routine diabetes care within a regional care group of general practitioners.

\section{Study Participants}

Practice nurses were trained in SMS and applied SMS in their diabetes consultations for a period of one year (Nov 2011-Nov 2012). Practice nurses $(n=19)$ and general practitioners $(n=13)$ participated in the evaluation.

\section{Interventions}

The psychosocial SMS approach included detection of patients with psychosocial problems and providing an evidenced-based self-management support intervention when needed. Implementation strategies were coordinated at a regional level, and were aimed at determinants for change such as knowledge, skills, systematic registration in patient records, and reimbursement of the time needed for SMS.

\section{Main Outcome Measures}

Experiences, satisfaction, impact of SMS for daily practice and barriers in applying SMS as perceived by practice nurses and general practitioners.

\section{Results}

Practices nurses valued the systematic approach of SMS, but felt restricted in time and expertise to fully adopt SMS in their regular care. The impact of SMS for the daily practice of general practitioners was limited. The registration system and financial support were not adequate for successful implementation of SMS.

\section{Conclusion}

There were not sufficient opportunities for practice nurses to become experts in applying the complete SMS approach. Practice nurses need time to make SMS an integral part of their routine practice. The challenge is to find effective ways to identify eligible patients, and to provide tailored training, support and effective financial incentives to health professionals to successfully incorporate SMS in their practice. 


\section{BACKGROUND}

Primary care nurses increasingly deliver chronic care in western health systems. In the Dutch setting, general practitioners (GPs) are nowadays supported by practice nurses (PNs) in more than 75 percent of family practices to provide follow-up care to people with diabetes, COPD and/or risk factors for cardiovascular disease. ${ }^{1}$ Because they see chronic patients on a regular basis, PNs can play a pivotal role in supporting patients in their self-management skills to make decisions and taking actions in everyday life that positively affect their health status. ${ }^{2}$ In the care for patients with type 2 diabetes mellitus, the high prevalence of emotional problems with a negative impact on patients' glycaemic control call for an integrated, i.e. a biopsychosocial approach of self-management support. ${ }^{3-5}$ The term biopsychosocial indicates a self-management approach that includes systematic attention for biomedical as well as emotional and role management tasks. ${ }^{2,6}$ Since the quality indicators and reimbursement of Dutch disease-management programmes are solely based on biomedical parameters, ${ }^{7-9}$ systematic attention to the psychosocial aspects of diabetes is currently lacking., ${ }^{80-12}$

For realising a biopsychosocial care approach, a nurse-led minimal psychological intervention that proved to be cost-effective among elderly patients with diabetes or COPD and a mild to moderate depression was integrated into routine diabetes consultations, delivered by PNs. ${ }^{13}$ For implementation purposes, a verbal detection procedure was added to the intervention for identification of eligible patients by the PN. The adjusted intervention has been called 'Self-Management Support' (SMS). SMS included the detection of patients with emotional distress and perceived problems in daily functioning, of whom patients with moderate mental health problems according to the Four-Dimensional Symptom Questionnaire (4DSQ) ${ }^{14}$ were offered the nurse-led minimal psychological intervention. This was aimed at supporting them in their selfmanagement skills by means of problem solving and reattribution techniques. Patients with severe mental problems according to the 4DSQ were referred to the GP.

The implementation of SMS was a joint effort of our research team together with a regional care group of GPs and a health insurance company. Both stakeholders play a significant role in the Dutch chronic care setting. Health insurers purchase an integrated bundle of care for a specific chronic condition from the care group as the general contractor in a region. Based on this annual contract, the care group assumes financial and clinical accountability and in turn subcontracts individual care providers 
like GPs and dieticians. ${ }^{15}$ In the SMS project, the health insurer promised to pay the costs for the extra care, and the care group gave commitment to create support for SMS amongst their GPs and to take care for training facilities and integration of SMS parameters into Electronic Medical Records. The implementation strategy for SMS has been described in box 4.1. Box 4.2 presents the implementation outcomes in terms of detection and self-management consultations delivered by the PNs.

Box 4.1 Implementation strategy for SMS

The implementation strategy included training, financial support and the development of a registration system for SMS. During follow-up, some activities were taken to further adjust SMS to the routine practice.

Training

PNs attended a three-days training programme that was integrated in the annual course programme for PNs in the care group. PNs learned to explore the need for SMS, and to apply the screening instruments and 4DSQ (day 1), and to use the technique of problem solving (day 2) and reattribution (day 3 ) for selfmanagement support. The sessions took place in two groups of 9 to 10 PNs. The PNs practiced the skills for SMS by means of role play exercises. The third session, PNs took part in encounters with two experienced Simulated Patients.

After the training, groups of three to five PNs were offered four booster sessions during the year of followup, to share experiences and discuss barriers regarding SMS. Supervision during these sessions was given by the principal trainer (JE). Barriers in the detection phase of SMS were discussed in session 1. The second session was about PNs' skills regarding exploring psychosocial problems, and their use of the instruments. In session 3 and 4, audio recordings of consultations in which PNs applied the techniques of problem solving and reattribution were discussed.

Financial support

A fee for SMS was added to the integrated bundle for diabetes care during the year of follow-up. This annual fee was based on the extra time that PNs needed for detection, extra time for cooperation between the PN and GP regarding SMS, and for providing the self-management support to 15 percent of all type 2 diabetes patients within the family practice. The practices received an amount of 25 euros per diabetes patients in their practice. Besides, the practices were given 10 euros per diabetes patients for participation in the effectiveness study. This was a compensation for absence of their PNs during the training, and for activities in the recruitment of patients for the trial.

\section{Registration}

The development of an electronic patient registration form to record process and outcome parameters of SMS was coordinated by the care group. It was aimed to function as a reminder for PNs to make SMS structural part of their care. Data registration would enable them to return to the outcomes of SMS in future consultations. Furthermore, it would facilitate information transfer between PNs and GPs.

Implementation activities during follow-up

After two months of follow-up, PNs were instructed by the trainer to use the eligibility criteria for the selfmanagement support in a more flexible manner because of the low detection of patients in need for the self-management support. The trainer also provided an example of a patient information letter about SMS. Furthermore, positive experiences of one PN with using the screening instruments as written questionnaires at the start of a diabetes consultation were communicated to all PNs. This option was added to the registration file in May 2012. 
Box 4.2 SMS in routine diabetes care

Uptake SMS during year of follow-up (Nov 2011 - Nov 2012) as derived from the electronic data file for SMS

Detection. PNs ( $n=19)$ were instructed to detect patients with a perceived burden of diabetes in daily functioning and emotional distress. They were provided two screening instruments: the 'Daily Functioning Thermometer (DFT)' and the 'Distress Screener (DS)'. The DFT is a visual analogue scale between 0 and 10. A cut-off score of 4 was chosen to select patients who could benefit from self-management support by the PN (DFT > 4). A score DS>3 was used as an indication of mental health problems. ${ }^{16}$

Outcomes of detection were registered for 2013 diabetes patients, approximately two thirds of all patients receiving diabetes care from the PNs. During one year, it was applied one to five times per patient. Four percent of the patients had a score DFT >4 and DS $>3$ at least once a year. In contrast to these findings, the detection rate of a written self-administered screening procedure in the same diabetes population was 20 percent.

Further diagnostics Patients with a score DS $>3$ were asked to complete the Four Dimensional Symptom Questionnaire (4DSQ). ${ }^{14}$ The score DS>3 was identified in 253 patients. However, the 4DSQ was handed out in only 118 consultations. In 33 of these 118 cases, patients did not have score DS $>3$. PNs decided not to hand out a 4DSQ when the emotional distress was caused by a specific and temporary stress factor. Other patients did not want or need further diagnostics or help. Some patients were directly referred to the GP.

Self-management support Patients with moderate problems according to the 4DSQ, and a DFT $>4$, were eligible to receive self-management support during one or more extra consultations. PNs used the techniques of problem solving and reattribution to support patients in their self-management skills. PNs $(n=10)$ registered 56 self-management support consultations to 47 patients.

The intention of the stakeholders was to continue the experimental phase of SMS with permanent implementation in case of positive evaluation outcomes. ${ }^{17}$ However, the project ended after one year as the effectiveness of SMS could not be demonstrated due to low exposure of intervention patients to the complete SMS approach. $^{18}$

This paper will address the experiences of participating health professionals regarding the implementation of SMS in their routine practice. It aims to get further insight into the facilitators and barriers of the implementation process, and the needs of primary care professionals to realise a biopsychosocial approach in chronic care.

\section{METHODS}

\section{Study design}

We performed a process evaluation in which quantitative and qualitative data were prospectively and retrospectively collected among health professionals regarding their 
experiences with implementation of SMS. The patients' perspective on SMS will be reported elsewhere. The process evaluation was conducted alongside a clinical trial. ${ }^{16}$

\section{Setting and participants}

SMS was integrated in the regional care group of primary care practices in the South of the Netherlands that consisted of 77 family practices (103 GPs). All GPs were informed by a letter from the director of the care group followed by a letter of the researchers. Then all practices were approached by phone by the researchers to ask the GPs for participation in the SMS project. In the period between September November 2011, PNs ( $n=19)$ working in ten solo practices, two duo practices, one group practice and three health centres, were trained in SMS. From that time, they were supposed to apply the detection phase of SMS in all quarterly consultations for diabetes patients, and to provide follow-up care when needed. The PNs cared for an estimated number of 3000 diabetes patients ranging from 8 to 365 per PN.

\section{Data collection}

Data were collected after the training of PNs, during the year in which the PNs applied SMS and attended booster sessions (Nov 2011-Nov 2012), and the end of this year. The measurements are presented in table 4.1.

Table 4.1 Measurements among practice nurses (PNs) and general practitioners (GPs)

\begin{tabular}{|c|c|c|c|c|}
\hline \multirow{3}{*}{ TOPICS } & \multicolumn{4}{|c|}{ Measurements } \\
\hline & \multicolumn{3}{|c|}{ PNs } & \multirow{2}{*}{$\frac{\text { GPs }}{\text { Interviews }}$} \\
\hline & $\begin{array}{l}\text { Evaluation } \\
\text { form } \\
\text { training } \\
\end{array}$ & $\begin{array}{c}\text { Recordings } \\
\text { booster } \\
\text { Sessions }\end{array}$ & $\begin{array}{c}\text { Structured } \\
\text { questionnaire }\end{array}$ & \\
\hline Comprehensibility of training components & $\mathrm{x}$ & & & \\
\hline Being informed about SMS & & & & $\mathrm{x}$ \\
\hline Impact of SMS for daily practice & & $\mathrm{x}$ & $\mathrm{x}$ & $\mathrm{x}$ \\
\hline Satisfaction with applying SMS & & $\mathrm{x}$ & $\mathrm{x}$ & $\mathrm{x}$ \\
\hline Barriers to apply SMS & $\mathrm{x}$ & $\mathrm{x}$ & $\mathrm{x}$ & $\mathrm{x}$ \\
\hline $\begin{array}{l}\text { Attitude towards SMS } \\
\text { delivered by PN (relevance, competences) }\end{array}$ & & & $x$ & $\mathrm{x}$ \\
\hline $\begin{array}{l}\text { Requirements for successful } \\
\text { adoption of SMS }\end{array}$ & & $x$ & $x$ & $x$ \\
\hline
\end{tabular}




\section{Measurements from PNs' perspective}

All PNs completed an evaluation form at the end of the training about their experiences and views on the comprehensibility of the training components, and if they felt enabled to integrate SMS in their practice.

Discussions during booster training sessions in the year of follow-up were audio recorded and/or minutes were drawn up for qualitative information about the impact of SMS for PNs' daily practice, and the barriers they experienced.

The qualitative findings of the booster sessions were translated into statements for a structured questionnaire which was used to enrich the qualitative data with a more quantitative approach. It was distributed among the PNs at the end of the follow-up period. PNs individually rated all items on a 5-point Likert scale with 1 indicating totally disagree and 5 indicating totally agree. The questionnaire included 20 statements about PNs' satisfaction with the detection and follow-up phase of SMS, and the barriers they experienced in applying SMS. Furthermore, 10 statements were formulated regarding the relevance of the different aspects of SMS, e.g. a systematic discussion of psychosocial issues, the use of screening instruments, the expertise to apply the self-management support, and the engagement of the GP regarding SMS. The questionnaire included three open-ended questions on what PNs experienced as the greatest benefit of SMS for their practice, the greatest barrier and what they would need in order to overcome this barrier.

\section{Measurements from GPs' perspective}

GPs were interviewed about their experiences of SMS. All GPs who were contact persons in the recruitment phase of the implementation project were approached by the interviewer $(A D)$ to participate in a semi-structured interview. We used questions with answer categories on a 5-point Likert scale with 1 indicating totally disagree and 5 indicating totally agree. The statements were about the provision of information about SMS, the impact of SMS for their daily practice, GPs' perspectives on the PNs' ability to apply SMS, and their views on sustainable implementation of SMS. We also asked open questions on what they experienced as the greatest benefit, and the greatest barrier with regard to implementation of SMS. 


\section{Data Analysis}

Descriptive statistics regarding the structured questionnaires were obtained using the statistical package SPSS 21 . Recordings of the booster sessions $(n=8)$ were transcribed verbatim. From booster sessions without audio recordings $(n=6)$, we used the minutes drawn up by the participants. The qualitative data of the booster sessions were organised by topic, and formulated into statements for the structured questionnaire. From the telephone interviews with GPs, an interview summary was submitted to the respondent for approval. The qualitative data were organised by topics for a content analysis.

\section{RESULTS}

All 19 PNs participated in the process evaluation. Of the 17 GPs, 11 were interviewed by phone, and 2 GPs preferred to complete a written questionnaire. The 4 GPs who decided not to participate were working in a solo practice, a duo practice, a group practice and one in a solo practice cooperating with a duo practice in a health centre setting. The demographic characteristics of the participating PNs $(n=19)$ and GPs $(n=13)$ are presented in table 4.2. PNs had graduated from a one or two-year curriculum from the school for PNs (bachelors' degree), except for one PN with a master degree in health education.

Table 4.2 Characteristics of participants in the process evaluation

\begin{tabular}{lcc}
\hline & $\begin{array}{c}\text { General Practitioners } \\
(\mathrm{n}=13)\end{array}$ & $\begin{array}{c}\text { Practice Nurses } \\
(\mathrm{n}=19)\end{array}$ \\
\hline $\begin{array}{l}\text { Age, mean/range (years) } \\
\text { Female }\end{array}$ & $54 / 45-65$ & $36 / 23-53$ \\
Working hours & 2 & 19 \\
$>28$ hours a week & 13 & 7 \\
$16-28$ hours a week & & 8 \\
$<16$ hours a week & & 3 \\
Variable & & 1 \\
\hline
\end{tabular}




\section{Experiences of practice nurses}

After the training, most PNs perceived their ability for SMS as sufficient. Five PNs explicitly mentioned that they first needed to apply SMS in daily practice to grasp the consequences for their practice, and to get insight in their skills and further training needs.

The systematic attention to psychosocial functioning was perceived as the most valuable part of SMS. However, PNs doubted the problem awareness of patients, and their perceived needs for SMS. Only a few patients could be offered the extra consultations, see box 2. It was disappointing for PNs that they could hardly become familiar with applying the reattribution technique and, to a lesser degree, the problem solving technique to support patients in their self-management skills. With respect to the latter, the principles of problem solving were also useful to help patients regarding healthy life style issues, of which some cases were brought up during booster sessions. In the booster sessions, PNs discussed difficulties with their new role regarding detection of psychosocial problems and activation of patients' selfmanagement skills. In the questionnaire after follow-up, half of the PNs agreed with at least one of the following barriers: feeling somewhat awkward as if they were too much 'searching for problems', finding it unnatural to explicitly ask patients screening questions about worrying, listlessness, and feeling tense, and finding it difficult to decide which problems fell within their scope of practice. Problems with good time management and taking the lead during the consultation came also forward during the booster sessions. In the questionnaire, 13 PNs agreed with the statement that they would need more time during a regular consultation; eight of them stressed time issues as the largest barrier for successful incorporation of SMS. Two PNs mentioned the limited support of the GP hence they felt not stimulated to put efforts in the detection and follow-up care of patients with psychosocial problems. Three PNs mentioned the burden of registration of SMS as the main implementation barrier. Due to construction issues, the registration file for SMS could not be integrated in the regional GP information system in which all Electronic Medical Records are stored digitally. PNs needed to open a separate data file for SMS, and therefore GPs as well. Three PNs registered the outcomes of SMS twice to enable GPs to be informed about SMS activities. 


\section{Experiences of General Practitioners}

The impact of SMS on the routine practice of GPs was low. As a consequence, GPs of three practices felt too unfamiliar with the implementation project and did not want to participate in the evaluation after follow-up.

Seven of the 13 participating GPs noticed during discussions with their PN a greater attention to the patients' psychosocial well-being. Some PNs referred patients with psychosocial problems to the GP. Two GPs mentioned this as a positive effect of SMS. In some other practices, the psychosocial problems of the referred patients were already known by the GP. While all GPs emphasized the relevance of discussing psychosocial aspects of diabetes by the PN, they were more ambivalent regarding the self-management support. Six GPs did not perceive a significant role for the diabetes PN to apply problem solving and reattribution techniques during extra consultations. In this respect, they referred to the time constraints, and the current workload of PNs. Some GPs suggested that mental health nurses should provide the self-management support. Only 5 of the 13 interviewed GPs were aware of the financial support for SMS. The fixed fee that was added to the bundled payment arrangement had not been translated in extra time for the PN to integrate SMS in daily practice. In one practice, the money was transferred to the organisation which employed the PNs.

\section{DISCUSSION}

Implementation of SMS had impact on the daily practice of PNs whereas the GPS hardly got involved. The systematic attention to psychosocial issues of diabetes was valued by both PNs and GPs. However, PNs struggled to fit the detection phase of SMS into the scope and duration of a regular consultation, and felt sometimes uncomfortable to address psychosocial issues. Despite PNs' efforts to discuss patients' psychosocial functioning in many consultations, only a limited number of patients could be offered the self-management support (see box 2). Furthermore, the organisational support was not optimal. An extra data file needed to be opened to register the outcomes of SMS. The awareness of GPs regarding the financial contribution for the implementation of SMS was limited, and the money was not translated into extra time for the PNs. 
PNs in the Dutch chronic care setting learnt to work according to protocols with a dominant focus on patients' biomedical management and healthy lifestyle. ${ }^{1}$ Several studies highlight the complex change from a somatic care approach towards integrated care. ${ }^{19-21}$ PNs need to get used to and become confident with their new role. ${ }^{22}$ In our study, PNs had only very limited chances to become adept at SMS due the low numbers of patients who were detected and could be offered the selfmanagement support. This negatively influenced PNs' motivation and their competence in applying SMS. The low detection yield could be explained by several factors like the PNs' learning curve, the quality of the screening tools, and the attitudes of patients regarding a discussion about their psychosocial well-being or their perceived needs to receive the self-management support. ${ }^{23-25}$ Adjustments in the detection procedure that were introduced along the way, i.e. to apply the screening criteria in a more flexible way, and to ask patients to complete a written screening questionnaire at the start of the routine consultation, did not significantly increase the provision of self-management support. It has been suggested in the literature that patients with long term conditions do not necessarily recognize the rationale for a psychosocial intervention. ${ }^{19}$ Although this issue has been addressed during the training and booster sessions, we do not know whether the rationale and potential value of the self-management support has been given a chance during the consultations. However, we may also have overestimated the number of patients who are open for detection and follow-up of psychosocial issues as part of their routine diabetes care.

GPs were informed several months before the actual start of SMS. The main focus of the information was on the effect evaluation of SMS rather than on GPs' role in the implementation process. GPs themselves did not receive training. The number of referrals of patients with psychosocial problems was limited and GPs did not directly see the outcomes of SMS in the Electronic Medical Records. Moreover, the financial support for SMS was based on the mere number of diabetes patients in their practice.

Our active collaboration with the regional partners was expected to be promising. However, our meetings with the partners in the year of follow-up were mainly focused on monitoring the outcomes of SMS rather than on improving the implementation process. The regional partners might have played a prominent role in improving the active involvement of individual GPs, and in the communication 
towards patients about the new care approach. However, this was hindered by several factors. First, personnel changes at the side of the care group and the health insurer were a complicating factor. The new representatives of the stakeholders needed to be briefed about the aims and agreements with regard to the project. Second, the care group decided to enhance the role of the mental health nurse instead of reinforcing the position of the diabetes nurse. This policy change affected the support for SMS. Third, we didn't discuss disappointing scenarios at the start of the project. Due to the disappointing net results of SMS, it became clear that the expectations of the partners regarding the results and contribution of each other should have been made more explicit.

\section{Limitations}

The actual implementation of SMS in the routine practice was evaluated by quantitative data registered by the PNs during their consultations regarding outcomes of detection, diagnostics and the number of extra consultations. As a result of the quantitative approach, the measurements were concentrated on the identification function of the detection procedure rather than its contribution to the communication about patients' daily functioning and their self-management skills in this regard. ${ }^{26}$ We do not know what psychosocial issues were discussed, and whether the integration of SMS influenced the effectiveness of the communication between PNs and patients. PNs valued the detection tools to give systematic attention to psychosocial issues, but this cannot be considered as an indicator for its effectiveness in terms of health outcomes or patient perceptions of the consultation content. ${ }^{27,28}$ The limitations of the data also refer to the self-management support. PNs could have used the problem solving and reattribution techniques during regular consultations, but we did not ask them to register these issues.

\section{Implications}

Several lessons regarding joint efforts to realise a biopsychosocial care approach in diabetes care can be formulated that also may apply to the care for patients with other chronic conditions delivered by PNs. First, one need to be sure that SMS will fill a gap in the routine care practice. As the original version of SMS was well-received by patients in the previous trial, ${ }^{29}$ we expected a high detection rate of patients eligible for SMS. A pilot study would have been valuable to confirm the feasibility of SMS in 
routine care. Second, the study has shown that implementation strategies should not only focus on providing adequate equipment to PNs but also have to include strategies that will ensure active involvement of GPs such as training for GPs. In this regard, a financial incentive based on process or outcome parameters of SMS may be more effective than an unconditional financial incentive. Third, the variety of types of practices and the personal skills, interests and opportunities of the PNs and GPs calls for a more tailored way in providing training and support for adjusting the intervention to each practice.

\section{CONCLUSIONS}

PNs were positive about a systematic discussion about psychosocial issues during a routine diabetes consultation. However, the efforts that were needed for the detection phase of SMS were in contrast to the low number of patients who could be offered the self-management support. This was experienced as a barrier in the implementation of SMS. PNs could hardly become confident about their new scope of practice. Adequate ways to identify patients in need for the self-management support are needed. Furthermore, regional stakeholders as well as individual GPs need to ensure that PNs are stimulated and facilitated to practice and to become adept at supporting patients with problems in their psychosocial functioning. This calls for an investment in terms of time, follow-up training and support to realise the shift from biomedical to biopsychosocial care for patients with chronic conditions. 


\section{REFERENCES}

1. Heiligers PJM, Noordman J, Korevaar JC, et al., Kennisvraag: praktijkondersteuners in de huisartspraktijk (POH's) klaar voor de toekomst? [Knowledge base: Practice nurses in the GP practices, ready for the future?].Utrecht: Netherlands Institute for Health Services Research (NIVEL), 2012.

2. Lorig KR, Holman H. Self-management education: history, definition, outcomes, and mechanisms. Ann Behav Med 2003; 26(1):1-7.

3. Fisher L, Mullan JT, Arean P, et al. Diabetes distress but not clinical depression or depressive symptoms is associated with glycemic control in both cross-sectional and longitudinal analyses. Diabetes Care 2010; 33(1):23-28.

4. Egede LE, Ellis C. Diabetes and depression: Global perspectives. Diabetes Res Clin Pract 2010; 87(3):302-312.

5. Jerant A, Kravitz R, Moore-Hill M, et al. Depressive symptoms moderated the effect of chronic illness self-management training on self-efficacy. Med Care 2008; 46(5):523-531.

6. Kousoulis A, Patelarou E, Shea $S$, et al. Diabetes self-management arrangements in Europe: a realist review to facilitate a project implemented in six countries. BMC Health Serv Res 2014; 14(1):453.

7. Netherlands Diabetes Federation. NDF Care Standard. Transparancy and quality of diabetes care for people with type 2 diabetes. Amersfoort: Nederlandse Diabetes Federatie (NDF), 2007.

8. Struijs J, de Jong-van Til J, Lemmens L, et al., Bundled payments of diabetes care: Effects on care delivery process and quality of care at three-year follow-up.Bilthoven: National Institute for Public Health and the Environment (RIVM), 2012.

9. Rutten G, De Grauw W, Nijpels G, et al. NHG-Standaard Diabetes mellitus type 2 (derde herziening) [NHG Practice Guideline Diabetes mellitus type 2 (Third revision)]. Huisarts Wet 2013; 56(10):512525.

10. Elissen A, Nolte E, Knai C, et al. Is Europe putting theory into practice? A qualitative study of the level of self-management support in chronic care management approaches. BMC Health Serv Res 2013; 13(1):117.

11. Pouwer F. Should we screen for emotional distress in type 2 diabetes mellitus? Nat Rev Endocrinol 2009; 5(12):665-71.

12. Van Weel C, Van Weel-Baumgarten E, Van Rijswijk E. Treatment of depression in primary care. BMJ 2009; 338:b934.

13. Jonkers CCM, Lamers $\mathrm{F}$, Bosma $\mathrm{H}$, et al. The effectiveness of a minimal psychological intervention on self-management beliefs and behaviors in depressed chronically ill elderly persons: a randomized trial. Int Psychogeriatr 2012; 24(02):288-297.

14. Terluin B, van Marwijk HWJ, Ader HJ, et al. The Four-Dimensional Symptom Questionnaire (4DSQ): a validation study of a multidimensional self-report questionnaire to assess distress, depression, anxiety and somatization. BMC Psychiatry 2006; 6:34.

15. Raaijmakers L, Hamers F, Martens M, et al. Perceived facilitators and barriers in diabetes care: a qualitative study among health care professionals in the Netherlands. BMC Fam Pract 2013; 14(1):114.

16. Braam C, van Oostrom SH, Terluin B, et al. Validation study of a Distress Screener. J Occup Rehabil 2009; 19(3):231-237.

17. Van Dijk-de Vries A, Van Bokhoven M, Terluin B, et al. Integrating nurse-led Self-Management Support (SMS) in routine primary care: design of a hybrid effectiveness-implementation study among type 2 diabetes patients with problems of daily functioning and emotional distress: a study protocol. BMC Fam Pract 2013; 14:77.

18. van Dijk-de Vries A, van Bokhoven MA, Winkens B, et al. Lessons learnt from a cluster-randomised trial evaluating the effectiveness of Self-Management Support (SMS) delivered by practice nurses in routine diabetes care. BMJ Open 2015; 5(6). 
19. Peters S, Wearden A, Morriss R, et al. Challenges of nurse delivery of psychological interventions for long-term conditions in primary care: a qualitative exploration of the case of chronic fatigue syndrome/myalgic encephalitis. Implement Sci 2011; 6:132.

20. Maxwell M, Harris F, Hibberd C, et al. A qualitative study of primary care professionals' views of case finding for depression in patients with diabetes or coronary heart disease in the UK. BMC Fam Pract 2013; 14(1):46.

21. Mulder BC, Lokhorst AM, Rutten GEHM, et al. Effective Nurse Communication With Type 2 Diabetes Patients: A Review. West J Nurs Res 2015; 37(8):1100-31.

22. Mulder BC, van Belzen $M$, Lokhorst AM, et al. Quality assessment of practice nurse communication with type 2 diabetes patients. Patient Educ Couns 2015; 98(2):156-61.

23. Coyne JC, Thompson R, Palmer SC, et al. Should we screen for depression? Caveats and potential pitfalls. Appl Prev Psychol 2000; 9(2):101-121.

24. Fleer J, Tovote KA, Keers JC, et al. Screening for depression and diabetes-related distress in a diabetes outpatient clinic. Diabet Med 2013; 30(1):88-94.

25. Ajdukovic $D$, Pibernik-Okanovic $M$, Sekerija $M$, et al. The reach of depression screening preceding treatment: are there patterns of patients' self-selection? Int J Endocrinol 2012; 2012:148145.

26. Garssen B, de Kok E. How useful is a screening instrument? Psycho-Oncology 2008; 17(7):726-728.

27. Parkin T, Skinner TC. Discrepancies between patient and professionals recall and perception of an outpatient consultation. Diabet Med 2003; 20(11):909-914.

28. Thompson C, Kinmonth AL, Stevens L, et al. Effects of a clinical-practice guideline and practice-based education on detection and outcome of depression in primary care: Hampshire Depression Project randomised controlled trial. The Lancet 2000; 355(9199):185-191.

29. Jonkers $\mathrm{C}$, Lamers $\mathrm{F}$, Bosma $\mathrm{H}$, et al. Process evaluation of a minimal psychological intervention to reduce depression in chronically ill elderly persons. Patient Educ Couns 2007; 68(3):252-257. 


\section{CHAPTER 5}

Patients' readiness to receive psychosocial care by practice nurses in routine diabetes consultations:

A mixed methods study

Anneke van Dijk - de Vries

Marloes A. van Bokhoven

Sabine de Jong

Job F. Metsemakers

Peter F. Verhaak

Trudy van der Weijden

Jacques Th. M. van Eijk

Submitted for publication 


\section{ABSTRACT}

\section{Background}

Psychosocial problems are prevalent among type 2 diabetes patients. For the implementation of psychosocial self-management support in diabetes care, practice nurses were trained to identify patients with psychosocial problems. The detection rates appeared to be strikingly low.

\section{Objectives}

Our study aimed to examine patients' readiness to discuss psychosocial problems with practice nurses during diabetes consultations.

\section{Design}

A mixed methods design within an experimental study evaluating a psychosocial selfmanagement approach integrated in routine diabetes care.

\section{Setting}

Routine diabetes care in a regional primary care group in the Netherlands.

\section{Participants}

Type 2 diabetes patients with psychosocial problems selected by a self-administered questionnaire.

\section{Methods}

In-depth interviews ( $n=12$ ) were conducted. Based on a qualitative content analysis of patients' current experiences and perspectives on psychosocial diabetes care, a structured questionnaire was designed to further explore the findings among a larger group of patients $(n=205)$. The questionnaire included 14 items measuring patients' agreement with statements about diabetes care and the role of the practice nurse therein.

\section{Results}

The qualitative part of the study showed that patients viewed a diabetes consultation primarily as a biomedical check-up. They did not perceive discussion of psychosocial well-being as an integral part of diabetes management. The quantitative part showed that younger patients were more open to discussing psychosocial problems with the practice nurse than patients over 65. Patients' openness to discussing psychosocial problems was not significantly associated with the practice nurses being trained in the psychosocial self-management approach.

\section{Conclusion}

Patients see practice nurses primarily as specialists regarding the biomedical management of diabetes. Although patients seemed to support the ideal of integrated care, they did not expect a discussion about psychosocial problems in diabetes consultations. The incorporation of systematic detection of psychosocial problems in diabetes care requires endeavours to make patients acquainted with the new role of the practice nurse. 


\section{INTRODUCTION}

In Dutch primary care, most patients with type 2 diabetes mellitus have quarterly consultations with practice nurses (PNs) in the family practice. ${ }^{1}$ Care is based on evidence-based guidelines, and on national guidelines regarding the content, organization and quality of integrated diabetes care. ${ }^{2-4}$ Self-management support is a key component of effective diabetes care. It refers to a collaborative approach between health professionals and patients aimed at supporting patients in acquiring the skills and confidence to manage their chronic conditions in their everyday lives. ${ }^{5}$ In order to facilitate self-management, the Dutch guidelines for diabetes care recommend drafting individual treatment plans, with agreements regarding biomedical targets and lifestyle changes. ${ }^{3}$ In daily practice, PNs concentrate on education about patients' physical condition, healthy behaviours and self-monitoring skills during the diabetes consultations. ${ }^{6}$ Thus, the PNs' current self-management support is primarily focused on the medical aspects of diabetes.

Nevertheless, diabetes patients do not only face challenges in daily life with regard to medication and lifestyle issues. They may also experience emotions like anger, fear, frustration and depression. ${ }^{7}$ Research has shown that symptoms of distress and depression are prevalent among diabetes patients. ${ }^{8}$ These emotional problems are associated with a negative impact on glycaemic control, adherence to treatment, complication rates and well-being. ${ }^{9,10}$ In addition to the medical and emotional selfmanagement tasks, patients with chronic conditions also have to create new, meaningful social roles. ${ }^{11}$ Qualitative studies have illustrated the social demands imposed by diabetes, and the challenges of finding a balance between diabetes management and living a 'normal life'. ${ }^{12,13}$ In this paper, the general term 'psychosocial problems' refers to problems that patients perceive with these emotional and role management tasks.

The project entitled 'Self-Management Support' (SMS) was initiated within a regional care group of general practitioners in the south of the Netherlands to implement a psychosocial self-management approach in routine diabetes care. ${ }^{14}$ PNs were trained to provide a minimal psychological intervention which had proved to be cost-effective in the self-management support of depressed chronically ill elderly persons. ${ }^{15}$ Exploration of psychosocial problems and a detection method involving four screening questions were added to this self-management support intervention to enable PNs to 
identify patients who perceive their illness as burdensome in their daily functioning and experience symptoms of emotional distress. The effectiveness of the SMS approach, including both the detection and self-management support of patients with problems of emotional and social functioning, was evaluated by means of a clusterrandomized trial ('SMS trial') in which patients who received diabetes support from PNs trained in SMS were compared with patients who received usual care. Simultaneously, we evaluated the facilitators of and barriers to successful implementation of the SMS approach. ${ }^{14}$

This paper reports on the evaluation of the SMS approach from the patients' perspective. During the SMS project, it appeared that the detection rate by PNs was low in comparison to the outcomes of a self-administered screening procedure that was used for research purposes to detect patients eligible for inclusion in the trial. ${ }^{16}$ This was unexpected, as similar questions were used. Given the different settings (i.e. written completion at home vs. face-to-face in the family practice) and different purposes (i.e. research vs. care), the context in which patients were asked about psychosocial problems appeared to be crucial for a good understanding of the outcomes. To improve our understanding of patients' readiness to receive the SMS approach, we formulated the following research question: How do patients experience their current diabetes care, and what are their perspectives on a psychosocial care approach delivered by PNs during routine diabetes consultations?

\section{METHODS}

\section{Design of the study}

We used a mixed methods design ${ }^{17}$ to obtain a comprehensive understanding of patients' readiness to receive psychosocial self-management support during routine diabetes consultations. The study used an exploratory-sequential approach, ${ }^{18}$ in which qualitative data collection from in-depth interviews was followed up by quantitative data collection. First, in-depth interviews were conducted and analysed, and the findings from these interviews were used to formulate items for a structured questionnaire. The subsequent quantitative part aimed to further explore associations between perspectives on diabetes care and patient characteristics among a larger group of patients. 


\section{Methods 1: qualitative part of the study}

\section{Participants}

The qualitative part of the study included diabetes patients with psychosocial problems in their daily functioning, as identified by PNs who had or had not been trained in SMS. We recruited patients from two sources:

1. Patients detected by the PNs and receiving the self-management support, consisting of problem solving and reattribution techniques (convenience sampling): from March till May 2012, patients who had received the selfmanagement support within the last two months were invited by their PNs to participate in an in-depth interview. Patients who showed interest were sent an information letter, followed by a phone call from the interviewer (SJ) to ask for their participation and to schedule an appointment for the interview.

2. Those who were identified by the screening for the SMS trial as having psychosocial problems in daily functioning and still perceived problems based on their scores on the 4-month follow-up measurement, but who had not been detected by the PN in routine practice and were therefore not receiving the selfmanagement support (purposive sampling from the trial participants who returned their 4-month follow-up questionnaire in April and May 2012, and had not been detected by their PN; we tried to achieve variation in terms of patients' age, sex and duration of diabetes). Patients were approached by the interviewer directly.

\section{Data collection}

Twelve semi-structured in-depth interviews, which took 45 minutes on average, were conducted at the patients' homes. An interview guide was used to ensure that the following topics were discussed: patients' experienced burden of diabetes, their perspectives on diabetes consultations in general, and their attitudes towards psychosocial care provided by PNs. Prior to an interview, information was given about the objectives of the study. Participants gave oral informed consent for the audiotaped interview. They were assured that the interview data would be dealt with confidentially and that the PN or general practitioner (GP) would not be informed about the content of the interview. All interviews were transcribed verbatim. 


\section{Data analysis}

The interviews were analysed using qualitative content analysis. ${ }^{19}$ The first step consisted of reading the transcripts, after which a process of condensation and abstraction started. Codes were assigned to meaningful units, that is, words or statements that were related to each other through their content or context. Two researchers (SJ and $A D$ ) coded the data independently. Coding discrepancies were discussed until consensus was reached. The next step was to look for connections between the codes. A process of reflection and discussion between SJ and AD resulted in agreement about the way to sort the codes into categories. These categories were clustered into key themes that reflected the underlying meaning of the categories. The discussions took place after interviews 4, 8, 11 and 12 . The impressions and codes derived from the interviews were discussed each time with $M B$. After the $11^{\text {th }}$ interview, data saturation was reached as no new codes emerged from the data. The findings were discussed with TW and JVE.

\section{Methods 2: quantitative part of the study}

\section{Questionnaire development}

The outcomes of the qualitative part were used to formulate statements for a structured questionnaire. We used 5-point Likert scales, with 1 indicating 'totally disagree' and 5 indicating 'totally agree', to measure agreement with these statements.

\section{Participants}

The questionnaire was distributed among all participants of the SMS trial, 12 months after baseline. These patients had in common that they had all been found to have emotional and social problems in daily functioning in the self-administered screening procedure at the start of the study.

\section{Data analysis}

The quantitative data were analysed using IBM SPSS Statistics version 21.0 for Windows. Descriptive statistics were used to describe the outcomes for each statement. For the purpose of subgroup analysis, we reduced the 14-item questionnaire to a smaller subset of meaningful components by means of a principal 
component analysis with varimax rotation. Loadings above 0.50 were considered to be clearly related to the factor. We also used Cronbach's alpha as an indicator of the internal consistency of a factor. The process was iterated until a subset of items was obtained showing a consistent and interpretable factor structure.

For each respondent, an individual scale score was obtained by calculating a mean score for the factor items. Missing values were imputed by the median of that item. Some items were reverse-coded to ensure that a higher score could be interpreted as more openness towards psychosocial care.

The results were presented as dichotomized scores (high/low mean composite score). Patients with predominantly low scores on a factor (mean score below 3) were allocated to the 'low group'. We used Pearson chi-square tests to test for differences in patients' composite score with regard to the training of PNs in SMS, patients' psychosocial problems at the time of measurement, sex, age, and duration of diabetes. The robustness of all findings was checked by means of linear regression analyses and independent t-tests. Data analysis was conducted by one of the authors (AD).

\section{RESULTS}

\section{Results 1 Qualitative part of the study}

\section{Interview participants}

The interviewees were five women and seven men. Table 5.1 presents their characteristics. The participants were aged 51 to 81 years, with a mean age of 65 years. The mean time that had elapsed since they were diagnosed with diabetes was 11 years. The sample included patients from seven PNs. Nine patients were invited by the PNs (source 1). Six of them refused to participate due to lack of interest, lack of time, or not feeling comfortable with an interview. Two of the 11 patients who were approached directly by the interviewer (source 2 ) refused to participate because of lack of time. 
Table 5.1 Characteristics of interview participants $(n=12)$

\begin{tabular}{lccc}
\hline Respondent & Sex & $\begin{array}{c}\text { Age } \\
\text { (years) }\end{array}$ & $\begin{array}{c}\text { Duration of DM2* } \\
\text { (years) }\end{array}$ \\
\hline 1 & F & 71 & 15 \\
2 & M & 72 & 13 \\
3 & F & 81 & 20 \\
4 & M & 66 & 36 \\
5 & M & 62 & 4 \\
6 & M & 53 & 6 \\
7 & F & 67 & 2 \\
8 & M & 70 & 2 \\
9 & M & 74 & 10 \\
10 & F & 51 & 5 \\
11 & F & 57 & 2 \\
12 & M & 62 & 3 \\
\hline
\end{tabular}

*Number of years after the diagnosis of diabetes mellitus

\section{Findings from the interviews}

The findings refer to patients' experiences with routine diabetes consultations, and their attitudes towards the psychosocial care provided by their PN. The findings are illustrated below by means of quotations.

\section{Perspectives on routine diabetes consultations}

Respondents regarded a diabetes consultation as a routine check-up for their diabetes. They described evaluation of biomedical measurements as the primary aim of these check-ups.

'The blood sampling.., what are the outcomes? That's just the key point of the consultation. And then... afterwards asking some questions. About experiencing symptoms and about something that may be related to my diabetes. Just to talk with her for a moment about these issues.' [4]

Some especially liked to receive feedback on how well they were managing their disease. Respondents appreciated getting advice regarding their diabetes management, thereby referring to biomedical parameters, medication and lifestyle issues.

'And she gives advice for that, about HDL and LDL and so on...How we can improve these things. (..) The basic cholesterol levels. She actually talks about all the measurements. And about my weight, obviously. We'll have to work on that.' [6] 
The extent to which respondents prepared themselves for a consultation differed. Some said that they came to a routine check-up without preparation, while others drew up a list of specific questions beforehand.

'When I think something may be related to my diabetes, then err.....I think, I need to ask her that question.' [4]

Some respondents seemed to assume that the issues that can be discussed in diabetes consultations are restricted to diabetes-related physical topics.

'Recently I ordered a book about diabetes, and it mentioned erectile dysfunction and so on. I thought, well, they mention it, so it is okay to talk about this issue with her. I didn't know that, I wasn't aware that it could be related to diabetes.' [9]

\section{Perspectives on psychosocial care provided by the PN}

Respondents appreciated the nurses' interest in their general well-being. Frequent visits and taking time for 'just a chat' were mentioned as facilitators of a good relationship with the $\mathrm{PN}$.

None of the respondents actively referred to a dialogue about the impact of diabetes on their daily functioning as a specific part of diabetes consultations. In this regard, some interviewees found it difficult anyway to define the burden of diabetes, since problems could also be ascribed to their physical condition in general, their age and/or another chronic condition. Patients with multimorbidity often regarded the other conditions as having more impact on their daily functioning than the diabetes.

I've just learnt to live with it [=diabetes]. It rarely comes up in my mind. The other diseases do bother me more than diabetes.' [5]

Respondents were confronted with several kinds of psychosocial issues in their daily functioning, like worries about other people, financial problems or specific life-events. Worries about poor diabetes control were not mentioned during the interviews. A few respondents referred to a possible negative influence of emotional distress on diabetes control, since the PN had stressed this.

'..also when I have feelings like distress, sadness. She said, I need to talk about it, I need to tell my story. Because it affects the diabetes.' [12]

The interviewer explicitly asked patients if they would appreciate a discussion of psychosocial problems during a diabetes consultation. The response of respondents who had experienced the self-management support by the PN was positive. 
Other interviewees were surprised and wondered what they could expect.

'What do you mean? What should I expect, that she can empathize with me, or something like that?' [5]

Some changed their attitude during the interview, from negative to positive, towards discussing psychosocial problems during the diabetes consultation with the PN.

'I think I'd like to discuss that [concerns about erectile dysfunction]... maybe with a doctor? I should raise the subject with the PN, I think. I think I'd dare to talk about it, that you [the interviewer] were here and I spoke with you about it.' [9]

Several barriers to discussing psychosocial problems with a PN were mentioned. Some respondents preferred to discuss mental health problems with their GP rather than the PN.

'Over the past, I've suffered from some mental health problems. They were caused by multiple factors. I wouldn't like to discuss these issues with the PN. They're just personal. I'd prefer to talk about these issues with the family doctor.' [4]

Several respondents said that they did not easily share worries or did not want to burden others in their social network with their problems. Two respondents stated their inability to discuss psychosocial problems in the presence of a third person (partner, relative, etc.).

'Most of the times, my husband is there and he dominates the conversation' [1]

Two men with diabetes-related sexual problems reported barriers to mentioning the consequences of these sensitive issues to a female nurse. Direct questions regarding this subject would be helpful, they stated. Other respondents confirmed the need to get direct and clear questions about their psychosocial well-being.

\section{In summary}

The interviews indicate that patients expect a biomedical diabetes check-up when they visit the PN, and are not used to raising psychosocial problems during a diabetes consultation. Specific barriers and needs regarding psychosocial care from the PN were mentioned. Based on the interview findings, 14 statements were formulated, as presented in table 5.2. 
Table 5.2 Outcomes on 14 statements to measure patients' expectations and attitude towards a psychosocial approach in routine diabetes consultations $(n=205)$

\begin{tabular}{|c|c|c|c|c|c|}
\hline Link* & \multicolumn{2}{|c|}{ Statement } & $\mathrm{N}$ & Mean** & SD \\
\hline \multirow{5}{*}{$a$} & \multicolumn{5}{|c|}{ Perspectives on routine diabetes consultations } \\
\hline & 1 & $\begin{array}{l}\text { A diabetes consultation is an important moment for me, } \\
\text { as this is when I find out how my diabetes is developing. }\end{array}$ & 205 & 4.58 & 0.693 \\
\hline & 2 & $\begin{array}{l}\text { My practice nurse provides good guidance on dealing } \\
\text { with my diabetes every day. }\end{array}$ & 204 & 4.40 & 0.828 \\
\hline & 3 & $\begin{array}{l}\text { Before I go to the diabetes consultation, I think about } \\
\text { the issues I want to discuss. }\end{array}$ & 205 & 3.94 & 0.948 \\
\hline & $4 * * *$ & $\begin{array}{l}\text { A diabetes consultation is only intended for discussing } \\
\text { issues that have to do with the physical consequences of } \\
\text { diabetes. }\end{array}$ & 200 & 2.89 & 1.190 \\
\hline \multirow[t]{11}{*}{$b$} & \multicolumn{5}{|c|}{ Perspectives on psychosocial care provided by the practice nurse } \\
\hline & 5 & $\begin{array}{l}\text { My practice nurse takes enough time to listen closely to } \\
\text { what I have to say. }\end{array}$ & 201 & 4.38 & 0.697 \\
\hline & 6 & $\begin{array}{l}\text { Each diabetes consultation should include a question } \\
\text { about the problems my diabetes is causing me in my } \\
\text { everyday life. }\end{array}$ & 203 & 3.84 & 0.900 \\
\hline & \multirow[t]{2}{*}{$7 * * *$} & It's not much use discussing emotional problems with & & & \\
\hline & & $\begin{array}{l}\text { the diabetes nurse, as she is not in a position to do } \\
\text { anything about them. }\end{array}$ & 203 & 3.21 & 1.181 \\
\hline & 8 & $\begin{array}{l}\text { I tell the practice nurse about it when I have emotional } \\
\text { problems (such as gloominess, stress or loneliness). }\end{array}$ & 204 & 3.88 & 0.995 \\
\hline & 9 & I worry about it if I can't sufficiently control my diabetes. & 204 & 3.76 & 0.950 \\
\hline & 10 & $\begin{array}{l}\text { I find it harder to sufficiently control my diabetes when } \\
\text { I'm having emotional problems. }\end{array}$ & 204 & 3.46 & 0.954 \\
\hline & $11^{* * *}$ & $\begin{array}{l}\text { When I'm feeling down, I'd rather discuss it with my GP } \\
\text { than with the practice nurse. }\end{array}$ & 204 & 2.97 & 1.247 \\
\hline & 12 & $\begin{array}{l}\text { I would appreciate it if the practice nurse would take the } \\
\text { initiative to ask me if I have any emotional problems. }\end{array}$ & 205 & 3.77 & 0.962 \\
\hline & $13^{* * *}$ & $\begin{array}{l}\text { I find it hard to talk to the practice nurse about my } \\
\text { worries and anxieties. }\end{array}$ & 202 & 3.22 & 1.168 \\
\hline \multirow[t]{2}{*}{$c$} & \multicolumn{5}{|c|}{ Extra: Social support } \\
\hline & 14 & $\begin{array}{l}\text { I have enough relatives and friends around me to } \\
\text { support me when I'm having a difficult time. }\end{array}$ & 203 & 3.79 & 1.019 \\
\hline
\end{tabular}

* The subheadings refer to the subheadings used in the results section about the qualitative part of the study. ${ }^{* *}$ Based on 5-point Likert scales, with 1 indicating totally disagree and 5 indicating totally agree. $* * *$ Items reverse-coded ( 1 indicating totally agree and 5 indicating totally disagree) such that a higher score indicates a more open attitude towards psychosocial care from the practice nurse.

\section{Quantitative part}

\section{Participants}

The 14-item structured questionnaire was completed by 223 participants of the SMS trial. We excluded ten patients who had participated in the qualitative part of the study, due to the potential influence of the interview on their perspectives on diabetes care. Another eight patients were excluded due to missing values for more 
than half of the 14 items. Data analysis included 86 patients who had received care from PNs trained in SMS, and 119 patients of PNs not trained in SMS. Patients' demographic characteristics are summarized in table 5.3.

Table 5.3 Demographic characteristics of patients participating in the questionnaire survey $(n=205)$ Values are numbers (percentages) unless stated otherwise

\begin{tabular}{|c|c|c|c|c|}
\hline \multicolumn{2}{|l|}{ Characteristic } & $\begin{array}{l}\text { Total } \\
(n=205)\end{array}$ & $\begin{array}{l}\text { Patients of PNs } \\
\text { trained in SMS } \\
\quad(n=86)\end{array}$ & \multirow{2}{*}{$\begin{array}{c}\begin{array}{c}\text { Patients of } \\
\text { PNs not }\end{array} \\
\text { trained in SMS } \\
(n=119)\end{array}$} \\
\hline Gender & Female & $98(47.8)$ & $42(48.8)$ & \\
\hline Age & Mean age in years (SD) & $66(9.4)$ & $65(10.5)$ & $66(8.5)$ \\
\hline Duration of diabetes & Mean duration in years (SD) & $10.0(7.0)$ & $10.5(8.0)$ & $9.5(6.2)$ \\
\hline \multirow[t]{4}{*}{ Highest level of education* } & Low & $144(70.2)$ & $60(69.8)$ & $84(70.6)$ \\
\hline & Medium & 40 (19.5) & $19(22.1)$ & $21(17.6)$ \\
\hline & High & $14(6.8)$ & $4(4.7)$ & $10(8.4)$ \\
\hline & Missing & $7(3.4)$ & $3(3.5)$ & $4(3.4)$ \\
\hline
\end{tabular}

* low refers to primary school and pre-vocational education, medium refers to upper secondary general or vocational education, high refers to higher professional education and university education.

\section{Outcomes of the questionnaire}

The outcomes of the 14-item questionnaire are summarized in table 5.2.

Patients' perspectives on diabetes consultations (items 1-4) were mainly positive. More than $90 \%$ of our sample valued being checked for general well-being with regard to their diabetes (item 1), and reported that the PN had provided valuable counselling on their daily functioning (item 2). About three quarters of the respondents stated that they would consider in advance what they were going to discuss during a consultation (item 3). Patients' beliefs about the purpose of diabetes consultations (item 4) showed some variation. Forty-two percent of the respondents agreed with the statement that a diabetes consultation is only intended to discuss medical issues of diabetes, while $34 \%$ disagreed with this statement.

The items 5 to 8 referred to patients' perspectives on psychosocial care by the PN. More than $90 \%$ stated that the $\mathrm{PN}$ had taken time to listen to them during a consultation (item 5). According to two thirds of the sample, a PN should ask questions about the burden imposed by their diabetes on their daily functioning at each consultation (item 6). Fifty-six respondents (28\%) agreed with the statement that it is useless to discuss psychosocial issues with the PN, as she cannot do anything 
about it (item 7). However, $72 \%$ of the sample stated that they would mention emotional problems to their PN (item 8), including half of the 56 respondents who agreed with item 7 .

Items 9 and 10 indicated the extent to which patients experience an association between their emotional well-being and diabetes control. Two thirds of the sample $(68 \%)$ would worry about poor diabetes control. Half of the respondents agreed that emotional problems negatively affected their diabetes management.

One third of the sample would prefer their GP to discuss psychosocial issues (item 11). Direct questions about emotional well-being asked by the PN would be appreciated by $67 \%$ of the respondents (item 12 ). Thirty percent reported that they found it difficult to share their worries and fears with the PN (item 13).

Sixty-eight percent of our sample reported that they would get social support from family and friends when they experienced difficulties in their daily lives (item 14).

Three items referring to patients' satisfaction with usual care (items 1, 2 and 5) were skewed and therefore not included in the principal component analysis. The principal component analysis yielded one consistent composite variable of four items $(4,7,11$ and 13) with a Cronbach's alpha of 0.74 , which was labelled 'Patients' attitude to discussing psychosocial problems in a diabetes consultation'. It represents patients' beliefs about the purpose of a diabetes consultation, difficulties of talking about emotional issues with the $\mathrm{PN}$, the extent to which they preferred to receive psychosocial care from their GP, and their expectations of the PNs' support. The sample included 85 patients (41.5\%) with a mean composite score below 3 , indicating a predominantly negative attitude. Examination of the composite measure, as presented in table 5.4, showed a significant association between age and patients' attitude ( $p<05$ ), in that patients aged 65 years or younger had a more positive attitude to discussing psychosocial issues during a diabetes consultation than patients older than 65 years. We found no statistically significant associations between patients' attitudes and whether or not their PNs had been trained in SMS. Furthermore, no significant associations were found with patients' current psychosocial problems, sex and time since diagnosis. 
Table 5.4 Outcomes of Pearson chi-square test for the composite score 'Patients' attitude towards discussing psychosocial problems in a diabetes consultation'

\begin{tabular}{|c|c|c|c|}
\hline & $\begin{array}{c}\text { Number of } \\
\text { patients }\end{array}$ & $\begin{array}{l}\% \text { with a positive attitude } \\
\text { towards discussing } \\
\text { psychosocial problems in a } \\
\text { diabetes consultation }\end{array}$ & P-value \\
\hline Type of diabetes care & & & 0.125 \\
\hline PNs trained in SMS & 86 & $52 \%$ & \\
\hline PNs not trained in SMS & 119 & $63 \%$ & \\
\hline Problems of daily emotional and social functioning* & & & 0.694 \\
\hline Yes & 78 & $58 \%$ & \\
\hline No & 119 & $61 \%$ & \\
\hline Sex & & & 0.128 \\
\hline Male & 107 & $64 \%$ & \\
\hline Female & 98 & $53 \%$ & \\
\hline Age & & & 0.017 \\
\hline$\leq 65$ years & 95 & $67 \%$ & \\
\hline$>65$ years & 110 & $51 \%$ & \\
\hline Diagnosis of diabetes & & & 0.910 \\
\hline$\leq 5$ years ago & 59 & $60 \%$ & \\
\hline$>5$ years ago & 133 & $61 \%$ & \\
\hline
\end{tabular}

*At time of measurement, according to the screening criteria of the SMS trial

\section{DISCUSSION}

The aim of the present study was to examine patients' readiness to receive psychosocial care integrated in routine consultations. The two parts of our mixed methods approach yielded complementary results. Our qualitative findings emphasized that patients currently visit the PN for the biomedical aspects of diabetes management and are not used to being questioned about psychosocial problems. The subsequent quantitative analysis indicated a positive attitude of patients towards the ideal of integrated care, i.e. attention for biomedical as well as emotional and social challenges in their everyday lives. Patients older than 65 years perceived more barriers to discussing psychosocial problems with the PN than younger patients. Patients' attitudes appeared to be independent from their PNs having been trained in SMS or not.

Our study emphasized patients' expectations as a determining factor for successful integration of a psychosocial self-management approach in routine diabetes care. Although patients reported a positive attitude towards integrated diabetes care, they are used to the biomedical approach of diabetes check-ups by PNs. These findings are in line with a recent ethnographic study which found that the idea of case-finding for 
depression in routine chronic care was appreciated, but at the same time, patients did not feel that the chronic disease review was the obvious place to discuss mood issues. $^{20}$ A longitudinal qualitative study in the UK suggested that routine consultations shape chronic patients' expectations of their care. ${ }^{21}$ The authors argued that patients with a chronic condition have been socialized 'into the role of passive subjects of surveillance' due to the biomedical focus of consultations. Just as in the UK, Dutch diabetes patients get regular, primarily biomedical, check-ups. Quality assessment is also mainly based on biomedical quality indicators. As a result, the PN becomes the 'bio-medical manager'. The crucial role of patients' expectations in routine diabetes check-ups emerged in another qualitative study as well. Diabetes patients in Sweden who were interviewed about the role of the nurse practitioner expected self-care advice regarding the medical management tasks. The psychosocial aspects were not reported in that paper. ${ }^{22}$ Another qualitative study regarding patients' understanding of depression associated with chronic physical illness found that patients do not normally expect their GP to play a role in, or have the capacity to provide help with emotional problems in situations like bereavement or relationship breakdown. $^{23}$

\section{Strengths and limitations}

The strength of our study is that we started with in-depth interviews to explore patients' experiences with current diabetes care and their perspectives on the role of the PN, and further explored our findings by means of a structured questionnaire distributed among a larger sample consisting partly of patients who had been exposed to the psychosocial SMS approach and partly of patients who had not. The sample consisted of patients who perceived a burden of diabetes in daily functioning and emotional distress and/or had experienced these problems in the last year (according to the screening outcomes). In developing our questionnaire, we stayed close to the findings of the qualitative analysis to ensure good content validity. We are aware, however, that the questionnaire was not tested on construct validity or reliability.

Our quantitative analysis did not show significant differences between patients who received care from PNs trained in SMS or from PNs not so trained. This could be ascribed to problems with the integration of SMS into daily practice, as well as to the period of time that professionals and patients need to change their roles and expectations. $^{20}$ Moreover, patients' agreement with statements about their current diabetes care may have been influenced by social desirability. 


\section{Implications}

A requirement for successful integration of a psychosocial care approach in routine diabetes care is the identification of patients who are in need of emotional and social self-management support. Given that patients were mainly positive about their current diabetes care in both the qualitative and quantitative parts of our study, it is unclear to what extent they perceived a need for systematic attention being given by a PN to difficulties in their daily psychosocial functioning. One may question to what extent PNs should be involved in the detection of psychosocial problems during diabetes check-ups when patients do not take the initiative. However, monitoring of well-being during routine visits fits in with a holistic approach, which is in theory seen as inherent to the care approach of primary care providers. ${ }^{24}$ As we found in this study, a challenge is the exclusively disease-focused context in which detection of psychosocial problems for the purpose of providing self-management support needs to be integrated. It calls for socializing health professionals in an integrated care approach and changing the chronic care context in such a way that patients are informed and enabled to express psychosocial problems. Both professionals and patients will need time to get used to this integrated care approach. As not all patients with poor diabetes control would be inclined to express psychosocial issues during a consultation even though the nurse-led support would be helpful for their self-management, broadening the inclusion criteria for receiving self-management support may improve the fit and success of the SMS approach.

\section{CONCLUSION}

Patients see their PNs as specialized biomedical diabetes managers. Their expectations regarding diabetes consultations by a PN are particularly related to the biomedical aspects of diabetes. As a consequence, patients would not feel inclined to raise the subject of psychosocial problems, although they have a positive attitude towards an integrated care approach. A decision by policy makers, health insurers and health professionals to incorporate systematic detection of psychosocial problems by PNs in routine diabetes care requires endeavours to inform patients and help them change their expectations and behaviors towards an integrated self-management approach. 


\section{REFERENCES}

1. Heiligers PJM, Noordman J, Korevaar JC, et al., Kennisvraag: praktijkondersteuners in de huisartspraktijk (POH's) klaar voor de toekomst? [Knowledge base: Practice nurses in the GP practices, ready for the future?].Utrecht: Netherlands Institute for Health Services Research (NIVEL), 2012.

2. Rutten G, De Grauw W, Nijpels G, et al. NHG-Standaard Diabetes mellitus type 2 (derde herziening) [NHG Practice Guideline Diabetes mellitus type 2 (Third revision)]. Huisarts Wet 2013; 56(10):512525.

3. Netherlands Diabetes Federation, NDF Care Standard. Transparancy and quality of diabetes care for people with type 2 diabetes.Amersfoort: Nederlandse Diabetes Federatie (NDF), 2007.

4. Struijs J, de Jong-van Til J, Lemmens L, et al., Bundled payments of diabetes care: Effects on care delivery process and quality of care at three-year follow-up.Bilthoven: National Institute for Public Health and the Environment (RIVM), 2012.

5. Bodenheimer T, Wagner EH Grumbach K. Improving Primary Care for Patients With Chronic Illness. JAMA 2002; 288(14):1775-1779.

6. Elissen A, Nolte $E$, Knai $C$, et al. Is Europe putting theory into practice? A qualitative study of the level of self-management support in chronic care management approaches. BMC Health Serv Res 2013; 13(1):117.

7. Pearce MJ, Pereira K Davis E. The psychological impact of diabetes: A practical guide for the nurse practitioner. J Am Assoc Nurse Pract 2013; 25(11):578-583.

8. Pouwer F. Should we screen for emotional distress in type 2 diabetes mellitus? Nat Rev Endocrinol 2009; 5(12):665-71.

9. Fisher L, Mullan JT, Arean P, et al. Diabetes distress but not clinical depression or depressive symptoms is associated with glycemic control in both cross-sectional and longitudinal analyses. Diabetes Care 2010; 33(1):23-28.

10. Egede LE, Ellis C. Diabetes and depression: Global perspectives. Diabetes Res Clin Pract 2010; 87(3):302-312.

11. Lorig KR, Holman H. Self-management education: history, definition, outcomes, and mechanisms. Ann Behav Med 2003; 26(1):1-7.

12. Hinder S, Greenhalgh T. "This does my head in". Ethnographic study of self-management by people with diabetes. BMC Health Serv Res 2012; 12:83.

13. Townsend A, Wyke S Hunt K. Self-managing and managing self: practical and moral dilemmas in accounts of living with chronic illness. Chronic IIIn 2006; 2(3):185-194.

14. Van Dijk-de Vries A, Van Bokhoven M, Terluin B, et al. Integrating nurse-led Self-Management Support (SMS) in routine primary care: design of a hybrid effectiveness-implementation study among type 2 diabetes patients with problems of daily functioning and emotional distress: a study protocol. BMC Fam Pract 2013; 14:77.

15. Jonkers CCM, Lamers $\mathrm{F}$, Bosma $\mathrm{H}$, et al. The effectiveness of a minimal psychological intervention on self-management beliefs and behaviors in depressed chronically ill elderly persons: a randomized trial. Int Psychogeriatr 2012; 24(02):288-297.

16. Van Dijk-de Vries A, van Bokhoven MA, Winkens B, et al. Lessons learnt from a cluster-randomised trial evaluating the effectiveness of Self-Management Support (SMS) delivered by practice nurses in routine diabetes care. BMJ Open 2015; 5(6).

17. Greene JC, Caracelli VJ Graham WF. Toward a Conceptual Framework for Mixed-Method Evaluation Designs. Educ Eval Policy Anal 1989; 11(3):255-274.

18. Edmonds WA, Kennedy TD, An applied reference guide to research designs. Quantitative, qualitative and mixed methods. 2013, Thousand Oaks, CA: Sage.

19. Graneheim UH, Lundman B. Qualitative content analysis in nursing research: concepts, procedures and measures to achieve trustworthiness. Nurse Educ Today 2004; 24(2):105-112.

20. Alderson SL, Russell AM, McLintock K, et al. Incentivised case finding for depression in patients with chronic heart disease and diabetes in primary care: an ethnographic study. BMJ Open 2014; 4(8). 
21. Chew-Graham C, Hunter C, Langer S, et al. How QOF is shaping primary care review consultations: a longitudinal qualitative study. BMC Fam Pract 2013; 14(1):103.

22. Grund J, Stomberg MW. Patients' Expectations of the Health Advice Conversation With the Diabetes Nurse Practitioner. J Prim Care Community Health 2012; 3(4):230-234.

23. Alderson S, Foy R, Glidewell L, et al. Patients understanding of depression associated with chronic physical illness: a qualitative study. BMC Fam Pract 2014; 15(1):37.

24. The Dutch College of General Practitioners (NHG), Core values of General Practice / Family Medicine. Position Paper.Utrecht: The Dutch College of General Practitioners (NHG), 2011. 


\section{CHAPTER 6}

Lessons learnt from a cluster-randomised trial evaluating the effectiveness of Self-Management Support (SMS) delivered by practice nurses in routine diabetes care

Anneke van Dijk - de Vries

Marloes A. van Bokhoven

Bjorn Winkens

Berend Terluin

J. André Knottnerus

Trudy van der Weijden

Jacques Th. M. van Eijk

BMJ Open 2015;5:e007014 


\section{ABSTRACT}

\section{Objective}

To evaluate the effectiveness of biopsychosocial Self-Management Support (SMS) delivered by practice nurses in routine diabetes care.

\section{Design}

A pragmatic cluster-randomised controlled trial within a hybrid effectiveness-implementation study design. Practice nurses were cluster-randomised.

\section{Setting}

A regional care group in the Netherlands consisting of 77 family practices. The study involved practice nurses $(n=40)$ providing care to approximately 4000 patients with diabetes.

\section{Participants}

Patients with type 2 diabetes patients $(n=264)$ selected by a self-administered questionnaire aimed at measuring emotional distress and diabetes-related reduced daily functioning.

\section{Intervention}

Practice nurses in the intervention arm $(n=19)$ were trained to integrate SMS into their routine consultations. SMS included detection of patients with emotional distress and reduced daily functioning, and supporting them when needed through problem solving and reattribution techniques. Practice nurses in the control arm $(n=21)$ provided usual care.

\section{Main outcome measures}

The primary outcome measure was a dichotomised score on a Visual Analogue Scale that measured the perceived effect of diabetes on daily functioning. Secondary measures included patients' diabetes-related distress, quality of life, autonomy and participation, self-efficacy, selfmanagement and glycaemic control. Outcomes were measured at baseline and at 4-month and 12-month follow-ups.

\section{Results}

Only 16 of the 117 patients in the intervention arm (14\%) who were found eligible by the posted research-driven screening questionnaire were detected by their practice nurses. Extra consultations for the self-management support were delivered to only 11 study participants. In the control arm, 147 patients received usual care. Multilevel analyses showed no significant differences in outcomes between the intervention and control arms.

\section{Conclusions}

SMS in its present form was not effective. The research-driven screening to select trial participants appeared to be inconsistent with nurse-led detection in routine practice. Adequate follow-up moments need to be built in to overcome barriers resulting from tension between the implementation and effectiveness parts of hybrid studies. 


\section{INTRODUCTION}

Patients with chronic diseases such as type 2 diabetes mellitus have to deal with challenging day-to-day management tasks regarding the medical, emotional and social consequences of their chronic condition. ${ }^{1,2}$ Research has shown a reciprocal relationship between the emotional health status of people with diabetes and their medical self-management: emotional distress may interfere with control over the disease whereas poor control over the disease can lead to emotional distress. ${ }^{3-6}$ Studies highlight the need to support the medical as well as the emotional and role management tasks in both newly diagnosed patients and patients who face the longer-term consequences of their chronic condition. ${ }^{7-9}$

In European countries, most patients with diabetes receive follow-up care in the primary care setting by nurses. ${ }^{10}$ Practice nurses (PNs) in the Netherlands work according to guidelines that focus on medical and behavioural management. ${ }^{11,12}$ Furthermore, the financial reimbursement of care and patients' health outcomes are determined by biomedical targets. ${ }^{13}$ Consequently, the psychosocial aspects of diabetes care are not systematically incorporated in clinical practice. ${ }^{10,13-15}$

In collaboration with a regional care group of general practitioners (GPs) in the Netherlands and a health insurer, the SMS('Self-Management Support') implementation project was initiated to realise a shift from biomedically oriented care towards a biopsychosocial approach in diabetes care. ${ }^{16}$ The starting point was a nurseled minimal psychological intervention. A previous randomised trial has shown that this intervention was cost-effective for patients with diabetes with minor to moderate depression: 9 months after receiving the intervention, depressive symptoms were significantly lower, there was a positive effect on patients' quality of life, and patients experienced less anxiety, possessed more self-efficacy skills, demonstrated better glycaemic control and showed more participation in comparison to control patients. ${ }^{17-19}$ There was an implementation momentum. The health insurer promised to pay the costs for the extra care, and the care group gave commitment to take care of training facilities and integration of SMS parameters into Electronic Medical Records. Some adjustments to the nurse-led intervention were crucial. Where the original intervention had been delivered at patients' homes by specifically trained nurses from the research team who selected eligible patients by means of an 
elaborate diagnostic procedure, in SMS it was provided by PNs as a structural part of their consultations delivered in the family practice. For the identification of eligible patients a simple detection method became an inherent part of SMS. The eligibility criteria changed from having a mild to moderate depression towards suffering from both emotional distress and interference in their daily functioning due to the burden of diabetes. This focus on daily functioning instead of a diagnosis of depression was supposed to fit the primary care setting. Patients who were detected by the PN received the nurse-led minimal psychological intervention or were referred to the GP to see whether more specialised care would be required, depending on the severity of the symptoms.

SMS was evaluated by means of a type 2 hybrid effectiveness-implementation study design, in which the regional implementation strategies and the effectiveness of SMS were evaluated simultaneously. ${ }^{20}$ This paper will focus on the effectiveness part of the SMS project, though it is closely connected to the implementation part. This paper reports the effectiveness of SMS integrated by PNs into routine diabetes consultations regarding patients' daily functioning, emotional health, quality of life, autonomy and participation, self-efficacy and self-management skills, and blood glucose levels.

\section{METHODS}

\section{Study design}

A two-arm, pragmatic cluster-randomised controlled trial was conducted with PNs as the unit of randomisation and their patients with type 2 diabetes mellitus as the unit of analysis. Measurements were at baseline, at 4 months and at 12 months. The study was conducted between November 2011 and February 2013 and was registered in a Dutch public trial registry [NTR2764]. The study protocol has been published elsewhere. $^{16}$

\section{Study participants}

All the family practices of one regional organisation of GPs (a so-called 'care group') in the South of the Netherlands were eligible to participate in the study. GPs were asked to participate in the SMS project. Their PNs for diabetes care were randomly assigned 
to an intervention or control arm. PNs in the intervention arm were trained in SMS, whereas PNs in the control arm provided usual diabetes care, conforming to the Dutch guidelines. Owing to the variety of PNs working solo versus in a team, and in one versus more practices, PNs were stratified into working alone in a practice, working in a team and working in different settings. The randomisation was performed by an independent research assistant who used a random number seed computer program to assign PNs to study arms assuming an allocation ratio of $1: 1$. PNs working together in a practice were clustered for being randomised to the same trial arm to avoid the risk of contamination if the SMS and usual care would be delivered in the same family practice. Regarding the analysis, a team of PNs was seen as one cluster if patients could receive diabetes care from these PNs alternately.

In the selection of patients for the effectiveness trial, the following issues were crucial. First, we wanted to select patients who would receive the complete intervention including detection and follow-up. Furthermore, patients from the intervention and control arms should be selected in a similar way, without interfering in their routine care. We set up a screening procedure by means of written questionnaires sent to patients' home addresses to identify patients with actual problems of daily functioning and emotional distress. Patients with a clinically established diagnosis of type 2 diabetes mellitus were sent a letter by their GPs to introduce the SMS-project. The enclosed self-administered questionnaire consisted of the screening instruments that intervention PNs would also apply for SMS in their routine practice. It included the 'Daily Functioning Thermometer' (DFT) which is a Visual Analogue Scale to measure how suffering under the burden of diabetes affects patients' perceived functioning in everyday life. Patients were asked to indicate a position between 0 (no burden at all) to 10 (extremely burden) at a continuous vertical $10 \mathrm{~cm}$ line. A score of 4 was chosen to differentiate between patients who could benefit from support in their self-management skills (score $>4$ ) and patients who had found a satisfactory way to live with the consequences of their diabetes (score $\leq 4$ ). The DFT has been developed for the purpose of this study. It is comparable to the Distress Thermometer, a validated questionnaire in the care for patients with cancer, ${ }^{21}$ and a validated Visual Analogue Scale regarding the worst (0) and the best possible life (10) for adolescents with type 1 diabetes mellitus. ${ }^{22}$ Next to the DFT, patients were asked to complete the three-item Distress Screener (DS) which is a quick-scan instrument for emotional distress and an indicator of potential underlying severe mental health problems. ${ }^{23}$ Patients with score DFT $>4$ and DS $>3$ were eligible for trial participation. 
The time interval between the researcher-driven self-administered screening questionnaire and the face-to-face nurse-led detection procedure in the consultation room needed to be as short as possible. However, intervention patients should complete the baseline measurement before SMS is applied. Owing to the logistics, patients received the posted screening questionnaire 4-6 weeks before a planned diabetes consultation. Reminders were sent at least 3 weeks before a consultation. Patients were asked to return the completed questionnaire to the research centre and to give informed consent to be approached if they were found to be eligible for research follow-up measurements. Within a week after receiving the screening questionnaire at our research centre, eligible patients were sent an invitation letter together with an informed consent form for trial participation and the baseline measurement. Patients who gave informed consent knew whether they would receive an addition to their usual care or not. No details were given about the content of the intervention.

\section{Intervention: SMS in routine care}

During three $8 \mathrm{~h}$ training sessions, PNs in the intervention arm were trained to integrate the detection and follow-up phase of SMS into their daily practice. The training sessions were followed up by booster sessions to maintain and improve PNs' skills in SMS. PNs attended these booster sessions three or four times during the year of follow-up.

After the training sessions, PNs started to integrate SMS into their routine care practice. PNs were blinded regarding the outcomes of the recruitment procedure and study participation of their patients. They applied SMS in all their consultations with patients with diabetes. Financial reimbursement for the extra time spent on SMS was added to the bundled payment arrangement for diabetes care. ${ }^{24}$

SMS included a detection and follow-up phase. The flow chart of SMS is presented in figure 6.1. 
Figure 6.1 Flowchart of the SMS-intervention in routine care

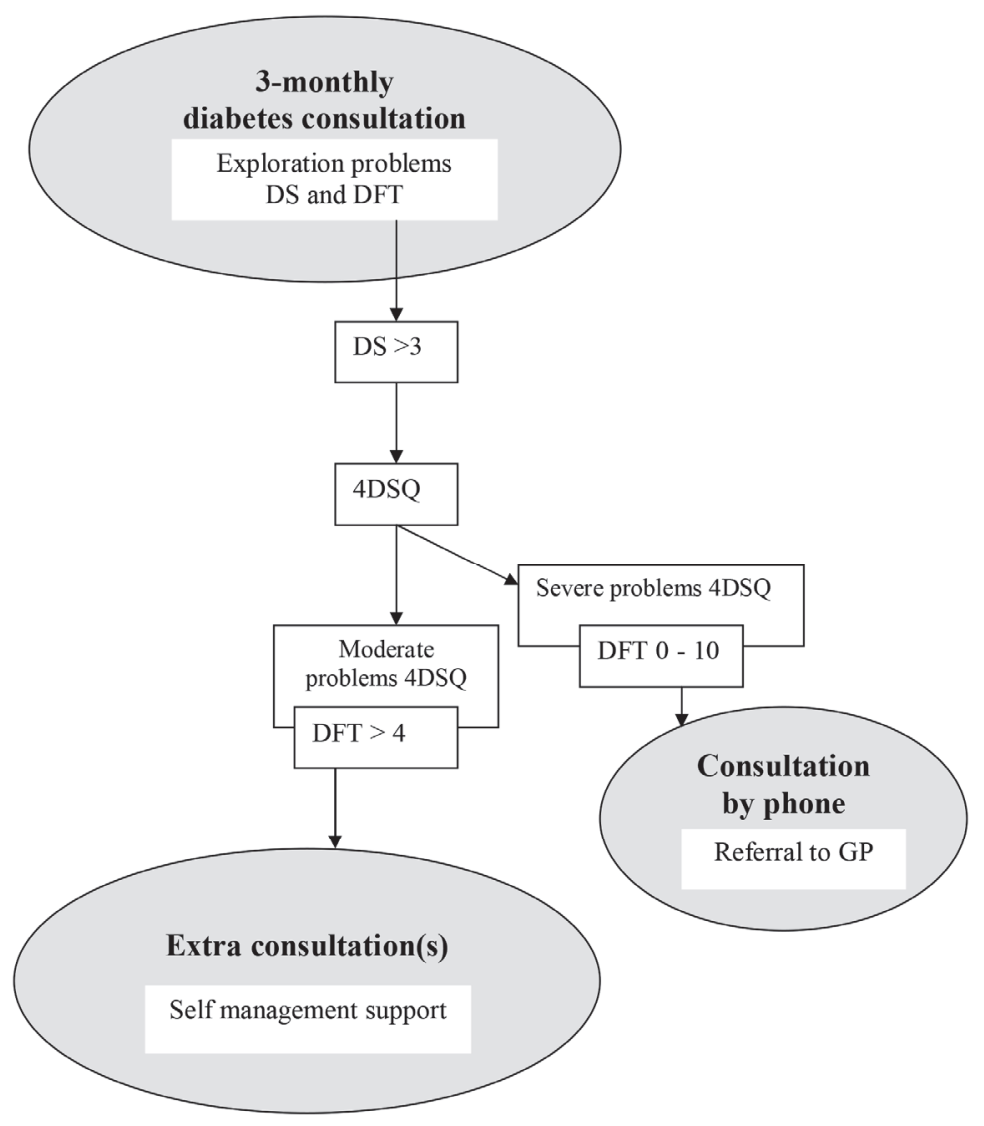

The detection phase of SMS started by exploring whether a patient experienced problems in daily life. PNs then applied the DFT by showing patients a vertical line numbered from 0 to 10 with 0 indicating no burden at all and 10 indicating extreme burden, and asking them to rate the burden of diabetes in their daily life ] PNs also verbally administered the three questions of the DS. ${ }^{23}$ Patients with score DS $>3$, which indicates underlying mental health problems, were asked to complete the FourDimensional Symptom Questionnaire (4DSQ) ${ }^{25}$ immediately after the consultation. This self-report instrument is widely used in Dutch primary care to distinguish nonspecific distress from depression, anxiety and somatisation. It differentiates between mild, moderate or severe symptoms. The completed 4DSQ was returned to the PN, who computed the sum scores on each domain. 
The follow-up phase of SMS was based on the outcomes of the DFT and 4DSQ. Patients registering a 'severe' score on at least one of the four subscales of the 4DSQ were referred to the GP for further diagnostics and treatment.

Patients who experienced problems of daily functioning (DFT >4) and emotional health problems (moderate scores on at least one subscale of the 4DSQ) were offered consultations for self-management support. These extra consultations delivered by PNs were aimed at supporting patients in their day-to-day management of diabetes and its emotional and social consequences. The intervention strategy derived from the principles of learning theory has been described elsewhere. ${ }^{26}$ PNs supported patients in the processes of defining problems and finding solutions themselves, by applying problem-solving and reattribution techniques. Problem-solving consists of seven stages that efficiently address problems and their possible solutions. ${ }^{27}$ The reattribution technique was applied to challenge patients to link feelings and cognition to consequent behaviour. Patients could use information from a diary in which they recorded symptoms, thoughts, worries, feelings, and behaviour. Both problem solving and reattribution techniques were intended to result in action plans indicating how patients would achieve their personal goals. ${ }^{28}$

\section{Measurements effectiveness trial}

We used postal questionnaires for patient measurements. Patient characteristics regarding their age, sex, year of diagnosis, treatment of diabetes (insulin therapy or tablets), marital status, work status and educational level were assessed at baseline. The glycaemic control of patients was measured during diabetes consultations. These measurements were extracted from the electronic patients databases.

In the year following the training, PNs in the intervention arm recorded process measures and outcomes of SMS on a specific registration form. These data were used to evaluate whether patients were exposed to SMS.

\section{Outcomes}

The effect of SMS on patients' daily functioning was measured by means of the DFT. The DFT was dichotomised to compare the number of patients who were improved in their daily functioning and had apparently found a satisfactory way to live with the consequences of their diabetes (DFT $\leq 4$ ) with patients who still perceived a burden of diabetes on their daily functioning (DFT $>4$ ). 
The secondary outcome measure 'diabetes-related emotional distress' was measured by the 20-item Problem Areas in Diabetes questionnaire (PAID). ${ }^{29-31}$ Scores were transformed to a $0-100$ scale, with 0 being the most favourable outcome. Missing items were imputed using patients' individual mean score if at least $50 \%$ of items were available.

Participation and autonomy were measured by means of the Impact on Participation and Autonomy (IPA) questionnaire. ${ }^{32}$ The response options of the 32 items ranged from 0 to 4 with higher scores representing poorer participation and autonomy. Five subscale scores were computed: autonomy indoors (range 0-28), family role (range 0-28), autonomy outdoors (range 0-20), social life and relationships (range 0-28) and work and education (range 0-24). In accordance with the manual, missing items were imputed using the individual means score of items that were not missing in patients for whom at least $75 \%$ of items were available. ${ }^{33}$

Patients' self-management knowledge and behaviours regarding their diabetes were measured using the Dutch version of the Partners in Health scale (PIH-NL). ${ }^{34}$ The 12 items covered four domains of patients' competency in relation to their selfmanagement (knowledge, coping, management of condition and adherence to treatment). We used the total sum score.

The 12-item Short-Form Health Survey (SF-12) measured the quality of life. ${ }^{35} \mathrm{~A}$ physical component summary and a mental component summary were computed by using item weights and regression constants for the Dutch population derived from the oblique rotation method. ${ }^{36,37}$ The norm-based summary scores have a mean of 50 and an SD of 10 in the Dutch population. ${ }^{37}$ Higher scores reflect better outcomes on the quality of life.

The General Self-Efficacy Scale (GSES-12) assessed patients' belief in their ability to organise and engage in certain behaviours. ${ }^{38,39}$ A higher sum score (range 12-60) reflects higher levels of self-efficacy. Missing items were imputed using patients' individual mean score if at least $50 \%$ of items were available. 
The glycated haemoglobin $\mathrm{A} 1 \mathrm{c}$ in $\mathrm{mmol} / \mathrm{mol}$ was measured during consultations. For the baseline measure, we used data from the first consultation after the patient's baseline measurement (with a maximum interval of 3 months). The consultation following this first consultation was used as the 4-month follow-up measurement. The last measurement was the assessment approximately 1 year after the patient's baseline measurement (at least more than 6 months after the first consultation).

\section{Statistical analysis}

The power calculation was based on the dichotomous DFT. ${ }^{16}$ On the basis of a group size of 46 PNs, we determined in advance that a sample size of 232 patients (at least 5 patients per PN) would have $90 \%$ power and an $\alpha$ of 0.05 to detect an improvement in perceived daily functioning (defined as DFT $\leq 4$ ) at 12 months measurement occurring in $20 \%$ of patients in the intervention arm versus $5 \%$ of those in the control arm. In this power calculation for cluster-randomised trials, an intraclass correlation coefficient of 0.04 was used. Assuming that not all positively screened patients would give informed consent for trial participation, and a $30 \%$ loss to follow-up, we planned to invite 10 eligible patients for each PN.

Baseline variables were compared by means of independent-samples tests and $x^{2}$ tests to detect statistically significant differences between both groups at baseline. For the effect evaluation, linear and logistic multilevel models were used with an unstructured covariance structure for repeated measures, and patients and PNs as random factors. These models account for the correlation between the repeated measurements for each patient and also for the hierarchical structure of the data, with measurements (level-1) clustered within patients (level-2) who in turn were clustered within PNs (level-3). Type of practice, that is, the stratification variable, time of measurement (categories: 0, 4 and 12) and the interaction between group and time of measurement were included in the models as fixed effects. Analyses were performed on an intention-to-treat basis.

For the dichotomised primary outcome, we used the research-led screening outcomes to ensure that all participants of the intervention and control arms started with a score DFT $>4$, indicating a perceived burden of diabetes. Consequently, the model only included 4-month and 12-month follow-ups as the baseline value was the same for all participants. 
A two-sided $p$ value $<0.05$ was considered statistically significant. Statistical analyses were conducted using the software packages IBM SPSS Statistics version 21.0 for Windows and SAS version 9.3.

\section{RESULTS}

\section{Participants}

From the 77 family practices that were approached between April and June 2011, 40 agreed to participate. Their PNs $(n=41)$ were by randomisation assigned to the intervention arm (20 PNs) and the control arm (21 PNs). After randomisation, but before patient recruitment, one family practice in the intervention arm withdrew from study participation due to the heavy workload of the PN. This left 19 PNs who received training in SMS and integrated it into their daily practice, and 21 PNs in the control arm who provided usual care. ${ }^{40}$ As some PNs worked together in a team, 15 units of analysis were left in the intervention arm and 19 units of analysis in the control arm.

A total number of 3822 patients with diabetes were sent a screening questionnaire in the period from October 2011 to March 2012. The response rate was 50\% in the intervention arm and $44 \%$ in the control arm. As screening questionnaires were sent by GPs, we could not compare responders with non-responders with regard to demographic characteristics.

From all 1805 patients who participated in the screening, 357 (20\%) met the detection criteria and were invited to take part in the trial. A total of 264 patients (74\%) gave informed consent to participate in the trial. Their research-led screening outcomes were not significantly different from outcomes from eligible patients who refused trial participation.

From the 117 intervention patients and 147 control patients who participated in the trial, $80 \%$ completed all of the follow-up measurements. In $10 \%$ of the sample, one follow-up measurement was missing. Three patients did not complete the baseline measurement and gave informed consent at the 4-month follow-up measurement. Another 23 patients completed only the baseline measurement. We found no baseline variables that were significantly related to incompleteness of measurements. Figure 6.2 illustrates the flow of recruitment and randomisation of PNs, screening of patients and measurements of trial participants. 
Figure 6.2 Flow of participants through the Self-Management Support (SMS)-trial

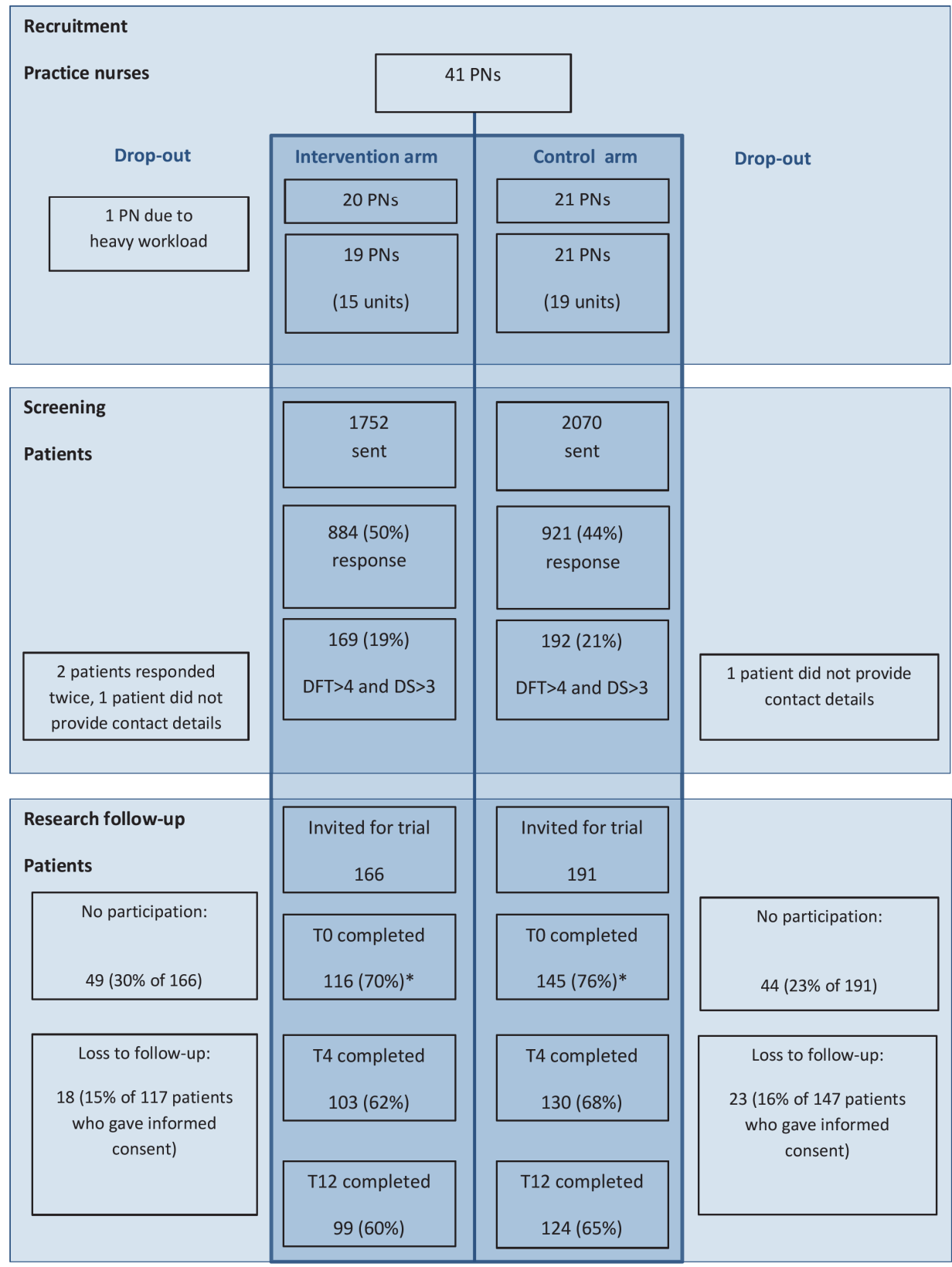

*Some patients ( $n=1$ in the intervention arm and $n=2$ in the control arm) did not respond at baseline, but agreed to participate in the trial at time of the T4 measurement. 


\section{Baseline characteristics}

Table 6.1 illustrates the baseline characteristics of participants in the SMS trial.

Table 6.1 Baseline characteristics of study participants in intervention arm and control arm

\begin{tabular}{|c|c|c|c|c|}
\hline Characteristics & Categories & $\begin{array}{l}\text { Intervention } \\
\operatorname{arm}(n=117)\end{array}$ & $\begin{array}{l}\text { Control arm } \\
(n=147)\end{array}$ & p-value \\
\hline Gender & Female & $55(47)$ & $67(46)$ & 0.817 \\
\hline Age & Mean (SD) age (years) & $64(10)$ & 65 (9) & 0.538 \\
\hline Diagnosis of diabetes & Mean (SD) duration (years) & $9(8)$ & $8(6)$ & 0.266 \\
\hline Ethnicity & Non-western & $2(1.7)$ & $0(0)$ & 0.112 \\
\hline Education* & Low & $80(72)$ & $103(74)$ & 0.538 \\
\hline $\begin{array}{l}\text { Work status of patients } \\
<65 \text { years } * *\end{array}$ & Paid job & 28 of $55(51)$ & 21 of $66(32)$ & 0.024 \\
\hline \multirow[t]{4}{*}{ Marital status } & Married & $76(66)$ & $92(64)$ & 0.575 \\
\hline & Single & $5(4)$ & $12(8)$ & \\
\hline & Divorced & $16(14)$ & $21(14)$ & \\
\hline & Widowed & $19(16)$ & $19(13)$ & \\
\hline \multirow[t]{4}{*}{ Treatment** } & Diet only & $8(7)$ & $12(8)$ & 0.017 \\
\hline & Tablets & $69(61)$ & $108(76)$ & \\
\hline & Insulin & $10(9)$ & $4(3)$ & \\
\hline & Insulin and tablets & $27(24)$ & $19(13)$ & \\
\hline \multirow[t]{3}{*}{ Psychological care } & No psychological care & $96(83)$ & $123(86)$ & 0.703 \\
\hline & In primary care setting & $17(15)$ & $16(11)$ & \\
\hline & In secondary care setting & $3(3)$ & $4(3)$ & \\
\hline Health outcomes & Scale (range) & Mean (SD) & Mean (SD) & $\begin{array}{c}\mathrm{p} \text {-value } \\
\text { t-test }\end{array}$ \\
\hline Daily functioning & DFT (0-10) at screening & $6.8(1.3)$ & $6.6(1.3)$ & 0.205 \\
\hline Blood glucose & $\mathrm{HbA} 1 \mathrm{c}$ in $\mathrm{mmol} / \mathrm{mol}$ & $53.0(11.2)$ & $51.8(10.2)$ & 0.429 \\
\hline Diabetes-related distress & PAID (0-100) & 29.9 (16.9) & $28.9(19.4)$ & 0.684 \\
\hline \multirow{5}{*}{$\begin{array}{l}\text { Participation } \\
\text { autonomy }\end{array}$} & IPA autonomy indoors (0-28) & $6.9(4.8)$ & $6.7(4.5)$ & 0.734 \\
\hline & IPA family role (0-28) & $12.7(5.5)$ & $12.8(5.7)$ & 0.921 \\
\hline & $\begin{array}{l}\text { IPA autonomy outdoors (0- } \\
\text { 20) }\end{array}$ & $8.6(4.2)$ & $8.4(4.2)$ & 0.681 \\
\hline & $\begin{array}{l}\text { IPA social relationships (0- } \\
\text { 28) }\end{array}$ & $9.6(4.6)$ & $9.4(4.3)$ & 0.631 \\
\hline & $\begin{array}{l}\text { IPA work and education (0- } \\
24)\end{array}$ & $11.1(3.5)$ & $9.4(3.2)$ & 0.116 \\
\hline Self-management & PIH (0-96) & 78.0 (8.9) & $73.2(14.5)$ & $0.002 * *$ \\
\hline \multirow[t]{2}{*}{ Quality of life } & SF-12 Physical component & $34.8(9.6)$ & $35.0(9.8)$ & 0.849 \\
\hline & SF-12 Mental component & $34.1(11.3)$ & $35.2(11.2)$ & 0.456 \\
\hline Self-efficacy & GSES (12-60) & $38.6(7.5)$ & $39.2(7.0)$ & 0.481 \\
\hline
\end{tabular}

Values are numbers (percentages) unless stated otherwise. * Low refers to primary school, lower vocational training or lower general education. ${ }^{* *}$ Significant differences: $\mathrm{p}<0.05$. HbA1c, glycated haemoglobin. DFT = Daily Functioning Thermometer; PAID = Problem Areas in Diabetes; IPA, Impact on Participation and Autonomy. Lower mean scores reflect better outcomes. PIH, Partners in Health Scale; SF-12, Short Form Health Questionnaire Physical and Mental component, mean score Dutch population is 50; GSES = General Self-efficacy scale. Higher scores refer to better outcomes. 
The sample comprised $46 \%$ female patients with the majority having a lower level of education. The average age of the participants was 65 . Of all 121 participants younger than 65 years, $41 \%$ had paid employment. The proportion of patients with a paid job was significantly higher in the intervention arm than in the control arm. On average, patients had been diagnosed with diabetes for 8-9 years. The majority were being treated with oral hypoglycaemic medication. The number of patients being treated with insulin was significantly higher in the intervention group (33\%) compared to patients in the control group (16\%). At the time of baseline measurement, $84 \%$ were not receiving psychosocial care from a health professional.

Patients of both groups were comparable for the primary and secondary outcomes at the baseline measurement except for the sum score on the PIH scale. This reflected better self-management skills of intervention patients regarding knowledge, symptom management and adherence to treatment. Both groups were comparable regarding the subdomain 'coping' that included three items about dealing with the effects of diabetes on daily life.

\section{Study participants' exposure to SMS}

An unexpected outcome was the very low exposure to SMS of the study participants in the intervention arm. It is presented in table 6.2. PNs did not register any data about SMS for 17 participants (15\%) in the patient file during the year of follow-up. For the other 100 participants, between 1 and 5 diabetes consultations were registered with data on the DFT and DS. The combination of DFT $>4$ and DS $>3$ was found in only 16 participants (14\%).

A total of 46 study participants scored neither DFT $>4$ nor DS $>3$ during consultations. The low detection rates also implied low exposure to the follow-up phase of SMS. From 30 participants who scored DS $>3$ and were therefore eligible for further diagnostics, ten patients did not receive the 4DSQ because (1) they were already undergoing psychological treatment, or (2) they were not interested, or (3) a specific stressor was clearly causing the distress. Extra consultations for SMS were provided for 11 participants, of whom there were only two patients with a nurse-led detection score of DFT $>4$ and DS $>3$. From the other 14 participants with positive scores for DFT and DS, six patients were referred to the GP and one patient to a mental nurse because severe mental health problems were recorded using the 4DSQ. Five participants with score DFT $>4$ and DS $>3$ did not want to receive follow-up care, and two participants were already receiving psychological treatment. 
Table 6.2 Exposure to SMS of study participants in the intervention arm ( $n=117)$

\begin{tabular}{|c|c|c|c|c|c|c|}
\hline & $\mathrm{N}$ & Outcome detection & $\begin{array}{c}\text { 4DSQ completed of } \\
\text { those who received } \\
\text { the } 4 \mathrm{DSQ}^{*}\end{array}$ & $\begin{array}{c}\text { 4DSQ } \\
\text { Outcome }\end{array}$ & $\begin{array}{c}\text { Self-management } \\
\text { support }\end{array}$ & Referral \\
\hline & \multirow[t]{2}{*}{46} & $\mathrm{DFT} \leq 4$ and $\mathrm{DS} \leq 3$ & - & - & 2 & - \\
\hline & & & 1 of 2 & 1 mild & - & - \\
\hline & \multirow[t]{3}{*}{24} & Only DFT >4 & - & - & 1 & \\
\hline & & & 3 of 3 & 2 mild & - & - \\
\hline & & & & 1 moderate & 1 & \\
\hline & \multirow[t]{2}{*}{14} & Only DS >3 & 5 of 8 & 2 moderate & 2 & \\
\hline & & & & 3 severe & 3 & \\
\hline & \multirow[t]{2}{*}{16} & DFT $>4$ and DS $>3$ & 12 of 12 & 4 moderate & 2 & 1 \\
\hline & & & & 8 severe & - & 6 \\
\hline & 17 & No registration & - & - & - & - \\
\hline Total & 117 & & 21 of 25 & & 11 & 7 \\
\hline
\end{tabular}

*PNs were instructed to give the 4DSQ to patients with score DS >3.

\section{Primary outcome}

As illustrated in table 6.3, the number of patients who improved in their daily functioning (score DFT $\leq 4$ ) was lower in the intervention group than in the control group at 4-month follow-up, but this was not a statistically significant difference (24\% vs. $32 \%$; OR 0.505 (95\% Cl 0.213 to 1.201$)$ ). At the 12 -month follow-up, more patients in the intervention group improved in their daily functioning compared to patients in the control group. However, this was not statistically significant either (33\% vs. $26 \%$, OR 1.754 (95\% Cl 0.742 to 4.148$)$ ).

Table 6.3 Multilevel analyses for differences between intervention and control arms regarding improvement on patients' daily functioning reflected by the dichotomous primary outcome (DFT $\leq 4)$ at 4-month follow-up and at 12-month follow-up

\begin{tabular}{lccccc}
\hline DFT $\leq 4$ & $\begin{array}{c}\text { Intervention } \\
\text { Yes/n (\%) }\end{array}$ & $\begin{array}{c}\text { Control } \\
\text { Yes/n (\%) }\end{array}$ & OR & $95 \% \mathrm{Cl}$ & p value \\
\hline 4 months & $24 / 102(23.5)$ & $40 / 126(31.7)$ & 0.505 & 0.213 to 1.201 & 0.12 \\
12 months & $32 / 96(33.3)$ & $32 / 121(26.4)$ & 1.754 & 0.742 to 4.148 & 0.20 \\
\hline
\end{tabular}

\section{Secondary outcomes}

For the secondary outcome measures, the intervention group perceived significantly more participation than the control group regarding autonomy indoors and family role $(p<0.05)$ after 4 months. The same applied, with nearly statistically significant differences, for autonomy outdoors $(p=0.06)$ and social relationships $(p=0.05)$. However, these effects disappeared at 12-month follow-up. As illustrated in table 6.4, we found no other statistically significant differences for the secondary outcome measures at 4 and 12 months. 


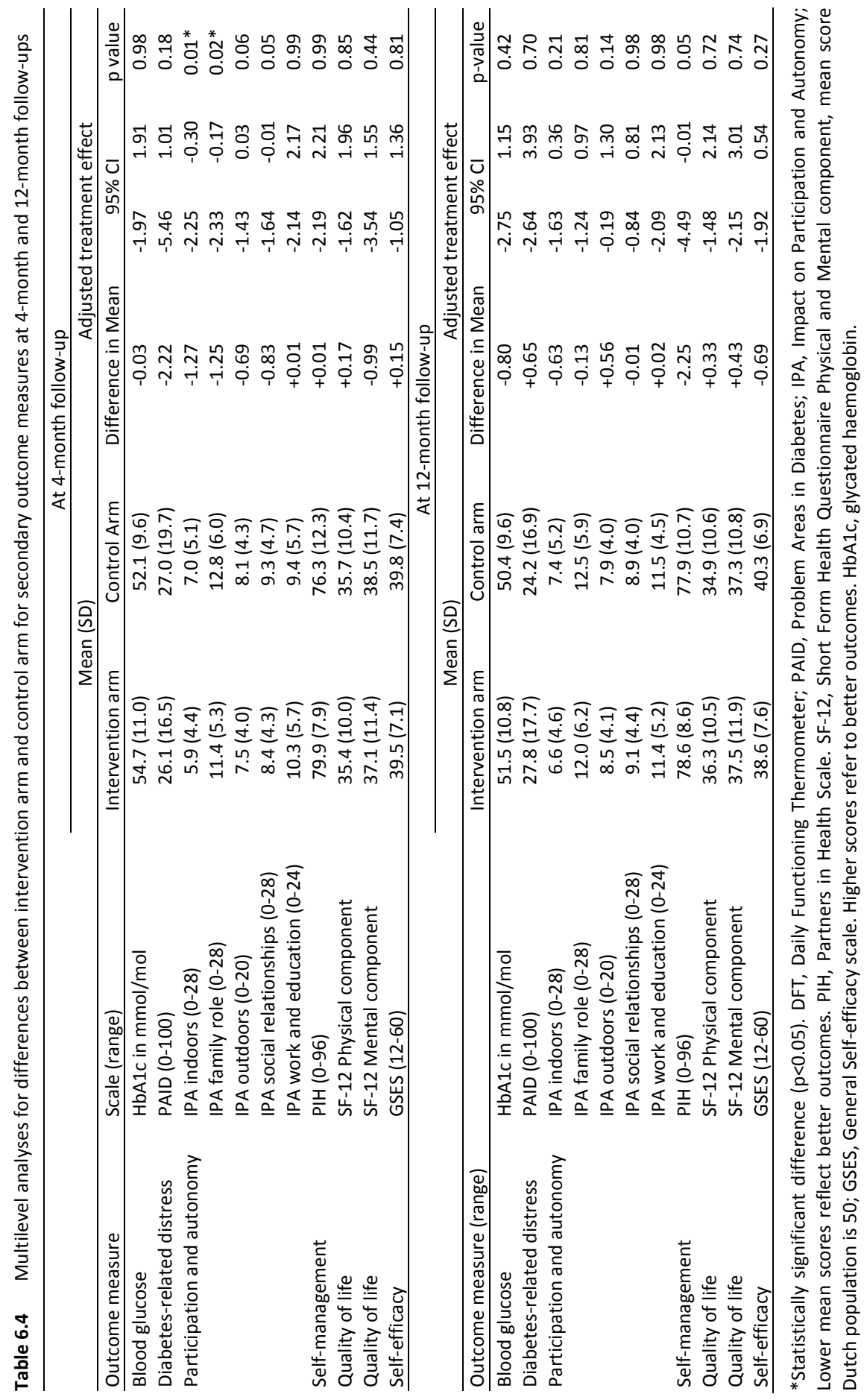




\section{DISCUSSION}

This study, with a low exposure of study participants to the complete intervention, could not demonstrate any effect of SMS on emotional, social or biomedical parameters, except for autonomy and participation with regard to activities indoors and the family role after 4 months. This effect in favour of the patients in the intervention arm had disappeared after 12 months.

The critical issue of the implementation of SMS was the addition of a detection procedure as an inherent and integrated part of SMS. PNs were trained to identify eligible patients for the follow-up phase of SMS by applying screening questions during diabetes consultations. The DFT and DS were considered to be simple, patientcentred indicators of patients' daily functioning and their emotional distress. The 4DSQ would enable the PNs and GPs to get more insight into the presence and severity of the emotional problems. For the effectiveness trial, a self-administered postal screening procedure was inserted into the study design to select patients from both the intervention and control arms similarly. To perform a pragmatic trial, we minimised the interference of the researchers in clinical practice as much as possible. The outcomes of DFT and DS on the research-driven screening were consistent with our assumptions based on the literature that approximately $20 \%$ of the diabetic population would be eligible for the follow-up phase of SMS. However, these efforts to select patients with emotional problems aimed at increasing the contrast between patients in the intervention and control arms appeared to be useless as the added detection method in routine practice did not function as expected. This was not a problem of PNs' adherence to the SMS protocol, as the screening tools were integrated into diabetes consultations of more than $85 \%$ of the study participants. The problem was that the majority of study participants who scored above the cut-off values on the postal questionnaires did not meet the required detection criteria when screened face to face by the PNs. These patients were therefore not exposed to the follow-up phase of SMS. We have no reason to assume that non-respondents on the research-driven screening were those most in distress, who would have been the easiest to be detected by the PNs, as low detection rates were reported for the whole diabetic population in the intervention practices. 
Differences between the self-administered screening outcomes and the nurse-led detection could be explained by the fluctuation in distress symptoms and the phenomenon of regression towards the mean. This may have resulted in study participants scoring less extreme values at nurse-led detection compared to values at research-driven screening. Furthermore, tests may function differently across settings and administration methods. ${ }^{41}$ Owing to patients' difficulty in expressing emotional problems during consultations and lack of recognition by health professionals of emotional problems experienced by patients with chronic physical illness, the chance of positive screening outcomes seems to have been higher in anonymous researchdriven screening than in clinical practice. ${ }^{42,43}$ Nonetheless, we did not expect such a large discrepancy between research-driven screening and nurse-led detection.

For 17 of the 117 study participants, no data on SMS activities were registered suggesting that these patients were exposed neither to the detection phase nor the follow-up phase of SMS. The reasons for this phenomenon could be twofold. First, PNs had to integrate SMS into all consultations while the effects were assessed in only a few patients per PN. PNs did not know which patients participated in the trial. As PNs' integration of SMS into consultations could have fluctuated during follow-up, they may have missed study participants. Second, registration bias may have occurred. PNs needed to open an extra data file to record the process and outcomes of SMS. This step might have created a barrier to their compliance. This underlines the need for a thorough process evaluation of how and under what conditions the intervention procedure was carried out. In this regard, the simultaneous evaluation of the implementation process will reveal important issues. The outcomes of this process evaluation will be presented elsewhere.

In the planning of the study, we considered avoiding research-driven screening by inserting the nurse-led detection phase of SMS into both study arms. However, monitoring and discussing psychological well-being as part of routine care may already have positive effects on patients' moods. ${ }^{44}$ Moreover, from an ethical perspective, patients in the control arm who would be detected positively for mental health problems would need to be referred for further diagnosis or psychosocial treatment, thus changing the usual care. Using research-led screening was therefore assumed to be the most adequate solution for the selection of participants for the effectiveness part of the study. In retrospect, a pilot study should have been part of 
our implementation project. It was not planned for several reasons. There was an implementation moment. Besides, we could use the experiences from the former study, in which the follow-up phase of SMS was evaluated. PNs would receive comprehensive training, and they would ask common questions about psychosocial functioning. Furthermore, the outcomes of the screening did not give rise to questions about the instruments: as expected, $20 \%$ of the respondents met the detection criteria.

Although collaboration with regional stakeholders resulted in organisational and financial benefits for family practices willing to participate, this incentive did not appear to be a decisive factor in the process of considering whether or not to participate. For robust multilevel modelling, it is necessary that sufficient clusters are recruited and sufficient patients are available per cluster. ${ }^{45}$ Our intention was to include 46 PNs but only 40 PNs participated. Furthermore, the final total number of clusters for analysis was actually only 33 as some patients were seen alternately by PNs working in a team. Owing to the regional approach of the SMS project, we were confined to the family practices within the region under study. The number of patients within clusters ranged from 1 to 19. The loss to follow-up of patients was less than expected which led to an acceptable total number of study participants. However, the availability of clusters as well as the balance between clusters needs attention in designing a cluster-randomised trial that will be performed in an implementation setting.

In implementation studies, formative evaluation methods can be used to adapt or optimise the implementation or intervention itself during the study. ${ }^{20}$ Owing to the trial protocol and time and research funding limitations, we did not further optimise the intervention or implementation strategies other than to inform PNs after 3-month follow-up to use the criteria DFT $>4$ and DS $>3$ less rigidly. The planning of a more flexible design of the effectiveness trial within the hybrid design would have been helpful in overcoming implementation problems. This calls for inclusion of specific evaluation moments to decide about the need for adjustments in the intervention itself, in implementation activities or with regard to follow-up measurements. 
In conclusion, the adjusted nurse-led intervention in its present form was not effective. There was a dilution of the contrast between intervention and control patients. This is because outcomes of the detection method, added for implementation purposes, were neither optimal nor congruent with outcomes of the screening method added for research purposes. We do not know whether SMS would be effective if PNs used other methods to identify patients in need for support in their emotional and role management tasks. Blending effectiveness and implementation studies may have the potential to facilitate a rapid adoption of evidence-based care innovations in routine practice and to provide useful information for decision-makers about effects and implementation issues, ${ }^{20}$ but researchers who are planning a hybrid effectiveness-implementation study need to be aware of the necessity to build in adequate follow-up moments and to take action either to remove identified barriers or to adapt the intervention to an acceptable level. 


\section{REFERENCES}

1. Fisher EB, Thorpe CT, DeVellis BM, et al. Healthy coping, negative emotions, and diabetes management. Diabetes Educ 2007; 33(6):1080-1103.

2. Holman H, Lorig K. Patient self-management: a key to effectiveness and efficiency in care of chronic disease. Public Health Rep 2004; 119(3):239-43.

3. Penninx BWJH, Kritchevsky SB, Yaffe K, et al. Inflammatory markers and depressed mood in older persons: results from the health, aging and body composition study. Biol Psychiatry 2003; 54(5):566572.

4. Fisher L, Mullan JT, Arean P, et al. Diabetes distress but not clinical depression or depressive symptoms is associated with glycemic control in both cross-sectional and longitudinal analyses. Diabetes Care 2010; 33(1):23-28.

5. DiMatteo MR, Lepper HS Croghan TW. Depression is a risk factor for noncompliance with medical treatment: meta-analysis of the effects of anxiety and depression on patient adherence. Arch Int Med 2000; 160(14):2101-2107.

6. Aikens JE. Prospective associations between emotional distress and poor outcomes in type 2 diabetes. Diabetes Care 2012; 35(12):2472-2478.

7. Macdonald W, Rogers A, Blakeman T, et al. Practice nurses and the facilitation of self-management in primary care. J Adv Nurs 2008; 62(2):191-199.

8. Van Houtum L, Rijken M, Heijmans M, et al. Self-management support needs of patients with chronic illness: Do needs for support differ according to the course of illness? Patient Educ Couns 2013; 93(3):626-632.

9. Rane K, Wajngot $A$, Wändell PE, et al. Psychosocial problems in patients with newly diagnosed diabetes: Number and characteristics. Diabetes Res Clin Pract 2011; 93(3):371-378.

10. Elissen A, Nolte E, Knai C, et al. Is Europe putting theory into practice? A qualitative study of the level of self-management support in chronic care management approaches. BMC Health Serv Res 2013; 13(1):117.

11. Netherlands Diabetes Federation, NDF Care Standard. Transparancy and quality of diabetes care for people with type 2 diabetes.Amersfoort: Nederlandse Diabetes Federatie (NDF), 2007.

12. Rutten GEHM, De Grauw WJC, Nijpels G, et al. NHG-Standaard Diabetes mellitus type 2 (Tweede herziening). Huisarts Wet 2006; 49(3):137-152.

13. Tsiachristas A, Hipple-Walters B, Lemmens KMM, et al. Towards integrated care for chronic conditions: Dutch policy developments to overcome the (financial) barriers. Health Policy 2010; 101(2):122-132.

14. Jansen D, Spreeuwenberg P Heijmans M, Ontwikkelingen in de zorg voor chronisch zieken: rapportage 2012 [Developments in chronic care: report 2012].Utrecht: Netherlands Institute for Health Services Research (NIVEL), 2012.

15. Heiligers PJM, Noordman J, Korevaar JC, et al., Kennisvraag: praktijkondersteuners in de huisartspraktijk (POH's) klaar voor de toekomst? [Knowledge base: Practice nurses in the GP practices, ready for the future?].Utrecht: Netherlands Institute for Health Services Research (NIVEL), 2012.

16. Van Dijk-de Vries A, Van Bokhoven M, Terluin B, et al. Integrating nurse-led Self-Management Support (SMS) in routine primary care: design of a hybrid effectiveness-implementation study among type 2 diabetes patients with problems of daily functioning and emotional distress: a study protocol. BMC Fam Pract 2013; 14:77.

17. Lamers F, Jonkers CCM, Bosma $\mathrm{H}$, et al. A minimal psychological intervention in chronically ill elderly patients with depression: a randomised trial. Psychother Psychosom 2010; 79(4):217-226.

18. Jonkers CCM, Lamers $\mathrm{F}$, Bosma $\mathrm{H}$, et al. The effectiveness of a minimal psychological intervention on self-management beliefs and behaviors in depressed chronically ill elderly persons: a randomized trial. Int Psychogeriatr 2012; 24(02):288-297.

19. Lamers $\mathrm{F}$, Jonkers CCM, Bosma $\mathrm{H}$, et al. Treating depression in diabetes patients: does a minimal psychological intervention affect diabetes-specific quality of life and glycemic control? A randomized controlled trial. J Adv Nur 2011; 67(4):788-799. 
20. Curran GM, Bauer M, Mittman B, et al. Effectiveness-implementation hybrid designs: combining elements of clinical effectiveness and implementation research to enhance public health impact. Med Care 2012; 50(3):217-26.

21. Tuinman MA, Gazendam-Donofrio SM Hoekstra-Weebers JE. Screening and referral for psychosocial distress in oncologic practice. Cancer 2008; 113(4):870-878.

22. Maas-van Schaaijk NM, Odink RJ, Ultee K, et al. Can one question be a useful indicator of psychosocial problems in adolescents with diabetes mellitus? Acta Paediatrica 2011; 100(5):708-711.

23. Braam C, van Oostrom SH, Terluin B, et al. Validation study of a Distress Screener. J Occup Rehabil 2009; 19(3):231-237.

24. Struijs JNBaan CA. Integrating care through bundled payments - Lessons from the Netherlands. $N$ Engl J Med 2011; 364(11):990-991.

25. Terluin B, van Marwijk HWJ, Ader HJ, et al. The Four-Dimensional Symptom Questionnaire (4DSQ): a validation study of a multidimensional self-report questionnaire to assess distress, depression, anxiety and somatization. BMC Psychiatry 2006; 6:34.

26. Van Eijk JTM, Diederiks JPM, Kempen GIJM, et al. Development and feasibility of a nurse administered strategy on depression in community-dwelling patients with a chronic physical disease. Patient Educ Couns 2004; 54(1):87-94.

27. Mynors-Wallis L. Problem solving treatment in general psychiatric practice. Advan Psychiatr Treat 2001; 7:417-425.

28. Lamers $\mathrm{F}$, Jonkers CCM, Bosma $\mathrm{H}$, et al. Effectiveness and cost-effectiveness of a minimal psychological intervention to reduce non-severe depression in chronically ill elderly patients: the design of a randomised controlled trial. BMC Public Health 2006; 6(1):161.

29. Polonsky WH, Anderson BJ, Lohrer PA, et al. Assessment of diabetes-related distress. Diabetes Care 1995; 18:754-760.

30. Snoek FJ, Pouwer F, Welch GW, et al. Diabetes-related emotional distress in Dutch and U.S. diabetic patients: cross-cultural validity of the problem areas in diabetes scale. Diabetes Care 2000; 23(9):1305-1309.

31. Welch G, Weinger K, Anderson B, et al. Responsiveness of the Problem Areas In Diabetes (PAID) questionnaire. Diabet Med 2003; 20(1):69-72.

32. Cardol M, De Haan RJ, De Jong BA, et al. Psychometric properties of the Impact on Participation and Autonomy Questionnaire. Arch Phys Med Rehabil 2001; 82(2):210-216.

33. Cardol M. Vragenlijst 'Impact op Participatie en Autonomie' (IPA) Handleiding. [Questionnaire 'Impact on Participation and Autonomy' (IPA) Manual]. 2005 [cited 201518 June]; Available from: http://www.nivel.nl/sites/default/files/bestanden/INT-handleiding_vragenlijstIPA.pdf.

34. Petkov J, Harvey $P$ Battersby $M$. The internal consistency and construct validity of the partners in health scale: validation of a patient rated chronic condition self-management measure. Qual Life Res 2010; 19(7):1079-1085.

35. Ware JE, Kosinski M Keller S. A 12-item short-form health survey: construction of scales and preliminary tests of reliability and validity. Med Care 1996; 34(3):220-233.

36. Fleishman JA, Selim AJ Kazis LE. Deriving SF-12v2 physical and mental health summary scores: a comparison of different scoring algorithms. Qual Life Res 2010; 19(2):231-241.

37. Mols F, Pelle AJ Kupper N. Normative data of the SF-12 health survey with validation using postmyocardial infarction patients in the Dutch population. Qual Life Res 2009; 18(4):403-414.

38. Bosscher RJSmit JH. Confirmatory factor analysis of the General Self-Efficacy Scale. Behav Res Ther 1998; 36(3):339-343.

39. Sherer M, Maddux JE, Mercadante $B$, et al. The self-efficacy scale: construction and validation. Psychol Rep 1982; 51(2):663-671.

40. Rutten GEHM, De Grauw WJC, Nijpels G, et al. NHG-Standaard Diabetes mellitus type 2 (Tweede herziening) [NHG Practice Guideline Diabetes mellitus type 2 (Second revision)]. Huisarts Wet 2006; 49(3):137-152.

41. De Waal MWM, Van der Weele GM, Van der Mast RC, et al. The influence of the administration method on scores of the 15-item Geriatric Depression Scale in old age. Psychiatry Res 2012; 197(3):280-284. 
42. Cape JMcCulloch Y. Patients' reasons for not presenting emotional problems in general practice consultations. Br J Gen Pract 1999; 49(448):875-9.

43. Mitchell AJ, Rao S Vaze A. Can general practitioners identify people with distress and mild depression? A meta-analysis of clinical accuracy. J Affect Disord 2011; 130(1-2):26-36.

44. Pouwer F, Snoek FJ, van der Ploeg HM, et al. Monitoring of psychological well-being in outpatients with diabetes. Diabetes Care 2001; 24(11):1929-1935.

45. Campbell MK, Mollison J, Steen N, et al. Analysis of cluster randomized trials in primary care: a practical approach. Fam Pract 2000; 17(2):192-196. 


\section{CHAPTER 7}

Identification of patients with emotional distress by practice nurses in routine diabetes care

Anneke van Dijk - de Vries

Marloes A. van Bokhoven

Berend Terluin

Trudy van der Weijden

Jacques Th. M. van Eijk

Submitted for publication 


\section{ABSTRACT}

\section{Objective}

To evaluate the identification and outcomes of detection of emotional distress by practice nurses in routine diabetes consultations.

\section{Study Design and Setting \\ Longitudinal cohort study in a Dutch primary care setting.}

\section{Methods}

Practice nurses $(n=19)$ were trained to identify patients with emotional distress by a verbal detection procedure. The study sample included type 2 diabetes patients $(n=117)$, selected by a research-driven written screening questionnaire for emotional distress. Detection outcomes of the practice nurses were derived from the medical records. Patients' mental health status was measured after four months by means of the Four-Dimensional Symptom Questionnaire (4DSQ). 4DSQ-scores were compared across detected and non-detected patients.

\section{Results}

Screening results were actually registered for 85 patients, of whom $48 \%$ were screened positive and $52 \%$ negative. Evidence of emotional distress was still present after 4 months follow-up in $90 \%$ of detected patients, and $83 \%$ of non-detected patients.

\section{Conclusion}

Practice nurses missed a substantial proportion of diabetes patients with persistent emotional distress. The verbal detection procedure did not meet its purpose to identify emotionally distressed patients in routine diabetes care. Further evaluation need also to focus on the contextual conditions in which the detection method is applied. 


\section{INTRODUCTION}

Because of the negative consequences of emotional distress associated with the glycaemic control of patients with type 2 diabetes, ${ }^{1-3}$ the need for a biopsychosocial care approach is recognised. ${ }^{4,5}$ Early identification of emotional distress is recommended rather than waiting for a deterioration in patients' health status. ${ }^{6}$ Several pencil and paper case-finding tools are developed for clinical practice. ${ }^{7}$ However, health professionals do not always see them as fitting in their routine care because of a tension between template-driven approaches and a holistic, patientcentred approach. ${ }^{8}$

For the implementation of Self-Management Support (SMS) in diabetes care, practice nurses (PNs) were trained to explore whether patients experienced emotional distress and a burden of diabetes in their daily functioning. This was followed by verbal screening questions to identify eligible patients for a nurse-led minimal psychological intervention. SMS was evaluated in a cluster-randomised trial, for which patients were selected by means of a self-administered screening questionnaire that they completed several weeks before the scheduled consultation. ${ }^{9}$ Although the research-driven screening questionnaire and the nurse-led detection procedure included the same questions, the agreement was only $14 \%$ among 117 patients. ${ }^{10}$ This could have been determined by patients' barriers to discuss emotional problems, ${ }^{11-14}$ limited skills of the $\mathrm{PNs},{ }^{15,16}$ and fluctuation in distress symptoms. ${ }^{10}$

In literature, both under-recognition of emotional distress by health professionals and overestimation by self-assessment questionnaires are mentioned. ${ }^{16-18}$ Assuming that patients with long-standing symptoms of emotional distress are the most relevant group for a psychological intervention, we will address the following research questions:

1. To what extent do PNs verbally detect emotional distress in a sample of emotionally distressed patients who have been preselected by means of a selfadministered questionnaire?

2. At four months after a routine diabetes consultation, what is the mental health status of patients whose emotional distress was not detected compared to patients who were detected by the PN as being emotionally distressed? 


\section{METHODS}

\section{Design}

A follow-up cohort study, evaluating patients' mental health status four months after being exposed to a verbal, nurse-led detection procedure in diabetes consultations.

\section{Setting and participants}

In a Dutch regional care group, PNs $(n=19)$ received three days of training to integrate the verbal nurse-led detection procedure and the provision of a minimal psychological intervention into quarterly consultations for patients with diabetes. ${ }^{19-21}$ The effectiveness of SMS was evaluated in a cluster-randomised controlled trial. ${ }^{10}$ In the intervention arm, 1752 patients received a screening questionnaire 4-6 weeks before their scheduled consultation. From the 884 respondents (50\%), 166 patients were invited for trial participation as their screening outcomes indicated emotional distress and a burden of diabetes in daily functioning. Participants completed self-reported measurements after four months.

\section{Measurements}

The instruments and measurements are presented in resp. table 7.1 and table 7.2. The Daily Functioning Thermometer (DFT) and the Distress Screener (DS) were included in the research-driven questionnaire and nurse-led detection procedure. The Four-Dimensional Symptom Questionnaire (4DSQ) was included in the follow-up measurement after four months.

The DFT is a Visual Analogue Scale to measure patients' perceived burden of diabetes in daily functioning. A score DFT $>4$ was used to indicate patients who could benefit from the nurse-led psychological intervention.

The DS is a validated quick-scan instrument for emotional distress with DS >3 indicating potential underlying mental health problems. ${ }^{22}$

The 4DSQ is aimed to distinguish distress from depression, anxiety and somatisation, and to measure whether these symptoms have a low, moderate or high probability for underlying mental disorders. This validated self-administered questionnaire is a commonly used instrument in family medicine. ${ }^{23,24}$ The item scores were summated to obtain scale scores. Missing items were imputed using patients' individual mean scores if at least $80 \%$ of a scale was available. 
PNs recorded the outcomes of the nurse-led detection in electronic patient data files. We used the data recorded with a maximum of 6 weeks after the written screening.

Table 7.1 Overview of the instruments

\begin{tabular}{|c|c|c|c|c|c|c|}
\hline Measurement & Instrument & \multicolumn{3}{|l|}{ Features } & \multicolumn{2}{|c|}{ Cut-off points } \\
\hline $\begin{array}{l}\text { Diabetes-related } \\
\text { reduced daily } \\
\text { functioning }\end{array}$ & $\begin{array}{l}\text { Daily Functioning } \\
\text { Thermometer } \\
\text { (DFT) }\end{array}$ & \multicolumn{3}{|l|}{$\begin{array}{l}\text { Visual Analogue Scale } \\
\text { with a continuous } \\
\text { vertical } 10 \mathrm{~cm} \text { line } \\
\text { between } 0 \text { ('no burden at } \\
\text { all') and } 10 \text { ('extreme } \\
\text { burden') }\end{array}$} & \multicolumn{2}{|c|}{ DFT $>4$} \\
\hline $\begin{array}{l}\text { Emotional } \\
\text { distress }\end{array}$ & $\begin{array}{l}\text { Distress Screener } \\
\text { (DS) }\end{array}$ & $\begin{array}{l}\text { Answer categories: 'no' } \\
(0), \text { 'sometimes' (1) and } \\
\text { 'regularly or more often' } \\
\text { (2) }\end{array}$ & & 3 & \multicolumn{2}{|c|}{ DS $>3$} \\
\hline $\begin{array}{l}\text { Mental } \\
\text { health } \\
\text { status }\end{array}$ & $\begin{array}{l}\text { Four-Dimensional } \\
\text { Symptom } \\
\text { Questionnaire } \\
\text { (4DSQ) }\end{array}$ & $\begin{array}{l}\text { Answer categories: 'no' } \\
\text { (0), 'sometimes' (1) and } \\
\text { 'regularly or more often' } \\
\text { (2) }\end{array}$ & $\begin{array}{l}\text { Distress } \\
\text { Depression } \\
\text { Anxiety } \\
\text { Somatisation }\end{array}$ & $\begin{array}{r}16 \\
6 \\
12 \\
16 \\
\end{array}$ & $\begin{array}{l}\text { Moderate } \\
\quad>10 \\
>2 \\
>3 \\
>10\end{array}$ & $\begin{array}{l}\text { Severe } \\
>20 \\
>5 \\
>9 \\
>20\end{array}$ \\
\hline
\end{tabular}

Table 7.2 Overview of the measurements

\begin{tabular}{llll}
\hline & Moment & Administration method & Outcomes \\
\hline Screening questionnaire & $\begin{array}{l}\text { Max. 6 weeks before a } \\
\text { diabetes consultation }\end{array}$ & $\begin{array}{l}\text { Written, self-administered } \\
\text { Const }>4 \text { and DS }>3\end{array}$ \\
& $\begin{array}{l}\text { Routine diabetes } \\
\text { consultation (TO) }\end{array}$ & $\begin{array}{l}\text { Verbal nurse-led } \\
\text { detection procedure }\end{array}$ & DFT $>4$ and/or DS $>3$ \\
Research follow-up & $\begin{array}{l}\text { Approximately four } \\
\text { months after diabetes }\end{array}$ & $\begin{array}{l}\text { Written, self-administered } \\
\text { patient questionnaire }\end{array}$ & Moderate and severe \\
& consultation & & \\
& & & \\
\end{tabular}

\section{Data analysis}

Descriptive variables (frequencies, means and percentages) were calculated using IBM SPSS Statistics for Windows, version 21.

\section{RESULTS}

Informed consent was given by 117 of 166 patients. Demographic characteristics are presented in table 7.3. Figure 7.1 presents the outcomes of the nurse-led detection procedure and 4DSQ. Nurse-led detection outcomes refer to 85 patients. The other 32 
patients did not appear at the scheduled consultation, or the PN did not apply the detection or did not record the outcomes. The scores DS $>3$ and DFT $>4$ were registered for 14 of the 85 patients (17\%) whereas 44 patients (52\%) were not detected by the PN.

At the 4-month measurement, 16 patients (14\%) were lost to follow-up. Of the remaining sample, the $4 \mathrm{DSQ}$ outcomes indicated mental health problems among 83 patients ( $82 \%$ ) of whom only 28 patients (34\%) were identified by the PN. Although the absolute sum scores on the 4DSQ were the lowest for the non-detected patients, $81 \%$ of them still had symptoms of distress, depression, anxiety or somatisation at four months. The percentage of patients with severe mental health problems was the highest in the group of detected patients (57\%) compared to the non-detected (45\%) and non-exposed patients (42\%).

Table 7.3 Characteristics of study sample $(n=117)$. Values are numbers (percentages) unless stated otherwise

\begin{tabular}{llc}
\hline Characteristics & Categories & \\
\hline Gender & Female & $55(47)$ \\
Age & Mean (SD) age (years) & $64(10)$ \\
Diagnosis of diabetes & Mean (SD) duration (years) & $9(8)$ \\
Ethnicity & Non-western & $2(1.7)$ \\
Education* & Low & $80(72)$ \\
Work status of patients $<65$ years & Paid job & 28 of $55(51)$ \\
Marital status & Married & $76(66)$ \\
& Single & $5(4)$ \\
& Divorced & $16(14)$ \\
Treatment & Widowed & $19(16)$ \\
& Diet only & $8(7)$ \\
& Tablets & $69(61)$ \\
Psychological care & Insulin & $10(9)$ \\
& Insulin and tablets & $27(24)$ \\
& No psychological care & $96(83)$ \\
\hline
\end{tabular}

*Low refers to primary school, lower vocational training or lower general education 
Figure 7.1 Flow chart of the study sample with their outcomes on the nurse-led detection and scores on the 4DSQ at four months

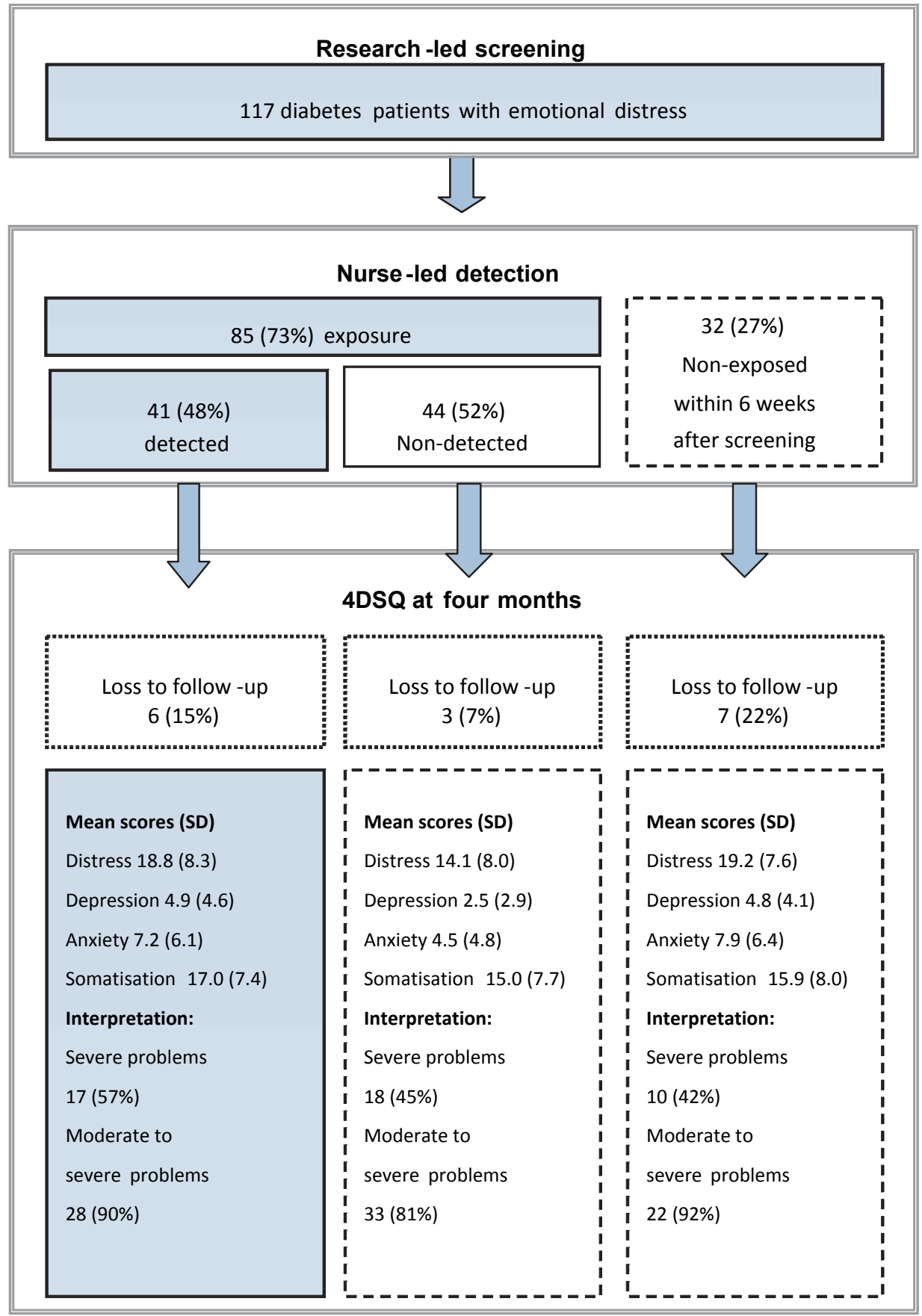




\section{DISCUSSION}

This study demonstrated that PNs detected about one-third of a sample of patients who were emotionally distressed according to a self-administered questionnaire and in whom mental health problems were also present after several months. This suggests an underestimation of patients' emotional distress by using a verbal detection method in diabetes consultations when compared to self-administered written questionnaires.

At first sight, the findings lean towards the use of pencil and paper tools in somatic care consultations to select patients for a psychological intervention, ${ }^{16}$ possibly added by a question about patients' need for help to improve the specificity of the screening procedure. ${ }^{14,25,26}$ However, instead of a quick conclusion of the inadequacy of our verbal procedure, we would argue to take the current setting of a somatic care consultation into account. These routine consultations, in which the PNs paid attention to emotional distress, are predominantly orientated on the biomedical aspects of diabetes. PNs work according protocols with a focus on patients' medical management and healthy lifestyle issues. ${ }^{27-29}$ Patients are used to these medical reviews and therefore may not expect explicit attention to their emotional wellbeing. ${ }^{30}$ Besides, PNs need to get confidence in the new role of discussing emotional problems. $^{31}$ To get more insight into the success of a verbal detection procedure in the routine care setting, further research need also to focus on the determinants and contextual conditions for successful implementation.

\section{Strengths and weaknesses}

In this study, data from a verbal, nurse-led detection method that was applied in a real-world setting could be compared with self-reported screening outcomes and patients' emotional health on a longitudinal basis. The outcomes of screening and 4-months follow-up suggest persistent problems of emotional distress in our study sample. However, we need to take into account that the self-administered screening outcomes referred to patients' emotional distress some weeks before they visited the $\mathrm{PN}$, which could have been different from the actual symptoms at time of the consultation. 
The study findings are based on data which were not collected for a comprehensive evaluation of the nurse-led detection procedure. They refer to a relatively small sample of patients who had positive outcomes on a screening questionnaire in a research setting. As the nurse-led detection was aimed at an explorative discussion about patients' emotional health, followed by a psychological intervention if problems had been identified, ${ }^{32}$ the interpretation of PNs and the registration could have been influenced by their impression of patients' attitude and openness for help. These interaction effects were not applicable in the anonymous research-driven questionnaire. We do not know whether the patients of whom data about the nurseled detection were missing ( $27 \%$ of the sample) did not visit the PN or the PNs did not apply or register the nurse-led detection.

Further research is needed to get a deeper understanding of the barriers to integrate a holistic detection procedure in routine care. These barriers might refer to the skills of the PNs, patients' expectations about the role of the PN in a diabetes consultations, and barriers related to the biomedical-oriented health care setting. A possible alternative to our holistic procedure is the combination of using a validated selfadministered questionnaire that has been completed by patients at home, with a subsequent discussion by the PN in the consultation room.

\section{CONCLUSION}

An open exploration followed by screening questions applied by trained PNs did not meet its purpose to identify emotionally distressed patients during routine diabetes consultations. More research is needed to evaluate whether this could be assigned to the verbal procedure, the nurses' skills or contextual conditions. 


\section{REFERENCES}

1. Egede LE, Ellis C. Diabetes and depression: Global perspectives. Diabetes Res Clin Pract 2010; 87: 302-12.

2. Fisher L, Mullan JT, Arean P, et al. Diabetes distress but not clinical depression or depressive symptoms is associated with glycemic control in both cross-sectional and longitudinal analyses. Diabetes Care 2010;33:23-8.

3. Schram M, Baan C Pouwer F. Depression and Quality of Life in Patients with Diabetes: A Systematic Review from the European Depression in Diabetes (EDID) Research Consortium. Curr Diabetes Rev 2009;5:112-9.

4. IDF Clinical Guidelines Task Force, Global guideline for Type 2 diabetes.Brussels: International Diabetes Federation, 2012.

5. American Diabetes Association. Standards of Medical Care in Diabetes 2013. Diabetes Care 2013; 36(Supplement 1):S11-S66.

6. Association AD. 4. Foundations of Care: Education, Nutrition, Physical Activity, Smoking Cessation, Psychosocial Care, and Immunization. Diabetes Care 2015;38(Supplement 1):S20-S30.

7. Williams Jr JW, Pignone M, Ramirez G, et al. Identifying depression in primary care: a literature synthesis of case-finding instruments. Gen Hosp Psychiatry 2002;24:225-37.

8. Pettersson A, Björkelund C, Petersson E-L. To score or not to score: a qualitative study on GPs views on the use of instruments for depression. Family Practice 2014;31:215-21.

9. Van Dijk-de Vries A, Van Bokhoven M, Winkens B, et al. Lessons learnt from a cluster-randomised trial evaluating the effectiveness of Self-Management Support (SMS) delivered by practice nurses in routine diabetes care. BMJ Open 2015.

10. Van Dijk-de Vries A, van Bokhoven MA, Winkens B, et al. Lessons learnt from a cluster-randomised trial evaluating the effectiveness of Self-Management Support (SMS) delivered by practice nurses in routine diabetes care. BMJ Open 2015;5(6).

11. Alderson S, Foy R, Glidewell L, et al. Patients understanding of depression associated with chronic physical illness: a qualitative study. BMC Fam Pract 2014;15:37.

12. Cape J, McCulloch Y. Patients' reasons for not presenting emotional problems in general practice consultations. Br J Gen Pract 1999;49:875-9.

13. Alderson SL, Foy R, Glidewell L, et al. How patients understand depression associated with chronic physical disease - a systematic review. BMC Fam Pract 2012;13:41.

14. Söllner W, Maislinger S, König A, et al. Providing psychosocial support for breast cancer patients based on screening for distress within a consultation-liaison service. Psycho-Oncology 2004; 13:893-7.

15. Thompson C, Kinmonth AL, Stevens L, et al. Effects of a clinical-practice guideline and practice-based education on detection and outcome of depression in primary care: Hampshire Depression Project randomised controlled trial. The Lancet 2000;355:185-91.

16. Pouwer F, Beekman ATF, Lubach C, et al. Nurses' recognition and registration of depression, anxiety and diabetes-specific emotional problems in outpatients with diabetes mellitus. Patient Educ Couns 2006;60:235-40.

17. Hermanns N, Caputo S, Dzida G, et al. Screening, evaluation and management of depression in people with diabetes in primary care. Prim Care Diabetes 2013;7:1-10.

18. Van Weel-Baumgarten E, Lucassen $\mathrm{P}$, Hassink-Franke L, et al. A different way of looking at depression. Int J Clin Pract 2010;64:1493-5.

19. Lamers $\mathrm{F}$, Jonkers CCM, Bosma $\mathrm{H}$, et al. Treating depression in diabetes patients: does a minimal psychological intervention affect diabetes-specific quality of life and glycemic control? A randomized controlled trial. J Adv Nur 2011;67:788-99.

20. Lamers $\mathrm{F}$, Jonkers CCM, Bosma $\mathrm{H}$, et al. A minimal psychological intervention in chronically ill elderly patients with depression: a randomised trial. Psychother Psychosom 2010;79:217-26.

21. Jonkers CCM, Lamers F, Evers SMAA, et al. Economic evaluation of a minimal psychological intervention in chronically ill elderly patients with minor or mild to moderate depression: a randomised trial (the DELTA study). Int J Technol Assess Health Care 2009;25:497-504. 
22. Braam C, van Oostrom SH, Terluin B, et al. Validation study of a Distress Screener. J Occup Rehabil 2009;19:231-7.

23. Terluin B, van Marwijk HWJ, Ader HJ, et al. The Four-Dimensional Symptom Questionnaire (4DSQ): a validation study of a multidimensional self-report questionnaire to assess distress, depression, anxiety and somatization. BMC Psychiatry 2006;6:34.

24. Terluin B, Oosterbaan DB, Brouwers EP, et al. To what extent does the anxiety scale of the FourDimensional Symptom Questionnaire (4DSQ) detect specific types of anxiety disorder in primary care? A psychometric study. BMC Psychiatry 2014;14:121.

25. Arroll B, Smith FG, Kerse N, et al. Effect of the addition of a "help" question to two screening questions on specificity for diagnosis of depression in general practice: diagnostic validity study. BMJ 2005;331:884.

26. Fleer J, Tovote KA, Keers JC, et al. Screening for depression and diabetes-related distress in a diabetes outpatient clinic. Diabet Med 2013;30:88-94.

27. Heiligers PJM, Noordman J, Korevaar JC, et al., Kennisvraag: praktijkondersteuners in de huisartspraktijk (POH's) klaar voor de toekomst? [Knowledge base: Practice nurses in the GP practices, ready for the future?].Utrecht: Netherlands Institute for Health Services Research (NIVEL), 2012.

28. Rutten G, De Grauw W, Nijpels G, et al. NHG-Standaard Diabetes mellitus type 2 (derde herziening) [NHG Practice Guideline Diabetes mellitus type 2 (Third revision)]. Huisarts Wet 2013;56:512-25.

29. Netherlands Diabetes Federation, NDF Care Standard. Transparancy and quality of diabetes care for people with type 2 diabetes.Amersfoort: Nederlandse Diabetes Federatie (NDF), 2007.

30. Chew-Graham C, Hunter C, Langer S, et al. How QOF is shaping primary care review consultations: a longitudinal qualitative study. BMC Fam Pract 2013;14:103.

31. Mulder BC, van Belzen $M$, Lokhorst AM, et al. Quality assessment of practice nurse communication with type 2 diabetes patients. Patient Educ Couns 2015;98:156-61.

32. Garssen B, de Kok E. How useful is a screening instrument? Psycho-Oncology 2008;17:726-8. 


\section{CHAPTER 8}

General discussion 
Chapter 8 


\section{OUTLINE}

This thesis started with the notion that, in the Dutch routine primary care setting, there is limited attention for the emotional and social aspects of living with a chronic condition. In collaboration with a regional care group and a health insurance company, 'Self-Management Support' (SMS) was implemented in the care for patients with type 2 diabetes mellitus to further realise a biopsychosocial self-management approach for these patients. SMS included detection of patients with problems in their emotional and social functioning and, if needed, self-management support delivered by the practice nurse (PN) or a referral to the general practitioner (GP) for further diagnostics and psychological treatment. The PNs were trained to support patients in formulating their own goals and plans, and to use problem solving skills and reattribution techniques in their everyday life. In that way, it would improve their daily functioning. The implementation strategies and the effectiveness of SMS in daily practice were simultaneously evaluated by using a hybrid effectivenessimplementation randomised trial design.

This chapter presents an overview of the main findings. Then it will reflect on the lessons learnt from translating an evidence-based psychosocial intervention into a clinical setting that is shaped by disease-oriented medical consultations. The focus is on making the shift from a biomedical towards a biopsychosocial care model, and the implications of a self-management support approach for PNs as well as patients. Subsequently, the challenges and complications that were faced by blending an effectiveness study and implementation study will be discussed. The chapter ends with implications for daily practice and further research.

\section{SUMMARY OF MAIN FINDINGS}

Stakeholders from various backgrounds in the Dutch primary care setting recognised the predominant focus on the medical aspects of chronic care, and emphasised the need to further realise a biopsychosocial care approach for patients with somatic chronic conditions. An evidence-based minimal psychological intervention was available for implementation in the daily practice of PNs. A regional care group and a health insurer facilitated the organisational conditions such as training, an electronic registration system for SMS, and financial reimbursement of the extra care. 
Adjustments were needed to make the original intervention feasible for routine diabetes care. The adjusted intervention, called Self-Management Support (SMS), included a two-stepped approach: a detection phase to identify patients with socioemotional problems, and a follow-up phase, when needed, that included the nurseled self-management support or a referral to the GP. SMS was implemented to support patients in coping with the medical, emotional and social challenges of living with diabetes. The primary outcome was patient's daily functioning. Our pragmatic randomised-controlled trial could not demonstrate any clinically significant effect of SMS on emotional, social or biomedical parameters after 4 and 12 months. Even though patients with persistent socio-emotional problems were selected for trial participation, their exposure to the complete two-stepped SMS approach in routine care was low. Only 16 out of the 117 intervention patients (14\%) were detected by the PNs to be eligible for the follow-up phase of SMS. As evidence of emotional distress was still present after four months in most of the non-detected patients, these outcomes on the detection phase indicate an underestimation of patients' emotional problems. Extra consultations for the nurse-led self-management support were given to 11 study participants only. The low exposure to the complete SMS approach caused a dilution of the contrast between intervention and control patients.

Although the effectiveness for patients' daily functioning could not be demonstrated, several lessons were learnt about the implementation of SMS in daily practice. Chapter 4 reports the health professionals' experiences with SMS. PNs valued the systematic attention to emotional and social aspects of diabetes. However, the detection phase of SMS appeared not to enable them to sufficiently identify patients for the follow-up phase of SMS. Therefore, they missed the opportunities to become adept in applying the problem solving and reattribution techniques. PNs needed more time to get used to SMS as a structural part of their routine practice. Besides, the financial reimbursement of care and the development of the registration system were not optimal. GPs' actual involvement with SMS was low. The GPs did not directly see the outcomes of SMS in the Electronic Medical Records, and only a limited number of patients with symptoms of severe mental health problems were referred to the GPs. Chapter 5 presents the patients' perspectives on SMS. Interviews with patients revealed that they see PNs primarily as specialists regarding the biomedical management of diabetes. Although they generally supported the ideal of biopsychosocial care, patients did not expect a discussion about socio-emotional 
problems in the routine consultations with the PNs. Thus the incorporation of the systematic detection phase of SMS in diabetes care would also require endeavours to make patients acquainted with this new approach of the PN.

\section{TRANSLATING EVIDENCE-BASED RESEARCH INTO EVIDENCE- BASED PRACTICE}

This thesis contributed to the knowledge about bridging the gap between clinical research and daily practice. Evidence-based interventions often do not find their way to clinical practice, because health care professionals have limited time and resources, or they miss incentives for using these interventions. Furthermore, the infrastructure and organisation to support the implementation are often inadequate. ${ }^{1}$ In our case, however, there was an implementation momentum, as the regional care group and health insurer were open to facilitate the proven effective intervention with financial and organisational support.

Besides these organisational conditions for implementation, we had the opportunity to start with an intervention that had been evaluated in a cluster-randomised trial among diabetes patients who lived in the same region of the Netherlands. ${ }^{2}$ The intervention had proven to be (cost-)effective ${ }^{2,3}$, and had been well-received by the professionals and patients in that study. ${ }^{4}$ Whereas most psychosocial interventions are evaluated in single, small-sample clinical trials that give no comprehensive understanding of the processes or answers to the question which interventions are most effective and for which patient groups ${ }^{5}$, our research team could learn directly from the experiences of the research team of the previous trial. For example, the reattribution technique appeared to benefit highly educated patients more than lower educated ones. As the region was characterised by a relatively low socioeconomic status, we decided to put greater emphasis on the problem solving technique during the training of the PNs.

However, we still faced a common problem in health services research that had been stated by Kennedy and colleagues ${ }^{6}$ as follows: "effective interventions are often not feasible, and feasible interventions are often not effective". Even though the minimal psychological intervention was evaluated in a trial that had been denoted as a pragmatic trial, it still needed fundamental adjustments to become feasible for the routine care practice. The shift from a clinical trial towards implementation in routine 
practice not only included changes in the providers, setting, and diagnostic approach. The intervention itself also needed to be adapted. Firstly, more than two extra nurseled consultations would not be feasible in a family practice setting. Secondly, a crucial change was the shift from patients diagnosed with a mild to moderate depression towards patients' problems with daily functioning and their emotional distress as the starting point of the intervention. Table 8.1 summarises the differences between the original minimal psychological intervention (MPI) and SMS.

Table 8.1 The Self-Management Support (SMS) approach contrasted with the original minimal psychological intervention (MPI)

\begin{tabular}{|c|c|c|}
\hline & MPI & SMS \\
\hline Target group & $\begin{array}{l}\text { Patients with both chronic disease } \\
\text { and mild or non-severe major } \\
\text { depression }\end{array}$ & $\begin{array}{l}\text { Patients with both chronic disease and } \\
\text { emotional distress and problems of } \\
\text { daily functioning }\end{array}$ \\
\hline Providers & $\begin{array}{l}\text { Research nurses } \\
\text { not working in the family practice }\end{array}$ & $\begin{array}{l}\text { Practice nurses } \\
\text { providing usual chronic care }\end{array}$ \\
\hline Diagnostic approach & $\begin{array}{l}\text { For research purposes. } \\
\text { Using an extensive diagnostic } \\
\text { interview, following strict } \\
\text { psychiatric criteria }\end{array}$ & $\begin{array}{l}\text { As a part of daily care. } \\
\text { Using simple tools, } \\
\text { following a stepped care approach that } \\
\text { fits the primary care setting }\end{array}$ \\
\hline Duration of treatment & Max 10 visits & Max 2 extra consultations \\
\hline Setting & At patients' homes & In the family practice \\
\hline
\end{tabular}

The above-mentioned adjustments for implementation purposes illustrate that an evidence-based intervention can easily turn into a different substitute to be feasible in routine practice. This may have hindered the potential to demonstrate effects in the SMS trial as research shows that symptoms of depression have a greater negative relationship with diabetes self-care than distress, and interventions aimed at depression may therefore have more potential to improve patients' diabetes self-care and disease outcomes. ${ }^{7}$ Positive outcomes are often reported for pragmatic trials that include intensive treatment programmes for patients with depression. In a study of Coventry and colleagues (2015), patients received up to eight sessions of psychological treatment from specially trained professionals in mental health care. ${ }^{8}$ This also applied to the collaborative care approach of Katon and colleagues. ${ }^{9}$ They evaluated an intervention involving nurses who provided intensive, guideline-based, patient-centred management of depression among chronic patients with structured visits every 2 or 3 weeks. ${ }^{9}$ 
Moreover, we also need to take into account that the time for implementation and follow-up is limited in a research setting. The effects of SMS on patients' functioning had to become visible within twelve months whereas the process evaluation suggested that the professionals and patients in our study would need more time for a successful adoption of SMS in their daily practice.

\section{THE CHANGING ROLE OF PRACTICE NURSES}

The implementation of SMS included two fundamental changes in the routine care of PNs. Firstly, PNs were trained to apply a biopsychosocial model in their consultations instead of the dominant biomedical care model. Secondly, PNs learnt to support patients in coping with their emotional and social challenges in daily functioning, in addition to provide support for patients' biomedical skills.

\section{Towards a biopsychosocial model}

Our findings showed that PNs valued the systematic attention for the socio-emotional aspects of diabetes. This support for the biopsychosocial approach given by PNs, but also by stakeholders in the primary care setting (chapter 2), GPs, and patients with diabetes (chapter 4) is neither new nor surprising, as the significance of a biopsychosocial, or patient-centred, or holistic model instead of a dominant biomedical, or illness-centred approach in chronic care has been emphasised since a long time. ${ }^{10,11}$ It goes back to 1948 , when the World Health Organization came with a ground-breaking definition of health as "a state of complete physical, mental and social well-being" and not merely the absence of disease or infirmity. ${ }^{12}$

By now, several screening and case-finding tools have been developed for the primary care setting to identify patients with symptoms of depression ${ }^{13,14}$, and our nurse-led minimal psychological intervention was just one out of many effective interventions aimed at psychological treatment in the primary care setting. ${ }^{15-17}$ Seeing the patient as a whole person in the context of his or her entire life has been stated as one of the core values of family medicine in a position paper of the Dutch College of Family Physicians (NHG). ${ }^{18}$ Besides, attentiveness to the emotional and social aspects of living with chronic conditions is described as one of the competencies of a Dutch PN. ${ }^{19}$ However, the actual adoption of the biopsychosocial care needs to be further improved in a health care setting that is still shaped by an acute care model instead of 
a chronic care model. As reported in chapter 2, this would ask a commitment of stakeholders on various levels, including training institutes, health policy makers, health insurers and the health inspectorate, to develop supportive health care and financial systems.

Based on the interviews with stakeholders (chapter 2), it was concluded that health professionals would need to be equipped with skills to understand patients' multifaceted needs. In the SMS study, PNs were provided simple tools for discussing socio-emotional problems with patients. However, one need to keep in mind that PNs originally were introduced in family medicine for monitoring patients with somatic conditions. They learnt to work according to protocols with a dominant focus on patients' biomedical management and healthy lifestyle. ${ }^{20}$ Although there is evidence that the care of PNs is effective in achieving positive health outcomes for patients, similar to that provided by GPs, and that nurse-led care may result in high levels of patient satisfaction, this does not say anything about the skills of PNs regarding the exploration and detection of patients' socio-emotional problems. ${ }^{21}$ In this respect, several authors suggest that the tightly structured and time-limited nature of chronic care reviews, and a quality system with a narrow focus on biomedical outcome indicators determine the interaction between PNs and patients. ${ }^{22-25}$ Given this background, it is not surprising that the PNs, but also the patients in the SMS study, were not familiar with discussing psychosocial issues in daily functioning during routine consultations.

\section{Towards a self-management support approach}

The detection phase of SMS was not a goal in itself, but it was necessary to identify eligible patients for this extra nurse-led support. This support was offered to enhance their coping with the challenges in daily life, given the relationship between socioemotional problems and patients' self-care. ${ }^{26}$

With this focus on improving patients' daily functioning, SMS fits in a new way of thinking about health. Huber and colleagues ${ }^{12}$ argued that the definition of health as "a state of complete physical, mental and social well-being" declares people with chronic diseases definitively as ill. In their new definition of health is the emphasis on patients' ability to adapt and self-manage in the face of social, physical and emotional challenges. $^{27}$ Nevertheless, not all patients are ready or able to take on greater responsibility for their own care due to personal resources or overwhelming personal 
and social circumstances. ${ }^{28}$ This applies in particular for patients with poor psychological health (such as health beliefs, self-efficacy), and because of psychosocial factors like lack of support from family, friends or the community. ${ }^{29}$ These patients could benefit from the nurse-led support. ${ }^{30}$ Unfortunately, PNs' experiences with supporting patients by means of the problem solving and reattribution techniques were limited, and the added value of SMS for patients' functioning could not be demonstrated.

Research indicates that the change for PNs to realise a biopsychosocial selfmanagement approach in their care, is complex. ${ }^{31,32}$ To date, PNs primarily focus on education about patients' conditions, self-monitoring and a healthy lifestyle. This implies that they decide what information and skills to improve instead of allowing patients to identify their problems and providing them with techniques to make decisions and take appropriate actions. ${ }^{31}$ Research has shown that PNs do not easily incorporate goal-setting in their routine consultations. ${ }^{33}$ The same applies to assisting patients in overcoming barriers in their self-management. ${ }^{34}$ PNs need to do a physical examination and to discuss biomedical information with the patient, and at the same time are supposed to help patients in their medical, emotional and social selfmanagement. A review of quantitative and qualitative research revealed that this combination of being a medical expert and counsellor at the same time may lead to role conflicts and lack of confidence in the communication skills of PNs. ${ }^{35}$ It calls for adequate education of PNs, and further training in their daily practice.

Self-management interventions potentially have a positive impact on patients' selfcare and disease outcomes. ${ }^{36,37}$ However, approaches to self-management support appear to be the least implemented area of chronic care management, ${ }^{31}$ and there are also studies that highlight the limited ability of self-management support interventions to deliver real benefits to patients. ${ }^{6,38}$ Kennedy and colleagues (2013) reported the assessment of a whole systems model of self-management in chronic care. $^{6}$ They took several effective self-management support components and delivered them as a comprehensive package in routine primary care. Like in the SMS study, the intervention was designed to be feasible for widespread implementation in primary care, and the implementation was facilitated by the health management organisation. However, no significant improvements were found. These findings indicate that we need to maintain realistic expectations regarding the time required for making a paradigm shift towards a self-management approach in the current chronic care setting. ${ }^{28,29,31}$ 


\section{THE PATIENTS' PERSPECTIVE}

For implementation of self-management in routine care, appropriate resources need to be provided and processes should be clear. However, the success is for the greater part determined by the influence and interpretation of the participants. ${ }^{29} \mathrm{~A}$ selfmanagement approach changes the activities of the PNs, and it also influences the values underlying the relationship between PNs and patients. ${ }^{39}$ In this regard, the SMS study highlights the need for a good understanding of the patients' perspective.

Our interviews with patients revealed that they are used to a medical check-up of their diabetes and advices for a healthy lifestyle. In this respect, Chew-Grahams and colleagues (2013) argued that the current care setting socializes patients into "passive subjects of surveillance" instead of becoming active partners in their care. ${ }^{23}$ Furthermore, a qualitative study in the UK examined the acceptability of collaborative care that integrated depression care within the management of chronic care. They found that patients with a chronic somatic condition and comorbid depression preferred a separate space to discuss emotional health problems. ${ }^{40}$ To be encouraged in a medical setting to disclose emotional problems to a $\mathrm{PN}$, patients first need to understand and value the role of the PNs in providing emotional support. This can be hindered by several factors with regard to patients' perceived needs, recognition and interpretation of emotional problems in relation to their diabetes. ${ }^{41-43}$ Moreover, patients' awareness of the importance of self-management in diabetes, and their own sense of responsibility seems to be low, at least according to Dutch health professionals. $^{44}$

The question is whether this perspective and behaviour are determined by patients' experiences with the $\mathrm{PN}$, and whether their expectations and preferences can be changed. Appropriate information and communication systems will be required, but preparing patients for change by information about the expanded role of the PNs may not be sufficient. Although one may want that changes can be realised quickly, in reality, it takes time for patients and professionals to trust a new initiative. ${ }^{29}$ In a research setting, however, this time is limited. 


\section{METHODOLOGICAL REFLECTION}

Our project intended sustainable implementation of SMS in the routine care setting of the regional care group. Adoption of SMS was facilitated by means of training, financial support, and development of an electronic registration system for SMS. We wanted to know whether SMS was feasible and adequate for integration in the routine care of PNs. Although there was evidence from the previous trial about the potential effects for patients' functioning, it was chosen to perform an effectiveness trial given the adjustments regarding setting, providers, target population, and features of the intervention.

The traditional development approach of evidence-based practice starts with clinical efficacy research, then clinical effectiveness research and finally implementation research. The continuum between clinical efficacy research and clinical effectiveness research has been represented by means of the PRECIS-2, a validated tool that includes nine key domains like setting, eligibility, delivery, flexibility, follow up and primary outcome. ${ }^{45,46}$ The continuum between clinical effectiveness research and implementation research has described by three variants of hybrid EffectivenessImplementation (E-I) designs. ${ }^{47}$ The benefits of hybrid E-I designs are their potential to speed and improve translation of research findings into routine practice. ${ }^{47}$ As the evaluation of the implementation process of SMS was as important as the effectiveness of SMS, a type 2 hybrid E-I design was performed that included a simultaneous test of the clinical intervention and implementation strategy.

The SMS study illustrates complex issues of using hybrid designs to simultaneously test the implementation and effectiveness of care interventions.

Firstly, the addition of the detection phase was a complicating factor in our hybrid design. The detection phase was an inherent part of SMS. PNs had to identify patients in need for extra consultations for the self-management support. The feasibility of the detection procedure was subject to the process evaluation. If the detection rates would not be accurate, the detection procedure could be improved in the implementation design. Conversely, for the effectiveness trial, low detection rates were a vital problem for patients' exposure to the follow-up phase of SMS. However, the team of researchers and regional partners were not ready in time to effectively solve the problem of the limited detection by PNs of the pre-selected study sample. 
In retrospect, a feasibility testing stage was needed to ensure that no major changes to SMS or to implementation structures would be necessary during the effect evaluation. The absence of a pilot study to test the nurse-led detection method in routine consultations had several reasons. As more than $90 \%$ of the participants in the previous study would recommend the minimal psychological intervention to other patients, there was not much doubt about patients' openness to SMS. ${ }^{4}$ It was also assumed that the questions about socio-emotional distress and daily functioning were common and easy to use. The PNs received a comprehensive training programme followed by booster sessions to integrate these questions into their consultations and to become adept in exploring and discussing psychosocial aspects of diabetes. Another reason to omit a pilot study refers to the implementation momentum. The SMS project could start because the implementation funding was guaranteed by the health insurer and care group, and we found the diabetes foundation willing to grant the effectiveness evaluation. There was neither time nor budget for a pilot study.

The second issue of the hybrid design was to find a good balance between the clinical effectiveness trial and the evaluation of the implementation process. Although Curran and colleagues (2012) state that the clinical intervention and implementation strategies does not necessarily have to be tested using randomised, strongly powered designs in type 2 studies, $^{47}$ we performed a comprehensive cluster-randomised trial, plus an extra screening for the selection of study participants.

This screening method was essential for the internal validity of our trial. Patients from the intervention and control groups were recruited in a similar way, and without interfering in their routine care. Furthermore, we wanted to keep the contrast between intervention and control patients as large as possible. Given that usual care could also include attention to patients' socio-emotional problems, it was chosen to preselect patients who would be eligible for the complete SMS approach, including the detection phase and follow-up phase.

We noticed in our study among all stakeholders an emphasis on the effectiveness part of the study rather than on the implementation process. This was reinforced by several issues.

Firstly, the individual health professionals needed to be involved in sending the screening questionnaires to patients' home addresses some weeks before the consultations. During the start of the study, the instructions about this logistic challenge had to be clear. As a consequence, the communication and collaboration of 
the research team with the health professionals was focused on the effect study of SMS, rather than on the responsibilities regarding the implementation process.

Secondly, we noticed that the sponsors of our study were mainly interested in the effectiveness of SMS on the patient level. The activities to improve the success of implementation became second to monitoring of the outcomes. Evaluators are faced with a choice: to remain passive observers, or to play an active role in addressing 'problems'. ${ }^{48}$ As our effect evaluation aimed to establish effectiveness under real world conditions, it was appropriate to play a more passive role in order to avoid interference with implementation and change in the mode of delivery of the intervention.

The choice to perform a highly pragmatic trial according to the original PRECIS-tool ${ }^{45}$ has also led to concessions regarding the evaluation of the implementation of SMS. To make the interference of researchers in routine practice as little as possible, it was chosen to focus on quantitative registrations of SMS and subjective experiences of the health professionals. However, more qualitative insight into how SMS was performed, and what the PNs and GPs needed on the practice and regional levels, would have been helpful to more thoroughly understand the facilitators and barriers in the implementation process.

With regard to hybrid E-I designs, Curran and colleagues (2012) state that researchers, journal reviewers and grant review bodies need not only expertise in clinical research but also in implementation science. ${ }^{47}$ Additionally, SMS illustrates how the priorities and preferences of the funding agents influence the balance between the effectiveness part and the implementation part. Implementation science is defined as "the scientific study of the methods to promote the uptake of research findings into routine healthcare in clinical, organisational, or policy contexts". ${ }^{49}$ In our case, the degree to which our study was truly implementation science is questionable as the central focus was on establishing the effectiveness of SMS rather than a study of the methods that promoted the uptake of SMS.

In the SMS study, the health insurer expected the care group to play a pivotal role in involving GPs to improve the implementation process. The regional care group lacked budget for these overhead tasks. This led to tension between the two partners. Owing to the disappointing outcomes of SMS in terms of effectiveness, the stakeholders decided to abandon further development and implementation of the SMS approach after one year of follow-up. As a consequence, there was no incentive anymore to 
further integrate and monitor SMS in routine practice, and PNs did not receive booster sessions to improve their skills for SMS. Thereby, the study did not meet the purpose of E-I-designs to speed and improve translation of evidence-based interventions into routine practice. ${ }^{47}$ In an ideal world without restrictions in financial resources and time, the traditional approach would be as follows:

- It starts with an efficacy study of the nurse-led minimal psychological intervention. The efficacy is evaluated by means of a randomised-controlled trial in an idealised setting, to give the intervention its best chance to demonstrate a beneficial effect. The intervention is performed by trained research nurses outside the primary care setting. Patients are selected by the research centre by means of strict inclusion criteria;

- Then the proven nurse-led minimal psychological intervention is subject to an effectiveness study, using a pragmatic, randomised-controlled trial design. The eligibility criteria and duration of the intervention are adapted to fit the routine care setting in which PNs and patients meet every three months for a diabetes check-up. The selection of eligible patients for the nurse-led intervention is done by the research centre. Alongside the trial, a process evaluation provides insight into the fidelity of the clinical intervention, and the facilitators of and barriers to successful implementation.

- Provided the outcomes of the effectiveness study are positive, an implementation study is performed. The intervention is extended by a detection phase to enable PNs to identify eligible patients by themselves during their consultations. The implementation strategy is tailored to individual practices. The implementation study, in which formative evaluation methods are used, primarily focuses on understanding the processes involved in the adoption, implementation, and sustainability. The research outcomes, for example, levels and rates of adoption and fidelity to SMS, are collected at the level of providers and practices. Patientlevel outcomes do not need to be assessed.

Glasgow and colleagues proposed another framework to describe the ideal process of moving research into practice. ${ }^{50}$ Following this approach we would have needed to start with research to understand on increase the uptake and implementation of the evidence-based minimal psychological intervention into the current care setting, and to find an accurate detection method. According to this model, the evaluation of the effectiveness of the intervention in the 'real world' is the final stage of translating research into practice. 


\section{CONCLUSION}

This thesis aimed to evaluate the implementation of an evidence-based intervention for biopsychosocial self-management of diabetes patients into the routine chronic care setting. Stakeholders from various backgrounds in the primary care setting emphasised the need to improve the attention for psychosocial aspects in diabetes care. The process evaluation showed barriers to successful implementation of SMS on the level of PNs and patients, but also with regard to the organisational support, and the current health care setting. For the moment, the effectiveness of SMS for patient's daily functioning and health could not be demonstrated.

\section{IMPLICATIONS FOR DAILY PRACTICE}

This thesis has demonstrated that SMS, including detection and follow-up delivered by PNs, does not fit the current Dutch routine care setting. However, PNs are in the right position to play a vital role in preventing a downward spiral in patients by a biopsychosocial approach of self-management support. Given the outcomes of the SMS study, two different directions for daily practice can be suggested. The first option is to further equip PNs to detect early symptoms of socio-emotional problems among patients with somatic chronic conditions, and to refer these patients to a specialist in psychosocial care. The other option is to further develop the SMS approach by adjustments to the detection method, a further integration of the problem solving and reattribution techniques in the consultations, and time for the PNs and patients to develop trust in the new approach. The pros and cons of both options will be discussed.

On the one side, one may argue that the proven nurse-led minimal psychological intervention does not fit current health care practice. As already was mentioned in this chapter, PNs for somatic chronic care have shown to be adept in working according to protocols, and in prevention activities. ${ }^{20}$ They can provide as high quality care as GPs, and achieve equally good health outcomes for patients. ${ }^{51}$ Besides, our study confirms that patients' satisfaction with the quarterly consultations of the PNs is high. ${ }^{52}$ Our findings do not clearly point out that SMS is an answer to patients' perceived needs. Although patients value a biopsychosocial approach of the PNs in 
theory, the openness for discussing the socio-emotional problems with PNs during a routine diabetes consultations appeared to be limited in our study sample.

Given the current organisation of the Dutch primary care setting, it is questionable whether the mind-sets of PNs and patients are stimulated towards the biopsychosocial self-management support approach. Even though the Dutch integrated payment system is aimed at the development of a well-functioning integrated chronic care system, the orientation is still on diseases rather than on patients. This can be illustrated by the disease-specific chronic care modules and the use of biomedical quality indicators such as blood glucose, blood pressure, and the percentage of patients screened for retinopathy. ${ }^{53,54}$ Experiments in the Netherlands with a primary care diagnosis-treatment combination for depression also highlight this focus on a disease instead of a patient.

Another development is the introduction of mental health nurses in Dutch family practices. The percentage of practices that are working with a mental health nurses have increased from $30 \%$ in 2008 till $80 \%$ in $2015 .{ }^{55}$ As these mental health professionals are experts in providing effective treatments for patients with depression, ${ }^{16}$ the nurse-led psychological intervention could be integrated in their care. The disease-management program for depression calls for PNs for somatic care who early detect patients with symptoms of depression, and refer these patients to the GP or mental health nurse in the family practice. ${ }^{56}$ However, this scenario gives rise to the question how many patients will be actually interested in getting support from another health professional. In this regard, several studies indicate that patients' beliefs about the diagnostic label 'depression', particularly relating to perceived stigma, will be a barrier to consult a GP or mental health for psychological treatment. ${ }^{57,58}$ A referral to a mental health professional also contrasts with the core values of Dutch family medicine, i.e. generalist, patient-oriented and continuous care. $^{18}$

On the other side, the provision of biopsychosocial self-management support can be considered as an essential quality improvement of somatic chronic care. While we could not demonstrate the effects of SMS, the research literature promotes problem solving therapy for improving patients' self-care behaviour as an evidence-based intervention for diabetes self-management. ${ }^{59,60}$ Besides, the Dutch government promotes the use of individual care plans (ICPS). ICPs are intended to help provide proactive, holistic, coordinated care to patients with chronic conditions, that is tailored to their needs and preferences. ${ }^{61}$ Supporting patients to set their own goals 
and to improve their self-management are vital aspects of ICPS. The use of ICPs in the Netherlands is still low (9\% in 2011), but patients with a low level of education and/or poor(er) self-rated health appeared to be more likely to report having an ICP. ${ }^{61} \mathrm{~A}$ further introduction of ICPs in the primary care setting may benefit from PNs who are trained in SMS to support patients in goal-setting, making action plans and in using techniques like problem solving and reattribution.

Several adjustments are needed to apply the lessons learnt about the SMS approach and to promote its uptake in the routine care. First, the SMS study showed the limitation of taking the patients' socio-emotional problems, as identified by means of a verbal detection procedure, as the starting point of the self-management support. Our holistic, verbal approach did not meet its purpose to identify patients with persistent emotional problems. Although nurses seem to be willing to integrate written screening instruments into their care, ${ }^{62}$ the pencil and paper tool also has limitations because of its narrow focus on a predefined group of patients with specific symptoms of distress. Qualitative studies suggest that PNs have to start with a good understanding of patients' life story and their beliefs about themselves and their views on treatment. ${ }^{41,58}$ To get such a multidimensional understanding of a patient's functioning, PNs could be supported by using tools that are based on a model like the WHO's International Classification of Functioning, Disability and Health (ICF), a widely accepted terminology for health, functioning, and health-related domains. This model could be a starting point to explore patients' impairments, activity limitations and contextual factors. An alternative is to use an instrument like the Psychological outcome profiles questionnaire (PSYCHLOPS), a short, self-administered questionnaire in which patients are asked to describe their main problem or problems and how this affects them in their functioning. ${ }^{63}$

Nevertheless, finding an accurate procedure for the identification of eligible patients is not the main issue. Above all, implementation of SMS makes high demands on the competences of the PNs. Not all PNs feel comfortable with helping patients regarding issues outside the biomedical domain. ${ }^{39}$ However, the success does not depend on PNs' willingness and enthusiasm but on the ability of PNs to grasp the spirit of the SMS approach, in which the patients' daily functioning is the focus of attention rather than their biomedical diabetes-related issues. ${ }^{64}$ When a patient does not achieve good diabetic control, PNs need to be able to broaden their view to get a more 
comprehensive understanding of the patient's situation and self-management skills. In this regard, observations and interviews with PNs in the UK showed that PNs fell into two groups: those with a more reflective attitude to their work, who show understanding of the principles underlying the self-management approach; and those who found it too challenging and preferred to hold on to their familiar way of doing their consultations. ${ }^{64}$ This suggests that the implementation of SMS need to be tailored to the abilities of PNs. The skills of PNs may be promoted by teaching selfmanagement support techniques in the curriculum of the training for PNs, followed by training on the job. ${ }^{65}$ It needs to focus on how PNs can support patients in assimilating the knowledge into their daily life rather than putting the emphasis on the skills regarding patient information and health promotion.

Like the health professionals have to learn 'to let go' their professional control by supporting self-management and value patients' own goals and autonomy, health insurance companies also have to learn to let go. Nowadays, health insurance companies predominantly have a narrow focus on biomedical process and outcome indicators in measuring the quality of care. Adding process indicators regarding biopsychosocial aspects of diabetes care could also easily result in a 'tick-box' culture due to many checklists that need to be completed by health professionals. ${ }^{22}$ The question is whether the biopsychosocial approach can be measured by quality indicators. In this regard, Gately and colleagues argued that initiatives in the area of self-management support in chronic care seek to link the provision of self-care with a reduction in demand, which contrasts with the complex and contextual nature of health service utilisation. ${ }^{66,67}$ This implies that health insurers have to accept the complexity of chronic care. Therefore, health insurers need to acknowledge that improving the quality of patient-centred care requires an investment of time and financial support.

\section{IMPLICATIONS FOR FURTHER RESEARCH TOPICS}

Several research themes emerge from the outcomes of the SMS study. First, we need a better understanding of what individual patients need to improve their selfmanagement skills. This could be nurse-led support but also group wise support from peers, ${ }^{68,69}$ or social support in patients' social networks. ${ }^{70,71}$ 
A second theme is the early detection of patients with emotional and social problems by PNs in diabetes consultations. PNs need training and tools to identify patients who need support in dealing with the emotional and social challenges of the chronic condition(s). By the verbal, integrative approach of SMS, many patients with persistent emotional distress were not identified. Further research is needed to compare pencil and paper screening procedures with more holistic approaches to identify eligible patients in need for nurse-led support.

Determinants of successful adoption of a self-management support approach in the routine care of PNs are a third theme that needs further research. This would include studies that focus on how PNs can learn the complex skills of understanding patients' needs in daily functioning, and providing self-management support.

A fourth theme is the development of indicators to measure the quality of a biopsychosocial care approach in chronic care consultation. 


\section{REFERENCES}

1. Glasgow RE, Lichtenstein E, Marcus AC. Why don't we see more translation of health promotion research to practice? Rethinking the efficacy-to-effectiveness transition. Am J Public Health 2003;93:1261-7.

2. Lamers $\mathrm{F}$, Jonkers CCM, Bosma $\mathrm{H}$, et al. Treating depression in diabetes patients: does a minimal psychological intervention affect diabetes-specific quality of life and glycemic control? A randomized controlled trial. J Adv Nur 2011;67:788-99.

3. Jonkers CCM, Lamers $\mathrm{F}$, Bosma $\mathrm{H}$, et al. The effectiveness of a minimal psychological intervention on self-management beliefs and behaviors in depressed chronically ill elderly persons: a randomized trial. Int Psychogeriatr 2012;24:288-97.

4. Jonkers $\mathrm{C}$, Lamers $\mathrm{F}$, Bosma $\mathrm{H}$, et al. Process evaluation of a minimal psychological intervention to reduce depression in chronically ill elderly persons. Patient Educ Couns 2007;68:252-57.

5. Gonder-Frederick LA, Cox DJ, Ritterband LM. Diabetes and behavioral medicine: the second decade. J Consult Clin Psychol 2002;70:611-25.

6. Kennedy $A$, Bower $P$, Reeves $D$, et al. Implementation of self management support for long term conditions in routine primary care settings: cluster randomised controlled trial. BMJ 2013;346:f2882.

7. Gonzalez JS, Delahanty LM, Safren SA, et al. Differentiating symptoms of depression from diabetesspecific distress: relationships with self-care in type 2 diabetes. Diabetologia 2008;51:1822-5.

8. Coventry P, Lovell K, Dickens C, et al. Integrated primary care for patients with mental and physical multimorbidity: cluster randomised controlled trial of collaborative care for patients with depression comorbid with diabetes or cardiovascular disease. BMJ 2015;350:h638.

9. Katon WJ, Lin EH, Von Korff M, et al. Collaborative care for patients with depression and chronic illnesses. N Engl J Med 2010;363:2611-20.

10. Borrell-Carrio F, Suchman AL, Epstein RM. The Biopsychosocial Model 25 Years Later: Principles, Practice, and Scientific Inquiry. Ann Fam Med 2004;2:576-82.

11. Lewin S, Skea Z, Entwistle V, et al. Interventions for providers to promote a patient-centred approach in clinical consultations. Cochrane Database of Systematic Reviews 2001;4.

12. Huber M, Knottnerus JA, Green L, et al. How should we define health? BMJ 2011;343.

13. Gilbody S, Sheldon T, House A. Screening and case-finding instruments for depression: a metaanalysis. CMAJ 2008;178:997-1003.

14. Hermanns N, Kulzer B, Krichbaum $M$, et al. How to screen for depression and emotional problems in patients with diabetes: comparison of screening characteristics of depression questionnaires, measurement of diabetes-specific emotional problems and standard clinical assessment. Diabetologia 2006;49:469-77.

15. Van der Feltz-Cornelis CM, Nuyen J, Stoop C, et al. Effect of interventions for major depressive disorder and significant depressive symptoms in patients with diabetes mellitus: a systematic review and meta-analysis. Gen Hosp Psychiatry 2010;32:380-95.

16. Markowitz SM, Gonzalez JS, Wilkinson JL, et al. A review of treating depression in diabetes: emerging findings. Psychosomatics 2011;52:1-18.

17. Stoop C, Spek V, Pop V, et al. Disease management for co-morbid depression and anxiety in diabetes mellitus: design of a randomised controlled trial in primary care. BMC Fam Pract 2011;12:139.

18. The Dutch College of General Practitioners (NHG). Core values of General Practice / Family Medicine. Position Paper. Utrecht: The Dutch College of General Practitioners (NHG); 2011.

19. (LHV) NAoGP. Competentieprofiel en eindtermen Praktijkondersteuner [Competence profile and requirements Practice Nurses]. Utrecht: National Association of General Practitioners (LHV), 2010.

20. Heiligers PJM, Noordman J, Korevaar JC, et al. Kennisvraag: praktijkondersteuners in de huisartspraktijk ( $P O H$ 's) klaar voor de toekomst? [Knowledge base: Practice nurses in the GP practices, ready for the future?]. Utrecht: Netherlands Institute for Health Services Research (NIVEL), 2012.

21. Keleher $\mathrm{H}$, Parker $\mathrm{R}$, Abdulwadud $\mathrm{O}$, et al. Systematic review of the effectiveness of primary care nursing. Int J Nurs Pract 2009;15:16-24. 
22. Alderson SL, Russell AM, McLintock K, et al. Incentivised case finding for depression in patients with chronic heart disease and diabetes in primary care: an ethnographic study. BMJ Open 2014;4.

23. Chew-Graham C, Hunter C, Langer $S$, et al. How QOF is shaping primary care review consultations: a longitudinal qualitative study. BMC Fam Pract 2013;14:103.

24. Butalid L, Verhaak PF, van Dulmen S, et al. Concerns voiced by patients and GPs' responses during psychosocial visits in primary care: a historical cross-sectional study. BMC Fam Pract 2014;15:188.

25. Grumbach K. Chronic Illness, Comorbidities, and the Need for Medical Generalism. Ann Fam Med 2003;1:4-7.

26. Fisher L, Mullan JT, Arean P, et al. Diabetes distress but not clinical depression or depressive symptoms is associated with glycemic control in both cross-sectional and longitudinal analyses. Diabetes Care 2010;33:23-28.

27. Mulder RT. An epidemic of depression or the medicalization of distress? Perspect Biol Med 2008;51:238-50.

28. Kousoulis A, Patelarou E, Shea S, et al. Diabetes self-management arrangements in Europe: a realist review to facilitate a project implemented in six countries. BMC Health Serv Res 2014;14:453.

29. Davy C, Bleasel J, Liu H, et al. Factors influencing the implementation of chronic care models: A systematic literature review. BMC Fam Pract 2015;16:102.

30. Mulvaney SA. Improving patient problem solving to reduce barriers to diabetes self-management. Clin Diabetes 2009;27:99-104.

31. Elissen A, Nolte E, Knai C, et al. Is Europe putting theory into practice? A qualitative study of the level of self-management support in chronic care management approaches. BMC Health Serv Res 2013;13:117.

32. Macdonald W, Rogers A, Blakeman T, et al. Practice nurses and the facilitation of self-management in primary care. J Adv Nurs 2008;62:191-99.

33. Jansink R, Braspenning J, van der Weijden $\mathrm{T}$, et al. Primary care nurses struggle with lifestyle counseling in diabetes care: a qualitative analysis. BMC Family Pract 2010;11:41.

34. Mulder BC, van Belzen M, Lokhorst AM, et al. Quality assessment of practice nurse communication with type 2 diabetes patients. Patient Educ Couns 2015;98:156-61.

35. Mulder BC, Lokhorst AM, Rutten GEHM, et al. Effective Nurse Communication With Type 2 Diabetes Patients: A Review. West J Nurs Res 2015;37:1100-31.

36. Heinrich E, Schaper N, de Vries N. Self-management interventions for type 2 diabetes: a systematic review. European Diabetes Nursing 2010;7:71-76.

37. Fitzpatrick SL, Schumann KP, Hill-Briggs F. Problem solving interventions for diabetes selfmanagement and control: A systematic review of the literature. Diabetes Res Clin Pract 2013;100:145-61.

38. Franek J. Self-management support interventions for persons with chronic disease: an evidencebased analysis. Ontario health technology assessment series 2013;13:1-60.

39. Dwarswaard J, van de Bovenkamp H. Self-management support: A qualitative study of ethical dilemmas experienced by nurses. Patient Educ Couns 2015;98:1131-36.

40. Knowles SE, Chew-Graham C, Adeyemi I, et al. Managing depression in people with multimorbidity: a qualitative evaluation of an integrated collaborative care model. BMC Fam Pract 2015;16:32.

41. Alderson S, Foy R, Glidewell L, et al. Patients understanding of depression associated with chronic physical illness: a qualitative study. BMC Fam Pract 2014;15:37.

42. Wittkampf KA, van Zwieten M, Smits FT, et al. Patients' view on screening for depression in general practice. Fam Pract 2008;25:438-44.

43. DeJean $D$, Giacomini $M$, Vanstone $M$, et al. Patient experiences of depression and anxiety with chronic disease: a systematic review and qualitative meta-synthesis. Ontario health technology assessment series 2013;13:1-33.

44. Raaijmakers L, Hamers F, Martens M, et al. Perceived facilitators and barriers in diabetes care: a qualitative study among health care professionals in the Netherlands. BMC Fam Pract 2013;14:114.

45. Thorpe $\mathrm{KE}, \mathrm{Zwarenstein} \mathrm{M}$, Oxman $\mathrm{AD}$, et al. A pragmatic-explanatory continuum indicator summary (PRECIS): a tool to help trial designers. CMAJ 2009;180:E47-57. 
46. Loudon $\mathrm{K}$, Treweek S, Sullivan $\mathrm{F}$, et al. The PRECIS-2 tool: designing trials that are fit for purpose. BMJ 2015; May 8;350:h2147.

47. Curran GM, Bauer M, Mittman B, et al. Effectiveness-implementation hybrid designs: combining elements of clinical effectiveness and implementation research to enhance public health impact. Med Care 2012;50:217-26.

48. Moore GF, Audrey S, Barker M, et al. Process evaluation of complex interventions: Medical Research Council guidance. BMJ 2015;Mar 19;350:h1258.

49. Wensing M. Implementation science in healthcare: Introduction and perspective. Z Evid Fortbild Qual Gesundhwes 2015;109:97-102.

50. Glasgow RE, Vinson C, Chambers D, et al. National Institutes of Health Approaches to Dissemination and Implementation Science: Current and Future Directions. Am J Public Health 2012;102:1274-81.

51. Laurant M, Reeves D, Hermens $R$, et al. Substitution of doctors by nurses in primary care. Cochrane Database Syst Rev 2005:CD001271.

52. Gorter KJ, Tuytel GH, de Leeuw RRJ, et al. Huisarts of ketenzorg: wat wilde de diabetespatiënt? [Who should treat diabetes patients?]. Huisarts Wet 2011;54:238-43.

53. Tsiachristas A, Hipple-Walters B, Lemmens KMM, et al. Towards integrated care for chronic conditions: Dutch policy developments to overcome the (financial) barriers. Health Policy 2010;101:122-32.

54. Struijs J, de Jong-van Til J, Lemmens L, et al. Bundled payments of diabetes care: Effects on care delivery process and quality of care at three-year follow-up. Bilthoven: National Institute for Public Health and the Environment (RIVM), 2012.

55. Dutch Ministry of Health WaS. Beantwoording Kamervragen over het VWS-jaarverslag 2014. Kamerstuk: Kamervragen. 16-06-2015. Bijlage bij "Kamerbrief over beantwoording Kamervragen bij VWS-jaarverslag 2014 en bij rapport jaarverslag van de Algemene Rekenkamer". [Answering questions asked by the Dutch Lower Chamber about the year report of 2014 by the Dutch Ministry of Health, Welfare and Sport] The Hague: Dutch Ministry of Health, Welfare and Sport, 2015.

56. Van de Rijt D, Van den Heuvel E, Michels M, et al. De ontwikkeling van een DBC Depressie. [The development of an integrated bundle of care for depression]. Psychopraktijk 2012;4:28-33.

57. Bushnell J, McLeod D, Dowell A, et al. Do patients want to disclose psychological problems to GPs? Fam Pract 2005;22:631-37.

58. Alderson SL, Foy R, Glidewell L, et al. How patients understand depression associated with chronic physical disease - a systematic review. BMC Fam Pract 2012;13:41.

59. Schumann KP, Sutherland JA, Majid HM, et al. Evidence-Based Behavioral Treatments for Diabetes: Problem-Solving Therapy. Diabetes Spectr 2011;24:64-69.

60. Arean $\mathrm{P}$, Hegel $\mathrm{M}, \mathrm{Vannoy} \mathrm{S}$, et al. Effectiveness of problem-solving therapy for older, primary care patients with depression: results from the IMPACT project. Gerontologist 2008;48:311-23.

61. Jansen DL, Heijmans M, Rijken M. Individual care plans for chronically ill patients within primary care in the Netherlands: Dissemination and associations with patient characteristics and patient-perceived quality of care. Scand J Prim Health Care 2015;33:100-6.

62. Braeken A, Kempen G, Eekers $D$, et al. The usefulness and feasibility of a screening instrument to identify psychosocial problems in patients receiving curative radiotherapy: a process evaluation. $B M C$ Cancer 2011;11:479.

63. Ashworth M, Robinson SI, Godfrey $\mathrm{E}$, et al. Measuring mental health outcomes in primary care: the psychometric properties of a new patient-generated outcome measure,'PSYCHLOPS'('psychological outcome profiles'). Primary Care Mental Health 2005;3:261-70.

64. Pill R, Rees $\mathrm{ME}$, Stott $\mathrm{NCH}$, et al. Can nurses learn to let go? Issues arising from an intervention designed to improve patients' involvement in their own care. J Adv Nurs 1999;29:1492-99.

65. Brunero S, Jeon Y-H, Foster K. Mental health education programmes for generalist health professionals: An integrative review. Int J Ment Health Nurs 2012;21:428-44.

66. Gately C, Rogers A, Sanders C. Re-thinking the relationship between long-term condition selfmanagement education and the utilisation of health services. Soc Sci Med 2007;65:934-45.

67. Van der Vlegel-Brouwer W. Integrated healthcare for chronically ill. Reflections on the gap between science and practice and how to bridge the gap. Int J Integr Care 2013;13. 
68. Burda $\mathrm{MH}$, van der Horst $\mathrm{F}$, van den Akker $\mathrm{M}$, et al. Identifying experiential expertise to support people with diabetes mellitus in applying for and participating effectively in paid work: a qualitative study. J Occup Environ Med 2012;54:92-100.

69. Steinsbekk A, Rygg LO, Lisulo M, et al. Group based diabetes self-management education compared to routine treatment for people with type 2 diabetes mellitus. A systematic review with metaanalysis. BMC Health Serv Res 2012;12:213.

70. Vassilev I, Rogers A, Blickem C, et al. Social networks, the 'work' and work force of chronic illness selfmanagement: a survey analysis of personal communities. PLoS One 2013;8:e59723.

71. Van Dam HA, van der Horst FG, Knoops L, et al. Social support in diabetes: a systematic review of controlled intervention studies. Patient Educ Couns 2005;59:1-12. 
Summary 
Chapter 1 starts with an introduction of the thesis. In the current Dutch primary care setting, self-management support has been widely recognized as a key component in the care for patients with chronic conditions. The thesis is focused on selfmanagement support in the care for patients with type 2 diabetes mellitus. It starts with the notion that Dutch chronic care is predominantly focused on the medical aspects, whereas socio-emotional problems are prevalent among patients with type 2 diabetes. The thesis follows a definition of self-management that includes patients' medical, emotional and social tasks in daily functioning. The chapter presents a nurseled minimal psychological intervention for elderly patients with type 2 diabetes with comorbid mild to moderate depression. This intervention has shown to be (cost)effective in a previous randomised trial. In collaboration with a regional care group of general practitioners and a health insurer, this intervention is implemented in the routine diabetes care provided by practice nurses in the family practice.

The chapter presents three research questions. The first question refers to the perspective of stakeholders on the need and urgency regarding the improvement of the psychosocial aspects of chronic care. The second question addresses the barriers to and facilitators of successful implementation of a biopsychosocial self-management approach in routine diabetes care as experienced by patients, practice nurses and general practitioners. The third question is whether the biopsychosocial selfmanagement approach provided by practice nurses during routine consultations is effective for patient's daily functioning and health.

Chapter 2 reports the findings that are based on 30 interviews with various stakeholders in the Dutch primary care setting. This qualitative study is aimed to explore their views on achieving a biopsychosocial approach to the care of patients with chronic diseases. The respondents were representatives of Dutch patients with chronic illnesses, primary care professionals, policy makers, health inspectorate, health insurers, educational institutes and researchers. The stakeholders were aware that a systematic biopsychosocial care approach is lacking in current practice. They emphasised the crucial role of active patient participation, training of professionals, high-quality guidelines, an integrated primary care setting, a stimulating role of researchers, and financial issues in realising a biopsychosocial care approach. The chapter concludes that all parties involved need to make a commitment to break through the wall of biomedically oriented care. 
Chapter 3 describes the protocol of the study 'Self-Management Support' (SMS) to simultaneously evaluate the effectiveness and process of implementation of the evidence-based nurse-led intervention into routine diabetes care. It describes how the proven nurse-led minimal psychological intervention needed to be adjusted to fit the routine consultations of practice nurses. The resulting SMS approach included a detection phase to identify patients with emotional distress and problems of daily functioning, and when needed, a follow-up phase. The follow-up phase included the nurse-led self-management support through problem solving and reattribution techniques, or a referral to the general practitioner.

The protocol also describes the strategies to embed SMS in daily practice. These strategies included training and booster sessions for practice nurses as well as organisational and financial arrangements. The chapter presents the methods to evaluate the facilitators and barriers regarding successful implementation of SMS. Furthermore, it provides all details and choices regarding the pragmatic clusterrandomised controlled trial for evaluating the effects of SMS on patients' daily functioning.

The process of implementation according to the experiences of health professionals, and the impact of SMS for their daily practice have been described in chapter 4 . Practice nurses who were trained in SMS, and general practitioners participated in this mixed-methods process evaluation. The study showed that the practice nurses valued the systematic approach of SMS, but felt restricted in time and expertise to fully adopt SMS in their regular care. The impact of SMS for the daily practice of general practitioners was limited. The registration system and financial support were not optimal for successful implementation of SMS. Chapter 4 highlights the challenge to find effective ways to identify eligible patients for the follow-up phase of SMS, and the need to provide tailored training, support and effective financial incentives to health professionals to successfully incorporate SMS in their routine practice.

Chapter 5 gives a comprehensive view on the patients' perspective regarding SMS. The findings are based on a mixed methods study design. The qualitative part of the study included a content analysis of twelve in-depth interviews with diabetes patients with socio-emotional problems. These interviews revealed that patients viewed a diabetes consultation primarily as a biomedical check-up. They did not perceive discussion of psychosocial well-being as an integral part of diabetes management. 
Based on these findings, a structured questionnaire was designed to further explore the findings among a larger group of patients $(n=205)$. The questionnaire included 14 items measuring patients' agreement with statements about diabetes care and the role of the practice nurse therein. This quantitative part indicated that patients support the ideal of integrated care. Chapter 5 indicates that the incorporation of systematic detection of psychosocial problems in diabetes care requires endeavours to make patients acquainted with the new role of the practice nurse.

The effect evaluation is reported in chapter 6 of this thesis. The cluster-randomised trial involved 40 practice nurses, of whom 19 were trained in SMS and the other 21 practice nurses provided usual care during the year of research follow-up. A total number of 264 diabetes patients, selected by a self-administered questionnaire aimed at measuring emotional distress and diabetes-related reduced daily functioning, gave informed consent for study participation. The primary outcome measure was a dichotomized score on a Visual Analogue Scale that measured the perceived effect of diabetes on daily functioning. Secondary measures included patients' diabetes-related distress, quality of life, autonomy and participation, self-efficacy, self-management and glycaemic control. Outcomes were measured at baseline and at 4-month and 12month follow-ups.

Only 16 of the 117 patients in the intervention arm (14\%) who were found eligible by the posted research-driven screening questionnaire were detected by their practice nurses. Extra consultations for the follow-up phase of SMS were delivered to only 11 study participants. In the control arm, 147 patients received usual care. Multilevel analyses showed no significant differences in outcomes between the intervention and control arms. The conclusion of chapter 6 is that SMS in its present form is not effective. The critical issue was the research-driven screening to select trial participants as it appeared to be inconsistent with nurse-led detection in routine practice.

Alongside the SMS trial, the identification and outcomes of detection of emotional distress by the practice nurses in routine diabetes consultations have been addressed. Chapter 7 presents the outcomes of this study. The study sample included the 117 intervention patients, who were selected by the written screening questionnaire some weeks before their diabetes consultation. The detection outcomes of the practice nurses, and patients' mental health status as measured after four months 
were reported. According to the nurse-led detection outcomes, 52\% of 85 patients had no emotional problems during the consultation, whereas emotional distress was present after 4 months follow-up in $90 \%$ of detected patients, and $83 \%$ of nondetected patients. The findings suggest that practice nurses missed a substantial proportion of diabetes patients with persistent socio-emotional distress. In chapter 7 , further evaluation is recommended with a focus on the contextual conditions in which the detection method is applied.

Chapter 8 presents a short overview of the main findings of the thesis. Subsequently, the chapter reflects on the challenges and the lessons learnt from translating an evidence-based psychosocial intervention into a clinical, medical setting. It discusses how practice nurses and patients have been socialized in the biomedical model. This makes the shift towards a biopsychosocial approach complex. This complexity also refers to the integration of a self-management approach in chronic care. Practice nurses as well as patients need time for this paradigm shift. The chapter reflects on the challenges and complications that were faced by blending an effectiveness study and implementation study. This was mainly caused by the detection phase of SMS as an inherent part of the intervention. The low detection rates in routine care were a vital problem for the effectiveness part of the study. In this regard, the absence of a pilot study to test the detection phase of SMS in routine consultations is discussed. Furthermore, chapter 8 discusses how the balance between the effectiveness part and the implementation part was influenced by the priorities and preferences of all stakeholders.

With regard to the implications of the SMS study, the chapter deliberates on two possible directions for daily practice. The first option takes the current biomedical care setting as the starting point, in which practice nurses refer patients with socioemotional problems to a GP or mental health professional. The alternative is to focus on a further adjustment and tailoring of SMS to the routine consultations of practice nurses. The chapter ends with conclusions, and with four specific recommendations for further research. 
Samenvatting 
Hoofdstuk 1 beschrijft de achtergrond en doelstellingen van dit proefschrift. In de zorg voor chronisch zieken in de Nederlandse eerstelijnszorg wordt steeds meer nadruk gelegd op het belang van zelfmanagementondersteuning. In dit proefschrift gaat het om de ondersteuning van zelfmanagement bij mensen met diabetes mellitus type 2 . Mensen met diabetes kunnen allerlei sociaal-emotionele problemen ervaren. Toch is de zorgverlening vooral gericht op de biomedische aspecten van het omgaan met deze chronische aandoening. Het proefschrift gaat uit van een brede definitie van zelfmanagementondersteuning, waarin naast de aandacht voor biomedische aspecten ook ondersteuning wordt geboden bij het omgaan met de emotionele en sociale gevolgen van diabetes in het dagelijks leven. In een voorgaand wetenschappelijk onderzoek is de kosteneffectiviteit aangetoond van een minimale verpleegkundige interventie, uitgevoerd bij ouderen met diabetes en een milde tot matige depressie. Deze interventie bestond uit het aanleren van probleemoplossende vaardigheden en reattributie, een aanpak die gebaseerd is op de leertheorie en ook wordt toegepast in de cognitieve gedragstherapie. In samenwerking met een regionale zorggroep en een zorgverzekeraar is deze interventie aangepast en geïmplementeerd in de reguliere zorg van praktijkondersteuners in de huisartsenpraktijk. In het proefschrift staan drie vraagstellingen centraal. De eerste vraag betreft de visie van stakeholders in de eerstelijnszorg in Nederland op het verbeteren van aandacht voor het psychosociale welzijn in de zorg voor mensen met een chronische aandoening. De tweede vraag gaat over de mogelijkheden en barrières ten aanzien van implementatie van biopsychosociale zelfmanagementondersteuning in de reguliere diabeteszorg, zoals ervaren door praktijkondersteuners, huisartsen en patiënten. De derde vraag gaat over de effectiviteit van biopsychosociale zelfmanagementondersteuning tijdens reguliere diabetesconsulten ten aanzien van het dagelijks functioneren van patiënten.

In hoofdstuk 2 worden de bevindingen gerapporteerd van een kwalitatief onderzoek, waarin 30 vertegenwoordigers van stakeholders in de Nederlandse eerstelijnszorg zijn geïnterviewd over (de noodzaak tot) het verbeteren van een biopsychosociale benadering in de zorg voor patiënten met een chronische aandoening. De geïnterviewden waren zorgverleners, beleidsmakers, wetenschappelijk onderzoekers, en vertegenwoordigers van patiënten, de Inspectie voor de Gezondheidszorg, zorgverzekeraars, en opleidingsinstituten. Volgens de respondenten is aandacht voor de problemen in het dagelijks leven van mensen met een chronische aandoening in de dagelijkse zorg niet gewaarborgd. Het is afhankelijk van de vaardigheden van 
individuele zorgverleners. Op basis van de interviews wordt geconcludeerd dat het realiseren van biopsychosociale chronische zorg vraagt om een commitment van alle partijen op verschillende niveaus, waarbij wordt gewerkt aan actieve participatie door patiënten, scholing van zorgverleners, een sterkere focus op integrale zorg in de richtlijnen en verdiscontering van integrale zorg in het bekostigingssysteem.

Hoofdstuk 3 beschrijf het onderzoeksprotocol van de implementatie en evaluatie van 'Self-Management Support' (SMS). Het implementatieproces en de effectiviteit van SMS zijn gelijktijdig geëvalueerd. De noodzakelijke aanpassingen die nodig waren om de oorspronkelijke minimale verpleegkundige interventie passend te maken voor reguliere diabetesconsulten worden beschreven. Het resultaat is de interventie 'SMS', bestaande uit 2 fasen: een detectie-fase om patiënten met sociaal-emotionele problemen in het dagelijks functioneren te identificeren en, indien nodig, een followup fase met het aanbod van ondersteuning door de praktijkondersteuner. Bij ernstige klachten ontvangt een patiënt een consult bij de huisarts voor eventuele verdere psychologische behandeling. De strategieën om SMS te verankeren in de reguliere zorg bestaan uit training voor praktijkondersteuners, opgevolgd door intervisiebijeenkomsten, bekostiging van de extra zorg, en het faciliteren van een geïntegreerd systeem om de uitkomsten van SMS te registeren. In hoofdstuk 3 worden de methoden om het succes van de implementatie te evalueren beschreven, evenals de procedures ten aanzien van het selecteren van onderzoeksdeelnemers, randomisatie, powercalculatie, meetinstrumenten en meetmomenten van de pragmatische clustergerandomiseerde trial.

Hoofdstuk 4 beschrijft hoe de impact van SMS op de dagelijkse praktijkvoering is ervaren door de betrokken zorgverleners. De praktijkondersteuners die waren getraind in SMS namen deel aan deze procesevaluatie. Tevens is per praktijk uit de interventiegroep een huisarts geïnterviewd. De praktijkondersteuners vonden de systematische manier waarop zij aandacht konden besteden aan de sociaalemotionele gevolgen van diabetes waardevol. Ze voelden zich echter beperkt in tijd voor het gesprek over het emotioneel welzijn, gegeven hun andere taken. Tevens vonden zij zichzelf niet deskundig genoeg en hadden zij te weinig kans om hun expertise te vergroten in het bieden van de zelfmanagementondersteuning, omdat er maar weinig mensen gedetecteerd waren voor de follow-up fase van SMS. De impact van SMS op de dagelijkse zorgverlening voor huisartsen was gering. De huisartsen 
stonden positief ten opzichte van de systematische aandacht van praktijkondersteuners voor het dagelijks functioneren van patiënten, ook al werden weinig mensen met emotionele of sociale problemen opgespoord bij wie de huisarts hier nog niet van op de hoogte was. Over het aanbieden van de zelfmanagementondersteuning door de praktijkondersteuner somatiek waren de meningen verdeeld. Verder komt in hoofdstuk 4 aan bod dat zowel de manier van bekostiging van SMS als het registratiesysteem onvoldoende konden bijdragen aan het bevorderen van de implementatie.

Hoofdstuk 5 combineert de bevindingen van een kwalitatieve evaluatie met een kwantitatief onderzoek om inzicht te geven in het perspectief van patiënten op SMS. Eerst worden de bevindingen gepresenteerd uit 12 interviews met mensen met diabetes en sociaal-emotionele problemen. Hieruit blijkt dat mensen een diabetesconsult zien als een biomedische controle, waarin zij niet verwachten dat de praktijkondersteuner ook zorg biedt voor sociaal-emotionele problemen. Deze bevindingen vormden de basis voor een vragenlijst, die kon worden uitgezet in een grotere groep van patiënten $(n=205)$. De vragenlijst bestond uit 14 items met stellingen over diabeteszorg en de rol van de praktijkondersteuner. De conclusie van het hoofdstuk luidt dat mensen wel open staan voor geïntegreerde zorg met zowel aandacht voor de biomedische als de sociaal-emotionele kant, maar dat zij meer informatie en tijd nodig hebben om gewend te raken aan het bespreken van sociaalemotionele aspecten met de praktijkondersteuner.

De effectevaluatie van SMS wordt gerapporteerd in hoofdstuk 6 van dit proefschrift. In het cluster-gerandomiseerde onderzoek deden 40 praktijkondersteuners mee, van wie 19 werden ingeloot voor de training in SMS. De overige 21 praktijkondersteuners boden reguliere zorg gedurende het jaar van onderzoek. In totaal 264 patiënten stemden toe om deel te nemen aan het onderzoek. Dit hield in dat zij een vragenlijst hebben ingevuld vóór het eerste consult en na 4 en 12 maanden. De patiënten waren geselecteerd met behulp van een schriftelijke screeningslijst die naar de patiënten thuis gestuurd werd. Deze screeningslijst bevatte vragen over het dagelijks functioneren en emotionele distress die ook door de praktijkondersteuners tijdens het consult werden gesteld. Tijdens de studie bleek dat slechts 16 van de 117 patiënten uit de interventiegroep (14\%) in het consult werden opgespoord door de praktijkondersteuner. Extra consulten voor de follow-up fase van SMS door de 
praktijkondersteuner werden aan slechts 11 onderzoeksdeelnemers aangeboden. Daarmee kwam de vergelijking tussen de 117 patiënten uit de interventiegroep en de 147 patiënten uit de controlegroep op losse schroeven te staan. Op basis van multilevel analyses kon geen significant verschil worden aangetoond tussen interventie- en controlegroep ten aanzien van het dagelijks functioneren van patiënten. Hetzelfde geldt voor de secundaire uitkomstmaten zoals diabetesgerelateerde emotionele distress, kwaliteit van leven, autonomie en participatie, zelfeffectiviteit, zelfmanagement en bloedsuikercontrole. Slechts op twee domeinen van autonomie en participatie (bezigheden thuis en gezinsrol) werd na vier maanden een significant verschil ten gunste van de interventiegroep gevonden, maar dit was na 12 maanden weer verdwenen. De conclusie in hoofdstuk 6 is dat SMS in huidige vorm niet effectief is. Hierin heeft de inconsistentie tussen de schriftelijke en mondelinge screening een cruciale rol gespeeld.

De uitkomsten van de mondelinge detectiefase van SMS zijn nader verkend in hoofdstuk 7. Bij de 117 patiënten uit de interventiegroep met een positieve score op de schriftelijke screeningslijst zijn de uitkomsten op de mondelinge vragen in het consult in kaart gebracht, evenals het emotioneel welzijn zoals gerapporteerd in een vragenlijst vier maanden na het consult. In 52\% van de diabetesconsulten werden geen sociaal-emotionele problemen geïdentificeerd. Toch was bij de meeste deelnemers na vier maanden sprake van emotionele distress; dit was het geval bij $90 \%$ van de opgespoorde patiënten, en bij $83 \%$ van de niet-opgespoorde patiënten. Deze bevindingen suggereren dat bij een substantieel deel van de mensen sociaalemotionele problemen niet op tafel zijn gekomen. De aanbeveling in hoofdstuk 7 is om verder onderzoek te doen naar de toepassing van mondelinge detectie van sociaal-emotionele problemen door eerstelijns zorgverleners, met expliciet aandacht voor de context waarin de detectie plaatsvindt.

Hoofdstuk 8 bevat een kort overzicht van de bevindingen uit dit proefschrift. De implementatie van SMS illustreert de complexiteit van daadwerkelijke invoering in de dagelijkse praktijk van een effectief gebleken interventie. De specifieke uitdaging in het SMS-project was de integratie van een psychosociale benadering in een biomedische setting. Dit vergt een omslag in het denken van zowel de zorgverleners als de patiënten, die allen zijn gesocialiseerd in het denken vanuit een medisch model. 
$\mathrm{Er}$ is tijd nodig voor deze paradigmaverandering. Hetzelfde geldt voor het werken volgens de principes van zelfmanagement.

$\mathrm{Na}$ deze inhoudelijke discussie over de resultaten volgt een reflectie op de complexiteit van onderzoeksdesign om zowel effectiviteit als implementatie te evalueren. Hierbij wordt specifiek ingegaan op de detectiefase als inherent onderdeel van SMS. Het feit dat er maar een beperkt aantal mensen werd opgespoord voor de follow-up fase van SMS, is nader onderzocht in het implementatieonderzoek. Doordat slechts een klein deel van de patiënten beide fasen van SMS ontving, werd het lastig om effecten aan te kunnen tonen van SMS. Een pilotstudie had de problemen met de detectie kunnen signaleren, maar daarvoor ontbraken de mogelijkheden. In de methodologische reflectie wordt tevens de invloed van stakeholders bij implementatie op de balans tussen het implementatiedeel en effectiviteitsdeel in een hybride design bediscussieerd. Na een samenvatting van de belangrijkste conclusies van het proefschrift, gaat hoofdstuk 8 in op de implicaties voor de praktijk en voor verder onderzoek. Voor de praktijk worden twee opties uitgewerkt. De eerste optie is om de huidige context als vertrekpunt te nemen, waarin praktijkondersteuners biomedische zorg bieden en bij sociaal-emotionele problemen verwijzen naar een andere zorgprofessional. In de tweede optie wordt SMS verder ontwikkeld en alsnog geschikt gemaakt voor toepassing door praktijkondersteuners in de reguliere diabeteszorg. Thema's voor verder onderzoek zijn behoeften van patiënten aan zelfmanagementondersteuning, onderzoek naar geschikte detectiemethodieken voor gebruik in de chronische zorg, determinanten van succesvolle implementatie van zelfmanagementondersteuning, en het ontwikkelen van indicatoren om inzicht te krijgen in de kwaliteit van biopsychosociale zorgverlening. 
Valorisatie 
Het proces waarin wetenschappelijke kennis beschikbaar wordt gemaakt voor de praktijk wordt in het Engels aangeduid met de term 'valorisation of knowledge'. Dit proefschrift gaat over het vertalen van een evidence-based interventie naar evidencebased practice. De implementatie van Self-Management Support (SMS) in de dagelijkse zorg voor mensen met diabetes is gefinancierd door een zorgverzekeraar en een regionale zorggroep van huisartsen. De evaluatie is deels gefinancierd vanuit het programma 'Stem van de Patiënt' van het Diabetes Fonds. Ervaringsdeskundigen van het Diabetes Fonds hebben het onderzoeksvoorstel positief beoordeeld en vonden het de moeite waard om gelden, door mensen gedoneerd voor diabetesonderzoek, in te zetten voor de evaluatie van SMS. De positieve houding van patiënten, huisartsen en zorgverzekeraars ten aanzien van SMS onderstreept de maatschappelijke relevantie van het project. De waarde van de onderzoeksresultaten voor patiënten, zorgverleners, zorggroepen, verzekeraars, beleidsmakers, onderwijsinstellingen en de wetenschap wordt in dit hoofdstuk verder toegelicht.

\section{PATIËNTEN}

De intentie van SMS was om mensen te ondersteunen in het omgaan met de gevolgen van de chronische ziekte voor hun dagelijks functioneren, in een poging een neerwaartse spiraal te voorkomen. Praktijkondersteuners werden getraind om signalen van sociaal-emotionele problemen te herkennen, bespreekbaar te maken en waar nodig een steun in de rug te geven door middel van het aanleren van problem solving en reattributie technieken. Om de chronisch zorg niet onnodig complex te maken, zouden praktijkondersteuners deze ondersteuning zelf bieden in plaats van verwijzen naar een andere zorgprofessional. Helaas kon het beoogde effect in termen van verbetering van het functioneren in het dagelijks leven van mensen met diabetes niet worden aangetoond.

Toch doet dit niets af aan de relevantie van ondersteuning in integrale zelfmanagementvaardigheden aan mensen met een chronische aandoening. De vergrijzing zorgt voor een toenemende zorgvraag en druk op de betaalbaarheid van de zorg. Er wordt bovendien steeds meer verantwoordelijkheid bij patiënten zelf gelegd. Dat blijkt bijvoorbeeld uit het nieuwe concept van gezondheid, door Huber (BMJ, 2011) gedefinieerd als "het vermogen zich aan te passen en een eigen regie te voeren, in het licht van de fysieke, emotionele en sociale uitdagingen van het leven". 
Volgens dit concept draait niet alles meer om ziekte en de behandeling daarvan, maar ook om het versterken van veerkracht, zelfregie en gezondheidsvaardigheden. De recente ontwikkelingen ten aanzien van het Individuele zorgplan sluiten hier bij aan. Het Individuele zorgplan is bedoeld om in de zorg zo goed mogelijk aan te sluiten bij de doelen die door patiënt en zorgverleners in een gezamenlijk proces zijn vastgesteld en die passen bij de behoeften en voorkeuren van het individu. Het kan afspraken bevatten over verandering van leefstijl en te behalen doelen en (meet)waarden, maar er kunnen ook doelen of afspraken worden opgenomen over de emotionele en sociale aspecten die een rol spelen bij het omgaan met de gevolgen van de aandoening. Toch kunnen veel chronisch zieken niet voldoen aan het ideaal van de proactieve zelfmanager, die in staat is persoonlijke doelen te formuleren en deze na te streven. Daar kunnen allerlei redenen voor zijn, zoals multimorbiditeit, gebrek aan sociale steun, beperkte gezondheidsvaardigheden of complexe omstandigheden in de sociale context. Deze mensen zouden baat kunnen hebben bij ondersteuning van de praktijkondersteuner in het vergroten van hun probleemoplossende vaardigheden.

Dit proefschrift maakt inzichtelijk hoe complex het is om dergelijke ondersteuning te realiseren in de dagelijkse routines van de huisartsenzorg. Het aanpassen van het zorgaanbod in routine diabetesconsulten sloot in het SMS-project niet voldoende aan bij het verwachtingspatroon waarmee mensen een praktijkondersteuner bezoeken voor hun specifieke chronische aandoening. Patiënten zijn gewend aan een biomedische check-up. In toekomstige zorgvernieuwingsprojecten is meer aandacht nodig voor verbreding van het verwachtingspatroon van patiënten ten aanzien van het zorgaanbod van de praktijkondersteuner.

\section{ZORGVERLENERS}

In het SMS-project zijn praktijkondersteuners getraind in het herkennen, bespreekbaar maken en ondersteunen van mensen met sociaal-emotionele problemen. Deze aandacht voor de 'hele mens' achter de ziekte is een belangrijke waarde in de huisartsgeneeskunde. De aandacht voor de sociaal-emotionele gevolgen van de chronische aandoening is ook beschreven in het competentieprofiel van de praktijkondersteuner somatiek. De invoering van het Individuele zorgplan in de chronische zorg benadrukt het belang dat praktijkondersteuners over de vaardigheden moeten beschikken om patiënten te ondersteunen in het stellen van 
doelen. Die doelen kunnen betrekking hebben op de somatische aspecten van de aandoening, maar kunnen ook over sociale of emotionele aspecten gaan.

SMS werd toegevoegd aan de routine diabetesconsulten. Praktijkondersteuners zijn gewend om protocollair te werken. Zij hebben in de routine consulten hun handen al vol aan het controleren van biomedische waarden en het begeleiden van mensen bij leefstijlveranderingen zoals gezond eten en meer bewegen. Hierop worden zij ook afgerekend aan de hand van indicatoren uit het kwaliteitssysteem. In het SMS-project hadden praktijkondersteuners de mogelijkheid om extra consulten in te plannen voor de zelfmanagementondersteuning. In de praktijk bleek dit lastig vanwege gebrek aan ruimte in werkuren en omdat spreekuren al lang van tevoren zijn volgepland. In de toekomst is het van belang om te streven naar het inpassen van zelfmanagementondersteuning in geplande consulten. Dit vraagt om zorg waarin minder in het keurslijf van het protocol wordt gewerkt en meer maatwerk wordt geleverd.

Praktijkondersteuners werden in het SMS-project getraind om systematisch na te gaan in hoeverre patiënten sociaal of emotioneel last ervaren in het dagelijks leven met diabetes. De mondelinge afname van screeningsvragen werd geïntegreerd in het consult. Deze detectiemethode bleek (nog) niet effectief voor het opsporen van de doelgroep voor de zelfmanagementondersteuning. Dit aspect vraagt om verder onderzoek.

\section{REGIONALE ZORGGROEPEN}

De SMS-benadering is ontwikkeld en geïmplementeerd in samenwerking met een regionale zorggroep van huisartsen. Deze samenwerking is voor een dergelijk implementatieproject onmisbaar. In Nederland wordt ten aanzien van de bekostiging, inhoud en kwaliteit van de zorg namelijk veel bepaald op regionaal niveau. De samenwerking met de zorggroep bleek echter geen 'magic bullet' in het implementeren en evalueren van SMS. Uit dit proefschrift kunnen lessen worden getrokken voor toekomstige regionale implementatieprojecten. Zo is het belangrijk dat bij de start van een implementatietraject wederzijdse verwachtingen duidelijk zijn. Het is essentieel dat taken van iedere partner goed wordt vastgelegd, bijvoorbeeld de rol van de zorggroep in het motiveren en ondersteunen van de zorgverleners en de afspraken die worden gemaakt tussen zorggroep en individuele huisartsenpraktijken. Het is essentieel dat het nakomen van gemaakte afspraken goed wordt gemonitord. 
Het integreren van nieuwe variabelen in het regionale elektronische keten informatiesysteem bleek in de praktijk lastig, maar is wel een belangrijke voorwaarde voor het toevoegen van nieuwe elementen aan een regulier consult. Het invullen van het keteninformatiesysteem is namelijk een belangrijke leidraad tijdens consulten.

\section{ZORGVERZEKERAARS}

Ten behoeve van de implementatie van SMS is een financiële bijdrage voor de extra zorgtijd toegevoegd aan het integrale bekostigingssysteem voor diabeteszorg. Deze keuze is door de zorgverzekeraar gemaakt het met oog op duurzame implementatie van SMS. Bij gebleken succes zou SMS vast onderdeel worden van de keten-dbc diabeteszorg. Dankzij deze financiële steun van de zorgverzekeraar was het voor huisartsen tijdens de wervingsfase duidelijk dat er op regionaal niveau prioriteit werd gegeven aan SMS. In de implementatiefase bleek de manier van financiering echter niet effectief. De investering van de zorgverzekeraar leidde niet tot verbetering in het implementatieproces. Dit is te wijten aan onvoldoende duidelijke voorlichting aan de deelnemende huisartsen over deze extra financiële bijdrage, en aan beperkte mogelijkheden van de huisartsen om het geld daadwerkelijk om te zetten in meer tijd voor de praktijkondersteuners. Vanwege de teleurstellende resultaten is door de zorgverzekeraar na een jaar besloten om niet langer te investeren in SMS.

Het proefschrift legt de spanning bloot tussen enerzijds de wens van zorgverzekeraars om te investeren in verbetering van de kwaliteit van zorg en anderzijds hun behoefte om snel resultaten te zien van die investering. Het blijkt lastig en het kost tijd om een werkzame interventie goed in te passen en te verankeren in de reguliere zorg. De vraag blijft wat een redelijke termijn is voor haalbare implementatie van complexe interventies als SMS.

\section{BELEIDSMAKERS IN DE GEZONDHEIDSZORG}

Het stimuleren van zelfmanagement bij chronisch zieken staat hoog op de agenda van beleidsmakers in de gezondheidszorg. In dit proefschrift wordt aangetoond dat het realiseren van een integrale benadering van zelfmanagement in diabetesconsulten meer vraagt dan alleen het trainen en begeleiden van praktijkondersteuners. De studie legt bloot dat de huidige chronische zorg nog sterk is georiënteerd op de 
biomedische aspecten, waarbij mensen een zorgverlener consulteren voor de behandeling van een specifieke aandoening. Deze benadering wordt gestimuleerd doordat proces- en uitkomstindicatoren uitsluitend gericht zijn op bloedsuiker, bloeddruk, nierfunctie, oogonderzoek, voetonderzoek, voeding, bewegen en roken. Het realiseren van integrale zelfmanagementondersteuning in de chronische zorg betekent een omslag in de structuur, financiering en toetsing van de zorg. Zolang de eerstelijns ketenzorg bij chronische aandoeningen nog primair gericht is op somatiek en de zorg uitsluitend wordt getoetst en gefinancierd aan de hand van biomedische indicatoren, is het de vraag in hoeverre van praktijkondersteuners kan worden verwacht dat zij ook aandacht en begeleiding bieden bij sociaal-emotionele problemen in het dagelijks leven van patiënten.

\section{ONDERWIJSINSTELLINGEN}

Op grond van onze bevindingen doen wij een beroep op relevante onderwijsinstellingen om zorgverleners al van meet af aan te trainen in het hanteren van een biopsychosociale benadering bij de zorgverlening aan patiënten met een chronische aandoening. Daarbij lijkt werkelijke aandacht voor zelfmanagement niet gebaat bij het nalopen van afvink-lijstjes door praktijkondersteuners. Het vraagt training in diagnostische en coachingsvaardigheden, om het vermogen van patiënten tot zelfmanagement te kunnen inschatten en motivatietechnieken daarop aan te kunnen passen.

\section{WETENSCHAP}

Het hybride design waarmee SMS werd geëvalueerd laat spanning zien tussen enerzijds de benodigde tijd en aandacht voor het uittesten en optimaliseren van het implementatieproces en anderzijds de behoefte om vanuit de praktijk op korte termijn zeker te zijn van de effectiviteit van de interventie.

Een belangrijke les uit de studie is dat schriftelijke screeningsvragen een heel andere uitkomst kunnen geven dan wanneer dezelfde vragen mondeling worden gesteld door een zorgverlener tijdens een regulier consult. De gekozen methodiek en de context waarin mensen worden gevraagd naar hun sociaal-emotioneel welbevinden blijken zeer bepalend te kunnen zijn voor de uitkomsten van screening. Verder illustreert 
SMS de noodzaak van een multilevel-benadering voor duurzame implementatie van zorginnovaties. Implementatie-activiteiten waren met name gericht op de uitvoering van SMS door praktijkondersteuners, terwijl SMS ook afstemming vergt met en door huisartsen. Het is in de studie verder van groot belang gebleken dat patiënten zonder verandering van hun verwachtingspatroon van de rol van de praktijkondersteuner hun sociaal-emotionele problemen maar moeilijk met de praktijkondersteuner bespreken tijdens een diabetesconsult. Ten slotte kunnen uit de SMS-studie lessen worden getrokken over de samenwerking tussen onderzoekers, regionale zorggroepen en zorgverzekeraars bij het implementeren en evalueren van een zorginnovatie.

Het probleem van de falende detectie, met cruciale gevolgen voor de effectevaluatie, is genomineerd voor Briljante Mislukking Award Zorg 2014. Deze prijs is in het leven geroepen om meer openheid te geven over mislukte onderzoeks- of implementatieprojecten. Deze zijn namelijk lastiger te publiceren in wetenschappelijke tijdschriften dan succesvolle interventies, waardoor de lessen die eruit te leren zijn minder makkelijk worden verspreid. De prijs beoogt de transparantie en het lerend vermogen in de zorg te vergroten en innoveren een stimulans te geven. Publiek en jury maakten een keuze uit acht ingezonden projecten. SMS eindigde op de tweede plek. 
Dankwoord 
Het uitvoeren van dit onderzoek en het afronden van het proefschrift was mogelijk dankzij de ondersteuning en bemoediging van veel mensen. In gedachten heb ik al vaak 'dankjewel' gezegd. Nu mag ik het ook op papier zetten.

Ik mocht deel uitmaken van een sterk promotieteam, bestaande uit Jacques van Eijk, Trudy van der Weijden, en Loes van Bokhoven. Jacques, ik vind het bijzonder jouw laatste promovendus te zijn op een project dat was bedoeld als een soort kroon op je werk. Met een enorme inzet, betrokkenheid en gedrevenheid ging je voor het SMSproject, en zocht je het beste voor mij. Jouw scherpe blik bracht de artikelen op een hoger niveau. Trudy, jouw nooit aflatende enthousiasme en gejubel na elke overwinning was (en is) erg bemoedigend! Ook je persoonlijke interesse in mij en mijn gezin waardeer ik. Loes, ik heb de eer om jouw eerste promovendus te zijn. Dankzij je vertrouwen in mij, je openheid, en alle tijd die je voor me neemt om dingen te bespreken en de puntjes op de $\mathrm{i}$ te zetten, heb ik me enorm gesteund geweten gedurende het hele promotietraject. Bedankt dat je me meenam naar Denemarken; dat was een hele leuke manier om elkaar beter te leren kennen. Ook bedankt voor de mooie kans die je me hebt gegeven om voor het zorgnetwerk Elsloo te werken. Ik leer veel van je.

Jacques, Trudy en Loes, terwijl ik met verlof was vanwege de geboorte van Eva hebben jullie samen met Anuska Muyres veel energie gestoken in het benaderen van alle huisartsenpraktijken in Oostelijk Zuid-Limburg. Toen ik terugkwam waren alle $\mathbf{4 0}$ praktijkondersteuners al gerandomiseerd en geïnformeerd over het SMS-project. Wat een luxe! In het contact met alle praktijkondersteuners rondom het screenen van patiënten heb ik alle medewerking ervaren. Ook het bijwonen van de training aan de praktijkondersteuners uit de interventiegroep vond ik leerzaam. Beste praktijkondersteuners, dank voor jullie inzet voor SMS. Ik heb veel respect voor jullie mooie werk. Ook alle mensen met diabetes die hebben deelgenomen aan het onderzoek ben ik dankbaar voor het invullen van de vragenlijsten. Soms zaten er persoonlijke berichtjes bij en zelfs een keer een foto van het Limburgse landschap. Erg leuk. Anuska, wat heb jij een werk gehad met alle logistiek en het invoeren van de resultaten. Bedankt!

De implementatie en evaluatie van SMS is mogelijk gemaakt door de investering van CZ Zorgverzekeraars (met dank aan Angelique Bonte, Truus Gootzen en Lynn Rulkens), en de Huisartsengroep Oostelijk Zuid-Limburg (met dank aan de ondersteuning van 
Frank Soomers, Yvonne Guldemond, Esther van Engelshoven, Leon Bejas en Samira Guerrouj). Hartelijk dank voor het meedenken, en de praktische ondersteuning rondom de training en het opzetten van het registratiesysteem. Eind 2010 hoorde ik het goede nieuws dat het Diabetesfonds vanuit het programma Stem van de Patiënt bereid was om het onderzoek te financieren. Daar kwam later ook een bijdrage van Stichting St. Annadal bij. Zonder deze subsidies was het onderzoek en promotietraject niet mogelijk geweest. Dank! Ook Erie van den Heuvel wil ik hier graag bedanken. Het is ongelofelijk hoe jij het overzicht kunt bewaren als het gaat om financiën en contracten. Je reactie op mijn vragen kwam altijd snel, en dankzij jou wist ik waar ik aan toe was.

Met enige regelmaat kwam de begeleidingscommissie naar Maastricht gereisd om mee te denken over het SMS-project. Berend Terluin, Job Metsemakers, Jeroen Dorenbos, Esther Stoffers, Karianne Jonkers en Peter Verhaak wil ik hierbij hartelijk bedanken voor het meedenken, en sommigen ook voor het meeschrijven aan artikelen. Dit laatste geldt ook voor Andre Knottnerus, die zijn bijdrage heeft geleverd aan het effectartikel. Bedankt voor alle behulpzame feedback. Albine Moser heeft een belangrijk aandeel geleverd aan hoofdstuk 1 . Albine, ik zie ons nog zitten met die revisie die voor kerst klaar moest zijn. Je hebt me er doorheen gesleept! Berend, je hebt veel meegedacht met het studieprotocol en meegeschreven aan artikelen. Jouw reactie was altijd snel, helder en constructief, en zonder jouw enthousiasme vraag ik me af of ik hoofdstuk 7 had doorgezet. Ik heb het bijzonder gewaardeerd dat je me kwam aanmoedigen toen ik de SMS-studie presenteerde voor de Award Briljante Mislukkingen Zorg 2014.

Het uitvoeren van een multilevel analyse leek me een spannend proces. Zou ik dat ooit begrijpen? Tijdens de cursus leerde ik Véronique Moulaert kennen. Samen stonden we sterk. Jouw databestand en eerste analyses zagen er eenvoudiger uit dan ik dacht en hielpen me over mijn drempelvrees. Véronique, ik ben blij met onze vriendschap en zie uit naar nog veel gezellige avondjes. De statistische analyses zijn verder mogelijk gemaakt door de professionele ondersteuning van Bjorn Winkens. Jouw deskundigheid en snelheid bij het uitvoeren van analyses en bij de rapportage was heel prettig. Dank voor de fijne samenwerking. 
Tijdens het promotietraject zijn er ook studenten bij delen van de SMS-studie betrokken geweest. Het was leuk om samen op te trekken met Sabine de Jong, Jill Fuss en Sadaf Edalat.

Als er dan zo veel tijd is gestoken in het schrijven van een artikel, dan is het heerlijk als er mensen zijn die letterlijk en figuurlijk nog even de puntjes op de i kunnen zetten. De tekst was nooit zo bondig en helder geworden zonder de bijdrage van vertalers Jan Klerkx en Roland Smith. Respect voor jullie werk!

De leescommissie, bestaande uit Sandra Beurskens, Hans Bosma, Brenda Penninx, François Schellevis en Nanne de Vries, wil ik hartelijk bedanken voor de tijd en interesse om mijn hele proefschrift zorgvuldig door te nemen.

Aan het begin klinkt een onderzoekstraject van ruim 5 jaar ontzettend lang, maar ik ben nooit met tegenzin naar mijn werk gegaan. Daar hebben al mijn collega's bij huisartsgeneeskunde, en in het bijzonder mijn kamergenootjes Vera-Christina, Jikke, Albine, Sofie, Carolien, Annerika en Esther een hele belangrijke rol in gespeeld. Dank voor alle gezelligheid, en momenten van een lach of soms een traan. Ik denk ook aan de steun van alle mede-promovendi. De humor en nieuwsgierigheid van (over)buurvrouw Anneke. De zorg en betrokkenheid van Ine en Ellen. De boeiende gesprekken over gezin, werk en familie met Annemieke. De momenten dat Ben even kwam buurten op de derde verdieping, en je babybezoekjes bij me thuis. Wat een gaaf mens ben je toch. Marije, jij hebt me wegwijs gemaakt op de afdeling, en in de wereld van promoveren. Het is fijn om onze levens met elkaar te blijven delen.

Bij de afdeling sociale geneeskunde was er ook een plekje voor me. Dank voor de fijne contacten en de gezellige dagjes uit.

Tijdens de promotie heb ik twee paranimfen achter me staan die erg belangrijk voor me zijn. Lieve Vera, eerst mochten we samen werken aan SMS, toen maakte jij de stap naar revalidatiegeneeskunde. Gelukkig bleef onze vriendschap. We gaan het zelfs meemaken dat we op dezelfde dag 'trouwen met de wetenschap', zoals je dat vaak noemt. De leuke, interessante, gezellige en bemoedigende gesprekken, en je helpende hand (oppas, catering, verhuizing, noem maar op) zijn onbetaalbaar. Ik hoop dat we ons jaarlijkse verjaardags-etentje er lang in zullen houden. 
Annerika, ik ben ook zo blij met jou! Toen jij mijn kamergenootje werd, kwamen er ineens allemaal plantjes, lampjes, versieringen, en werd onze kamer een goed toeven, ook voor de andere collega's. Zo had ik gegarandeerd genoeg afleiding. Jij zorgde voor mij als ik niet goed voor mezelf zorgde. Je was er als ik thuis hulp nodig had. Ik zal die ochtend voordat ik met de kinderen naar Barcelona vloog nooit vergeten. Je was een reddende engel.

Ik ben dankbaar voor de vele vrienden en bekenden die betrokken zijn bij mijn werk en leven. Ik kan niet iedereen bij naam noemen, maar er zijn uitzonderingen. Hinke en Theodoor, gaaf om met jullie op te trekken. Femmie, Jantha, Marieke, Kim, Renske we wonen best ver van elkaar, maar jullie blijven dichtbij me staan en de vriendschap is kostbaar voor me.

Ook mijn ouders, broers en zussen wil ik bedanken. Al lang voordat WhatsApp bestond deelden wij anekdotes, foto's en grappen met elkaar via een forum - mijn heerlijke dagelijkse portie afleiding. Papa, promoveren als je onderzoek een 'briljante mislukking' is, kan echt! Mama, ik hoefde maar op tijd te bellen en u was bereid om vanuit Kampen naar Maastricht te komen om te helpen. De collecte voor het Diabetes Fonds heeft nu een extra speciaal tintje gekregen. Lieve leke, wat een geluk met een schoonmoeder als jij. Jouw bezoekjes aan ons zijn altijd een feestje. Ook bij het schrijven van dit dankwoord is Wander in mijn gedachten. Hij zou vast en zeker graag aanwezig zijn geweest bij mijn promotie.

Allerliefste Tjerk, wat kan ik zeggen? Mijn woorden 'je bent een wonder' van 11 jaar geleden waren toch best goed ingeschat. Mijn naam staat voorop op dit boekje, maar het is - net als al het andere in ons leven - een resultaat van echt teamwork. Je gelooft in me, je gaat met me op reis, en we kunnen samen veel lachen. Ik ben trots op je toewijding en creativiteit als papa van Lydia, Eva en David. Lieve schatten, wat is het leven met elkaar als familie op missie mooi en goed! Ik voel me zo gezegend!

Bless the Lord, O my soul.

For all Your goodness I will keep on singing

Ten thousand reasons for my heart to find. 
Curriculum Vitae 
Anneke de Vries was born on 15 July 1982 in Hoogeveen, the Netherlands. From 19942000, she attended secondary school at Greydanus College. After completing her preuniversity education, she started to study health sciences at the Faculty of Health, Medicine and Life at the Maastricht University. She obtained her master's degree in 2005. Her main subjects were 'Care Sciences' and 'Work and Health'. She graduated with a qualitative study about sickness absence of young highly educated women with mental health problems. The findings of her master thesis were described in a brochure, published by the WAHO foundation. In 2006, she worked as a research assistant at the department of Family Medicine to evaluate patients' experiences with cardiovascular risk management. She continued her career in the area of primary care at the Beyaert Robuust Limburg Foundation. There, she explored supply and demand in primary care, and developed an instrument for practice nurses to assess needs of diabetes patients in health promoting activities. From 2007 - 2009, she evaluated teamwork in COPD-care at the Department of Integrated Care of the Maastricht University Medical Center. In 2010, she started working at the department of Family Medicine at Maastricht University on her PhD-research project that resulted in this thesis. It was funded by the Dutch Diabetes Research Foundation, Voice of the Patient programme, and by the 'Annadal Foundation' in Maastricht. Since 2015, Anneke has been working as a coordinator of a network of interprofessional caregivers who collaborate in the care for frail elderly in Elsloo. She also works at a project of health insurer CZ to evaluate a transmural integrated care model for frail elderly patients in three areas of Limburg. Anneke is happily married to Tjerk van Dijk and the proud mother of Lydia (2009), Eva (2011) and David (2014). 


\section{LIST OF PUBLICATIONS AND PRESENTATIONS}

\section{Publications related to this thesis}

Van Dijk - de Vries A, Van Bokhoven MA, Winkens B, Terluin B, Knottnerus JA, Van der Weijden T, Van Eijk JTM. Lessons learnt from a cluster-randomised trial evaluating the effectiveness of Self-Management Support (SMS) delivered by practice nurses in routine diabetes care. BMJ Open 2015; 5(6).

Van Dijk - de Vries A, Van Bokhoven M, Terluin B, Van der Weijden T Van Eijk JTM. Integrating nurse-led Self-Management Support (SMS) in routine primary care: design of a hybrid effectiveness-implementation study among type 2 diabetes patients with problems of daily functioning and emotional distress: a study protocol. BMC Fam Pract 2013; 14:77.

Van Dijk - de Vries A, Moser A, Mertens VC, van der Linden J, van der Weijden T van Eijk JT. The ideal of biopsychosocial chronic care: How to make it real? A qualitative study among Dutch stakeholders. BMC Fam Pract 2012; 13(1):14.

Van Eijk J, Van Dijk A. Meer aandacht voor mentale aspecten chronisch zieken. Tijdschrift voor praktijkondersteuning 2010; 5(4): 98-99.

\section{Manuscripts submitted for publication}

Van Dijk - de Vries A, Van Bokhoven MA, Metsemakers JFM, Jonkers CCM, Van der Weijden T Van Eijk JTM. Experiences of practice nurses and general practitioners with implementation of biopsychosocial self-management support in diabetes care.

Van Dijk - de Vries A, Van Bokhoven MA, Terluin B, Van der Weijden T Van Eijk JTM. Identification of patients with emotional distress by practice nurses in routine diabetes care.

Van Dijk - de Vries A, Van Bokhoven MA, De Jong S, Metsemakers JFM, Verhaak PF, Van der Weijden T Van Eijk JTM. Patients' readiness to receive psychosocial care by practice nurses in routine diabetes consultations: A mixed methods study. 


\section{Other publications not related to this thesis}

Koelewijn-van Loon MS, Van Dijk - de Vries A, Van der Weijden T, Elwyn G, Widdershoven GAM. Ethical issues in cardiovascular risk management: Patients need nurses' support. Nurs Ethics published 19 November 2013.

Van Dijk - de Vries AN, Duimel - Peeters IGP, Vrijhoef HJM. Instrument to assess the needs of patients with type 2 diabetes for health promotion activities. The Patient: Patient-Centered Outcomes Research 2011; 4(1), 115-123.

Verdonk P, De Rijk A., Klinge I, De Vries A. Sickness absence as an interactive process: Gendered experiences of young, highly educated women with mental health problems. Patient Educ Couns 2008; 73(2): 300-306.

Van Dijk - de Vries A, Duimel - Peeters I, Muris J, Wesseling G, Beusmans G, Vrijhoef B. Het meten van samenwerking in de zorg voor COPD-patiënten. TSG 2010; 88(7): 388-395

Van Dijk A, Frederix M, Van Summeren E, Vrijhoef B. Gezond leven in Limburg. Tijdschrift voor verpleegkundigen 2009; 2: 40-42.

De Vries AN, De Rijk A, Verdonk P, Klinge I. (2006) "Ik dacht: een weekje uitrusten en dan weer aan het werk". Een onderzoek naar de ervaringen van werkende vrouwen die op jonge leeftijd in de WAO terechtkwamen. Amsterdam: Stichting WAHO. http://www.innovatiefinwerk.nl/sites/innovatiefinwerk.nl/files/field/bijlage/een_wee kje_uitrusten.pdf

De Vries AN, De Rijk A, Klinge I, Verdonk P. Schipperen tussen werkeisen en eigen wensen. Verzuim en reïntegratie van jonge hoger opgeleide vrouwen. Maandblad Reïntegratie 2006; 6, 1/2.

\section{Oral presentations}

Detection of psychosocial problems by practice nurses in routine diabetes care: are patients ready? WONCA Europe. Istanbul, October 2015. 
Een té goed onderzoek. Presentatie t.b.v. verkiezing van de Briljante Mislukkingen Award Zorg 2014. Amsterdam, december 2014.

Patients' openness to integrated self-management support in routine diabetes care. 12th International Conference on Communication in Healthcare (ICCH) organized by European Association of Communication in Healthcare (EACH). Amsterdam, October 2014.

Van een effectieve interventie naar reguliere eerstelijnszorg: lessen uit het SMSproject. NHG Wetenschapsdag. Leiden, juni 2013.

Implementation of psychosocial care in routine diabetes care: detection of eligible patients by practice nurses. European Association for Consultation-Liaison Psychiatry and Psychosomatics (EACLPP) \& the European Conference on Psychosomatic Research (ECPR). Aarhus (Denmark), June 2012.

Implementatieonderzoek in de reguliere zorg: voorbeeld van een methodologisch probleem. NHG Wetenschapsdag. Maastricht, juni 2012.

De integrale benadering van Self Management Support. Implementatie in de reguliere zorg: het wat, waarom en hoe. Duo-presentatie met een praktijkondersteuner uit de interventiegroep SMS. Symposium CZ 'Zorg op maat in de praktijk'. Tilburg, januari 2012. 